\title{
Taxonomy of Sulawesi Onthophagus lacking a basal pygidial ridge (Coleoptera: Scarabaeidae: Scarabaeinae)
}

\author{
J. Krikken \& J. Huijbregts
}

\begin{abstract}
Fifteen endemic Sulawesi species in the dung beetle genus Onthophagus Latreille, 1802 lacking a ridge along their pygidial base are keyed, diagnosed, and illustrated. Eight new species are described in three of four operational groups here recognized: Onthophagus (ambang group) tonywhitteni, ambang; (imbutus group) toraut, sarasinorum, gonipa, tambing, sulawesiensis; (fuscostriatus group) rosenbergi. The species Onthophagus ambang and rosenbergi are each divided into two new subspecies: Onthophagus ambang ambang and ambang morowali, and Onthophagus rosenbergi rosenbergi and rosenbergi divergens. Lectotypes are designated for six available species-group names liable to misinterpretation. Onthophagus forsteni Lansberge, 1887 is considered a junior synonym of Onthophagus griseoaeneus Lansberge, 1885.

J. Krikken, NCB Naturalis, PO Box 9517, NL-2300 RA Leiden, The Netherlands. jan.krikken@ncbnaturalis.nl

J. Huijbregts, NCB Naturalis, PO Box 9517, NL-2300 RA Leiden, The Netherlands.hans.huijbregts@ncbnaturalis.nl
\end{abstract}

\section{Introduction}

The great majority of species in the ubiquitous scarab genus Onthophagus Latreille, 1802 have a complete, well-defined ridge along the base of their pygidium, separating the more or less convex, semielliptic pygidial surface from the propygidium above it. The number of exceptions, i.e. the number of species lacking a ridge along their pygidial base, seems disproportionately high on the Indonesian island of Sulawesi compared to adjacent regions (roughly one in five of the Sulawesi species currently known to us). In this paper we describe eight new Sulawesi species with a minimal or completely absent ridge on their pygidial base, and review them along with seven previously named congeners with the same condition. All 15 species are here illustrated for the first time. They are allocated to four operational groups in Onthophagus, which are defined in the first section of the key below, before getting to the keys to the species.

Previously the named Sulawesi species in these groups, as well as others in adjacent regions, were loosely classified, Boucomont (1914) and Balthasar (1963) spreading them over different sections of their keys, and in at least three cases missing the absence of the pygidial ridge. The species certainly do not constitute a single natural group; in phylogenetic terms, the absence of the basal ridge, even within this limited island fauna, does not represent a synapomorphy. The present joint treatment and grouping of the Sulawesi Onthophagus with this condition serves practical identification purposes, and nothing else. The overall diversity of the included species suggests a further subdivision, but the creation of additional groups seems useless in the present practical context, and the synoptic table of characters below (Table 1) 
Table 1

\begin{tabular}{|c|c|c|c|c|c|c|c|c|c|}
\hline character & 1 & 2 & 3 & 4 & 5 & 6 & 7 & 8 & 9 \\
\hline species & & & & & & & & & \\
\hline tonywhitteni & (d) & a & b & d & $\mathrm{a}$ & b & b & b & b \\
\hline ambang & a & $\mathrm{a}$ & b & $\mathrm{b} / \mathrm{c} / \mathrm{d}$ & $\mathrm{a}$ & $a /(b)$ & $b$ & b & $a>$ \\
\hline toraut & d & a & b & c & $\mathrm{a}$ & (b) & a & b & b \\
\hline imbutus & d & $b$ & b & c & $\mathrm{a}$ & $\mathrm{b}$ & a & $\mathrm{a}$ & $b$ \\
\hline sarasinorum & d & $\mathrm{a}$ & b & d & $\mathrm{a}$ & b & $\mathrm{a}$ & $\mathrm{a}$ & b \\
\hline gonipa & (d) & $a>b$ & b & $c>d$ & $\mathrm{a}$ & b & a & a & a \\
\hline griseoaeneus & a & $\mathrm{a}$ & b & d & a & b & a & $\mathrm{a}$ & a \\
\hline tambing & b & $\mathrm{a}$ & b & $b>c$ & $\mathrm{a}$ & $\mathrm{a}$ & $\mathrm{a}$ & $\mathrm{a}$ & $\mathrm{a}$ \\
\hline sulawesiensis & e & c & $\mathrm{b}$ & $\mathrm{d}$ & $\mathrm{a}$ & b & a & $\mathrm{b}$ & $b$ \\
\hline
\end{tabular}

\begin{tabular}{lllllllllll} 
fulvus & $\mathrm{a}$ & $\mathrm{a}$ & $\mathrm{a}$ & $\mathrm{a}$ & $\mathrm{b}$ & $\mathrm{a}$ & $\mathrm{c}$ & - & $\mathrm{b}$ & \\
spiculatus & $\mathrm{a}$ & $\mathrm{a}$ & $\mathrm{b}$ & $\mathrm{a}$ & $\mathrm{b}$ & $\mathrm{a}$ & $\mathrm{a}$ & $\mathrm{a}$ & $\mathrm{b}$ & $\mathrm{b}$ \\
$\begin{array}{l}\text { fuscostriatus } \\
\text { magnipygus }\end{array}$ & $\mathrm{c}$ & $\mathrm{a}$ & $\mathrm{b}$ & $\mathrm{a}$ & $\mathrm{a}$ & $\mathrm{a}$ & $\mathrm{a}$ & $\mathrm{b}$ & $\mathrm{b}$ & $\mathrm{b}$ \\
$\begin{array}{l}\text { rosenbergi } \\
\text { c }\end{array}$ & $\mathrm{c}$ & $\mathrm{a}$ & $\mathrm{b}$ & $\mathrm{a}$ & $\mathrm{a}$ & $\mathrm{a}$ & $\mathrm{a}$ & $\mathrm{b}$ & $\mathrm{b}$ & $\mathrm{b}$ \\
aureopilosus & $\mathrm{a}$ & $\mathrm{a}$ & $\mathrm{a}$ & $\mathrm{e}$ & $\mathrm{a}$ & $\mathrm{c}$ & $\mathrm{a}$ & $\mathrm{b}$ & $\mathrm{b}$ & \\
\hline character & 1 & 2 & 3 & 4 & 5 & 6 & 7 & 8 & 9
\end{tabular}

character

10

$11 \quad 12$

13

14

15

16

$17 \quad 18$

19

species

\begin{tabular}{|c|c|c|c|c|c|c|c|c|c|c|}
\hline tonywhitteni & b & $\mathrm{b}$ & $\mathrm{a}$ & $\mathrm{b}$ & $\mathrm{b}$ & - & a & $a>b$ & b & $6-6.5$ \\
\hline ambang & c & $a / b$ & $\mathrm{a} / \mathrm{d}$ & $\mathrm{a}$ & $\mathrm{a} / \mathrm{c}$ & $\mathrm{a}$ & - & $a / b$ & b & $3.5-5$ \\
\hline toraut & a & b & a & $\mathrm{a}$ & $a>b$ & - & - & a & $\mathrm{b}$ & $3-5$ \\
\hline imbutus & a & b & a & $\mathrm{b}$ & $\mathrm{b}$ & - & $\mathrm{b}$ & $\mathrm{a}$ & $\mathrm{b}$ & $7.5-10$ \\
\hline sarasinorum & a & b & a & $\mathrm{b}$ & b & - & $\mathrm{b}$ & (a) & $\mathrm{b}$ & $5.5-8.5$ \\
\hline gonipa & $\mathrm{b}$ & b & c & c & $\mathrm{b}$ & - & a & $\mathrm{b}$ & $\mathrm{b}$ & 8.5 \\
\hline griseoaeneus & $\mathrm{a}$ & b & (c) & b & b & - & a & b & b & $5.5-8$ \\
\hline tambing & a & $\mathrm{a}$ & $\mathrm{a}$ & a & $\mathrm{a}$ & - & a & b & $\mathrm{b}$ & $8-9$ \\
\hline sulawesiensis & a & b & c & a & a & - & - & a & b & $5-8$ \\
\hline fulvus & b & b & a & b & b & $\mathrm{a}$ & a & $\mathrm{a}$ & (b) & $4.5-6.5$ \\
\hline spiculatus & $\mathrm{a}$ & $b$ & a & c & $\mathrm{b}$ & b & a & b & $\mathrm{b}$ & $3.5-5.5$ \\
\hline fuscostriatus & $\mathrm{a}$ & b & a & $\mathrm{b} / \mathrm{c}$ & $b>d$ & $\mathrm{a}$ & a & a & b & $4.5-6$ \\
\hline magnipygus & $\mathrm{b}$ & b & a & a & $\mathrm{a}$ & - & - & a & a & $6-6.5$ \\
\hline rosenbergi & $\mathrm{a}$ & b & b & a & $b>c$ & a & a & b & a & $4.5-6.5$ \\
\hline aureopilosus & a & b & a & a & b & - & a & b & c & $6.5-13$ \\
\hline character & 10 & 11 & 12 & 13 & 14 & 15 & 16 & 17 & 18 & 19 \\
\hline
\end{tabular}


Table 1. Synoptic guide to species

\section{Characters and character states}

* character states marked with asterisk are most significant (unique in their group)

1. Clypeal apex (shape, major male)

a simply rounded to slightly truncate(-bisinuate)

b distinctly bisinuate

c distinctly bidentate

d lobate and reflexed (tip rounded)

$\mathrm{e}^{*}$ with long, slender, upright (spatuliform) protrusion

2. Border of head in front of clypeogenal transition (shape, major male)

a virtually continuous, very widely rounded

b slightly salient, abruptly curving, straight to apex

$c^{*}$ concave-sinuate

3. Clypeofrontal transition (shape, major male)

$\mathrm{a}^{*}$ with distinct transverse (more or less arcuate) ridge

$\mathrm{b}$ without transverse ridge

4. Vertex (shape, major male)

a at most with vague transverse swelling

b with low but distinct transverse median protrusion only

c with tapering median protrusion only

d with single median protrusion expanded laterad as (continuous or angulate) plate

$\mathrm{e}^{*}$ with a pair of paraocular protrusions and intervening lamina (cf. 6c)

5. Frons in front of posterior border of eyes (shape, major male)

a without transverse ridge

b with distinct transverse ridge

6. Anterior declivity of pronotum (shape, major male)

a evenly convex, (virtually) unmodified

b steep or protruding, well-defined, may be medially impressed

$c^{*}$ distinctly, evenly bulbous anteromedially, impressed on either side (cf. $4 \mathrm{e}$ )

7. Pronotal surface (type of microsculpture)

a simply punctate(-rugulate)

$\mathrm{b}^{*}$ annulate

$c^{*}$ densely asperate

8. Pronotal disc (density of punctation slightly away from midline)

a with punctures mostly separated by more than their diameter

b with punctures (or asperities) crowded, mostly separated by their diameter or less

9. Pronotal disc (pilosity)

a (virtually) glabrous

b with numerous setae

10. Elytral interstriae (microsculpture, on disc)

a simply punctate (or indistinctly micro-asperatepunctate)

b distinctly asperate

c distinctly granulate
11. Elytral interstriae (pilosity, on disc)

a (virtually) glabrous

b with numerous setae

12. Apical edge of protibia (upper side view, male)

a more or less transverse, at most slightly, broadly protruding (convex), apico-external denticle oblique to tibial axis

$b^{*}$ transverse, collinear with apico-external denticle, perpendicular to tibial axis

$c^{*}$ apico-internal angle projecting, apico-external denticle oblique to tibial axis

d with extra accrete apico-internal spine (underside view)

13. Colour of pronotum (apart from punctural infuscation)

a (virtually) unicolour black-brown

b (virtually) unicolour yellow-brown-orange

c distinctly (symmetrically) patterned (yellow-brown versus blackish)

14. Colour of elytra (apart from punctural infuscation and lighter margins)

a (virtually) unicolour black-brown

b (virtually) unicolour yellow-brown-orange (disc may be slightly infuscated)

$c^{*}$ distinctly (symmetrically) patterned (basal markings usually well defined)

d yellow-brown with striae distinctly infuscated (infuscation may be expanded)

15. Elytral colour pattern (conditional on 14c)

a dark with well-defined rufous or brownish markings on base and/or apex

b distinct, but different from a (not unicolour)

16. Punctation mostly

a not infuscated

b distinctly infuscated (at least on pronotum)

17. Dorsal light reflection (as seen from some distance, not magnified and strongly lighted)

a strong (shining, or shiny at least between microsculptural units, like punctures or granules)

b limited (matt, due to microsculptural features)

18. Parameres

a long, strongly sclerotized, evenly curved, tapering (in profile), tip dilated (upper side view)

b short, tip more or less (jointly) beak-like (axial view), with small distal-inferior paramerite

c short, tip not protruding, parameral tip spatulate

19. Estimated usual body length, in $(0.5) \mathrm{mm}$

symbols in table:

I more states occur

$>\quad$ intermediate state(s) occur(s)

() state slightly pronounced

- character or character state not applicable 
shows alternative grouping options better anyway - better than a dichotomous key. Character states particularly useful in species identification (unique to a limited number of species) are in the character list marked with an asterisk.

Virtually all our own Sulawesi material was collected by means of baited pitfall trapping, on forest sites (mainly multistratal evergreen forest), the Species accounts below and Appendix 1 listing further ecological details. The species treated in this paper are likely all endemic, and, although for most the number of records is limited, some are probably widespread over the island, occurring also in manmade environments. Thus far only one was found on both the mainland and a nearby smaller island (Selayer), but we know from other Onthophagus groups that several mainland species occur on Sulawesi's satellite islands.

Among the Sulawesi Onthophagus with a completely ridged pygidium no relatives of the species in our four groups were recognized, and, with one exception, relationships with congeners elsewhere also remain vague, to say the least. Some species in the Onthophagus imbutus group superficially look like those in the group around Onthophagus javanensis Balthasar, 1959 (Huijbregts \& Krikken 2011), mainly due to the presence of a tapering median postfrontal-vertexal plate in the male sex (character states $3 \mathrm{~b} \& 4 \mathrm{c} / \mathrm{d}$ in Table 1). Boucomont (1914) indeed placed some of them in his group 9 - incorrectly so, considering his statement that all group 9 members should have a ridged pygidial base. Only in one of our four groups extralimital relationships are obvious on the basis of the presence of a more complex (synapomorphic) vertexal ornamentation in the male sex (in our Table 1, character state 4e). This concerns the few species with a non-ridged pygidial base placed by Boucomont in his group 11, i.e. the group around Onthophagus orientalis Harold, 1868. The group has a single species on Sulawesi (dealt with below), and in addition to orientalis and other Sundaland taxa, one species is known from New Guinea (Onthophagus hirtuosus Gillet, 1930, cf. Balthasar 1969).

Due to the limited number of records per species, the taxonomic translation of interrelated phenomena like geographic variation, populational isolation, intraspecific polymorphism, and individual variation remains challenging. More material from lowland as well as upland localities (upland = over 1000 $m$ altitude) undoubtedly will reveal the existence of additional relatives of the (sub)species dealt with in this paper, including cryptic ones we have missed. Here the infraspecific diversity observed is straight- forwardly but briefly characterized, and in two polytypic species the recognition of subspecies, possibly representing cases of speciation on different parts of Sulawesi, was considered appropriate.

This paper is part of an ongoing series on laparostict scarabs of Sulawesi and other Southeast Asian islands. Most of the material recorded here was collected during Project Wallace 1985 and follow-up campaigns.

\section{Technical remarks}

Both the key and the synoptic table have been designed with major males in mind, as females and minor males not associated with major males may be hard to identify. Note that the qualification major males refers to the development of their structural ornamentation (mainly forebody elevations), and not necessarily to larger body size. After having reached a species name, always check the diagnoses of this species and any close group members for supplementary characters, taking into account polymorphism and individual variation. The numerous technical pictures of Onthophagus body parts in this paper should be helpful where textual description reaches its limits; for each species a male type or voucher specimen plus a standard set of body parts are depicted as is. In the pictures fringe features, like light marginal setae, may be obliterated in an equally light background. Although the parameral morphology of the species is relatively simple, and apical parts may be more or less membraneous, some features proved to be helpful in species identification (Figs 110-129); paramerites (as mentioned in Table 1, character state $18 \mathrm{~b}$ ) are sclerotized lateral(-inferior) protrusions near the tip of the parameres (consequently parameres may be auriculate in axial view, fig. 129). Unless explicitly mentioned otherwise, the parameres are, in upper side view, more or less tapering distad.

Observation and consequent interpretation of microsculpture and pilosity heavily depend on lighting circumstances under the microscope (we mostly use LED ring lights on our microscopes). The term asperate(-punctate) refers to the presence of fine, frequently granule-like integumental asperities, an asperity usually being placed on the periphery of a puncture depression and associated with a seta (the term stubble refers to a very short bristle). The puncture depression may be obliterated; the asperity may be very fine, just distinct at magnifications of $40 \times$ or higher. The term double punctation refers to the presence of two discrete size classes of punctation (primary and finer secondary) on a particular surface, usually the forebody; multi-sized refers to the 
presence of a continuous range of size classes. As for the presence of a non-ridged pygidial base: in case of doubt (slight fold may give impression of ridge), the character set given in the diagnosis under the group heading should always fit. The term full-face view, in descriptions and captions, refers to the general plane of a structural element being perpendicular to the line of view. Body length estimates rounded off to $0.5 \mathrm{~mm}$; body part measurements taken through the microscope with calibrated ocular micrometer scale, rounded off to $0.1 \mathrm{~mm}$.

As for nomenclature, in the Species accounts lectotypes are designated for six available species-group names with a risk of misinterpretation, i.e. cases where the original author cannot indubitably be assumed to have worked with a homogeneous syntype series and where any confusion with close relatives cannot be excluded.

The full lists of Material examined are given in Appendix 1 at the end of the paper in order not to unnecessarily clutter the running text with more detail. About 4650 specimens in 260 records, belonging to 17 species-group taxa, were seen. Holotype and lectotype label data are mentioned under the relevant species heading.

Note that the compass indications given for the island parts in the running text denote the four Sulawesi peninsulas (northern, eastern, southeastern, southern) and the central core, and that they do not necessarily correspond to any administrative divisions given on specimen labels (our eastern peninsula is in the Indonesian province of Central Sulawesi); widespread (in the list of species) means: recorded from at least three of these island parts. The \# symbol precedes sample codes. For further technical and terminological matters refer to companion papers, like Huijbregts \& Krikken (2009).

\section{Collections}

BMNH The Natural History Museum, London, UK

MBBJ Museum Zoologicum Bogoriense, Bogor/ Cibinong, Indonesia

MCGD Museo Civico di Storia Naturale Giacomo Doria, Genoa, Italy

PBouc Collection A. Boucomont (MNHN, Muséum National d'Histoire Naturelle, Paris, France)

$\mathrm{POb}$ Collection R. Oberthür (MNHN, Muséum National d'Histoire Naturelle, Paris, France)

RMNH National Museum of Natural History / NCB Naturalis, Leiden, Netherlands

ZMAN Zoological Museum Amsterdam / now NCB Naturalis, Leiden, Netherlands

The abbreviations indicate the current deposition of specimens.

\section{Taxonomy}

\section{List of Sulawesi Onthophagus species treated in this paper}

In order of systematic treatment in this paper, with indication of nomenclatural acts

Format:

species name author, date of publication, or sp.n. approximate range (type locality and type status, in parentheses); type status:

LT bold, lectotype designated in this paper (see Species accounts)

HT holotype

\section{Onthophagus Latreille, 1802}

ambang group (pronotum crowded with annular punctures)

tonywhitteni sp.n. - Sulawesi (central: Lake Tambing HT)

ambang sp.n. - Sulawesi: widespread (northern: Mt Ambang HT)

ambang ambang subsp.n - Sulawesi: widespread ambang morowali subsp.n. - Sulawesi: eastern (Morowali HT)

imbutus group (male vertex with median protrusion or ridge, pronotum with simple punctures)

toraut sp.n. - Sulawesi: widespread (northern: Toraut River region $\mathrm{HT}$ )

imbutus Sharp, 1875: 61 - Sulawesi: northern (Manado LT); South: Selayer

sarasinorum sp.n. - Sulawesi: widespread (central: Dongi-Dongi HT)

gonipa sp.n. - Sulawesi: northern (Mt Mogogonipa HT)

griseoaeneus Lansberge, 1885: 390 (= forsteni Lansberge, 1887: 18 syn.n., Tondano HT) - Sulawesi: widespread (Southeast: Kendari LT)

tambing sp.n. - Sulawesi: central (Lake Tambing HT), Southeast

sulawesiensis sp.n. - Sulawesi: northern (Mt Mogogonipa HT), Central

fuscostriatus group (male vertex lacking median protrusion, pronotum with simple punctures)

fulvus Sharp, 1875: 62 - Sulawesi: widespread (northern: Manado LT)

spiculatus Boucomont, 1914: 318 - Sulawesi: widespread (northern: Toli-Toli LT)

fuscostriatus Boucomont, 1914: 319 - Sulawesi: northern (Toli-Toli LT), Southeast

magnipygus Boucomont, 1914: 319 - Sulawesi: widespread (southern: Bantimurung HT) 
rosenbergi sp.n. - Sulawesi: widespread (northern: Mt Mogogonipa HT)

rosenbergi rosenbergi subsp.n. - Sulawesi: northern, central

rosenbergi divergens subsp.n. - Sulawesi: southeastern (Watuwila HT)

orientalis group (male vertex with pair of erect protrusions and intermediate lamina)

aureopilosus Boucomont, 1914: 299 - Sulawesi: widespread (southern: Patunuang LT)

\section{Key to Sulawesi species (males)}

\section{Key to groups}

1. Frontovertex posteriorly with transverse ridge, higher single elevation, or without any elevation

- Frontovertex with pair of horns and intervening lamina. Anterior declivity of pronotum medially bulbous between depressions on either side. Largest of all, up to $13 \mathrm{~mm}$ long. - Onthophagus orientalis group, one species on Sulawesi ............. aureopilosus

2. Pronotum may be crowded with punctures, but not annulate-punctate. Punctation of elytral interstriae usually simply punctate or finely asperate

- Pronotum crowded with superficial but distinct annular punctures, anterior declivity at most slightly protruding and/or medially depressed. Elytral interstriae distinctly granulate or asperate. Vertexal protrusion may be reduced, no ridge on clypeofrontal transition or between eyes. Clypeal apex anteromedially rounded, at most slightly lobate, not dentate or with long lobe. Protibial dentation unmodified ........ Key A ambang group

3. Vertex of major males always with some transverse elevation, medially usually with tapering denticle. Clypeal apex reflexed and rounded(-truncate), just expanded, or more strongly lobiform, in one species with longer projection

Key B imbutus group

- Any elevations on head situated between eyes and/or on clypeofrontal transition, vertex without any distinct elevation. Clypeal apex excised-bidentate, truncate, or widely rounded Key C fuscostriatus group

\section{Key A ambang group}

1. General colour black(-brown), matt, elytra may have rufous markings. Clypeal apex rounded or truncate. Dorsal pilosity short, 3 discally 2 rows of setae per interstria. Elytral interstriae abundantly to densely granulate. Metasternum usually black-brown. Smaller, usually up to $5 \mathrm{~mm}$ long. Males with or without vertexal denticle.

ambang, with 2 subspecies

- General colour brown(-yellow), slightly shiny, occasionally infuscated. Clypeal apex rounded, protruding and reflexed. Dorsal pilosity very long on all interstriae. Elytral interstriae finely asperate-granulate. Ventral side yellowish, metasternum patterned. Larger, over $5.5 \mathrm{~mm}$ long. Major males with tapering vertexal denticle tonywhitteni

\section{Key B imbutus group}

1. Clypeal apex at most with reflexed lobe (its tip rounded). Clypeal margin laterally widely curved (convex) or straight to apex (full-face view). Protibial apex at most slightly protruding. Colour different

- Clypeal apex with long, upright projection. Clypeal margin laterally concave (full-face view). Male protibial apex distinctly angularly expanded. Generally uniformly shiny black-brown .................. sulawesiensis

2. Pronotum without distinct symmetric colour pattern (irrespective of infuscated punctures) . . 3

- Pronotum simply deplanate, with distinct symmetric black(ish) versus yellow-brown pattern. Elytra finely but distinctly asperatepunctate-setose. Vertex with tapering median projection. Integument without distinctly infuscated punctures gonipa

3. Pronotum and elytra darker or lighter, but lacking infuscated punctures. Pronotum evenly convex or slightly impressed in front . . 5

- Yellow-brown, with at least pronotal punctures distinctly infuscated. Pronotum protruding in front

4. Punctures on all elytral interstriae large. Clypeal border from clypeogenal transition abruptly curving, thence straight to apical lobe. Male clypeus sparsely punctate. Basolateral ridge of vertexal protrusion low

imbutus

- Punctures on discal interstriae small, fine. Clypeogenal border evenly widely rounded to apical lobe. Male clypeus abundantly to densely punctate. Basolateral ridge of vertexal protrusion plate-like, high (arcuate ridge near eye) sarasinorum

5. Small, compact, shiny species (usually 4$5 \mathrm{~mm}$ long). Pronotal punctation dense to crowded 
- Relatively slender, larger, dorsally deplanate, matt species. Pronotal punctation less abundant, mostly separated by more than their own diameter.

6. Dorsum light (yellow-brown), more shiny. Vertexal denticle long, tapering .... griseoaeneus

- Dorsum dark (unicolour black-brown), remarkably matt. Vertexal denticle very short to obsolescent tambing

\section{Key C fuscostriatus group}

1. Male protibial apex unmodified, with apicoexternal denticle obliquely forward. Elytra unicolour, or with different pattern ......... 2

- Male protibial apex transverse, broad apicoexternal denticle subperpendicular to tibial axis, spur short. Elytra black or brown with distinct (rufous) brown markings, or more extensively brown; pronotum usually black. Clypeal apex bidentate

rosenbergi, with 2 subspecies

2. Pronotum usually unicolour yellow-brown or black; if patterned (disc infuscated), clypeal apex bidentate

\section{The Onthophagus ambang group}

\section{Group diagnosis}

Clypeal apex rounded-truncate or slightly lobate (in no way excised or bidentate). Clypeofrontal transition in both sexes without distinct elevation, males with variably developed tapering postfrontal-vertexal protrusion (dentiform, minor forms with transverse swelling only). Eye foramina narrow. Pronotum distinctly annulate-punctate, intra-annular surface superficial, matt due to microgranulation. Pronotal disc deplanate, base medially subangular. Elytral interstriae with numerous serially arranged or scattered granules (or asperities). Antennae not conspicuously modified, 9-segmented. Mentum slightly concave in front. Propectoral sides unmodified, with simple coxal-marginal ridge. Anterior intercoxal lobe of metasternum unmodified. Pygidial-propygidial transition subabrupt, but without discrete ridge. Protibia with 4 (3 larger + 1 smaller) external denticles; apex in upper side view not expanded, apicoexternal denticle oblique. Meso- and metatarsi slender, unmodified. Colour varying from light-brown to black; pronotum unicolour, elytra may have lighter (brownish, rufous, yellowish) basal and/or apical markings. Dorsum with numerous setae. Parameres with distal-lateral down-curved paramerite. Body length usually 3-6.5 mm.

3. Clypeal apex more or less bidentate. Clypeofrontal surface without any protrusion 4

- Clypeal apex rounded(-truncate). Frons with short transverse ridge between eyes; clypeofrontal transition with arcuate ridge. Distalexternal denticles of protibia broad. Both pronotum and elytra densely asperate-setose

4. Dorsal colour very variable, yellow-brown to largely black, pronotal margins remaining light, elytral striae may be infuscated versus lighter interstriae. Elytra with discal interstriae simply punctate-setose, shiny. Punctation of head simple. Paramers shorter, not elongate-curved fuscostriatus

- Dorsum unicolour dark (brown-black). Elytra with discal interstriae asperate-punctate-setose, matt. Punctation of head double. Parameres robust, elongate-curved .. magnipygus

\section{Onthophagus tonywhitteni sp.n.}

Figs 1, 17-23, 110

Material examined. Holotype male (RMNH) from C Sulawesi: Lore Lindu NP: Danau Tambing forest, 1600 m, 05-09/xiii/1985, J Krikken \#pw51a, multistr evergr forest, 4 human excr traps. Paratypes listed in Appendix.

\section{Diagnosis}

The following combination of characters sets Onthophagus tonywhitteni apart from the other Sulawesi species treated in this paper: the crowded annulate forebody punctation (which it shares with ambang), a dorsally light-brown colour, long brownish pilosity, finely granulate elytral interstriae (all of them, from disc to interstria 8), non-patterned pronotum and elytra, and a well-delineated yellowbrown versus black ventral colour pattern. Major males share the vertexal denticle with varieties of Onthophagus ambang, but that species has different attributes: forebody of ambang is black-brown; elytra 

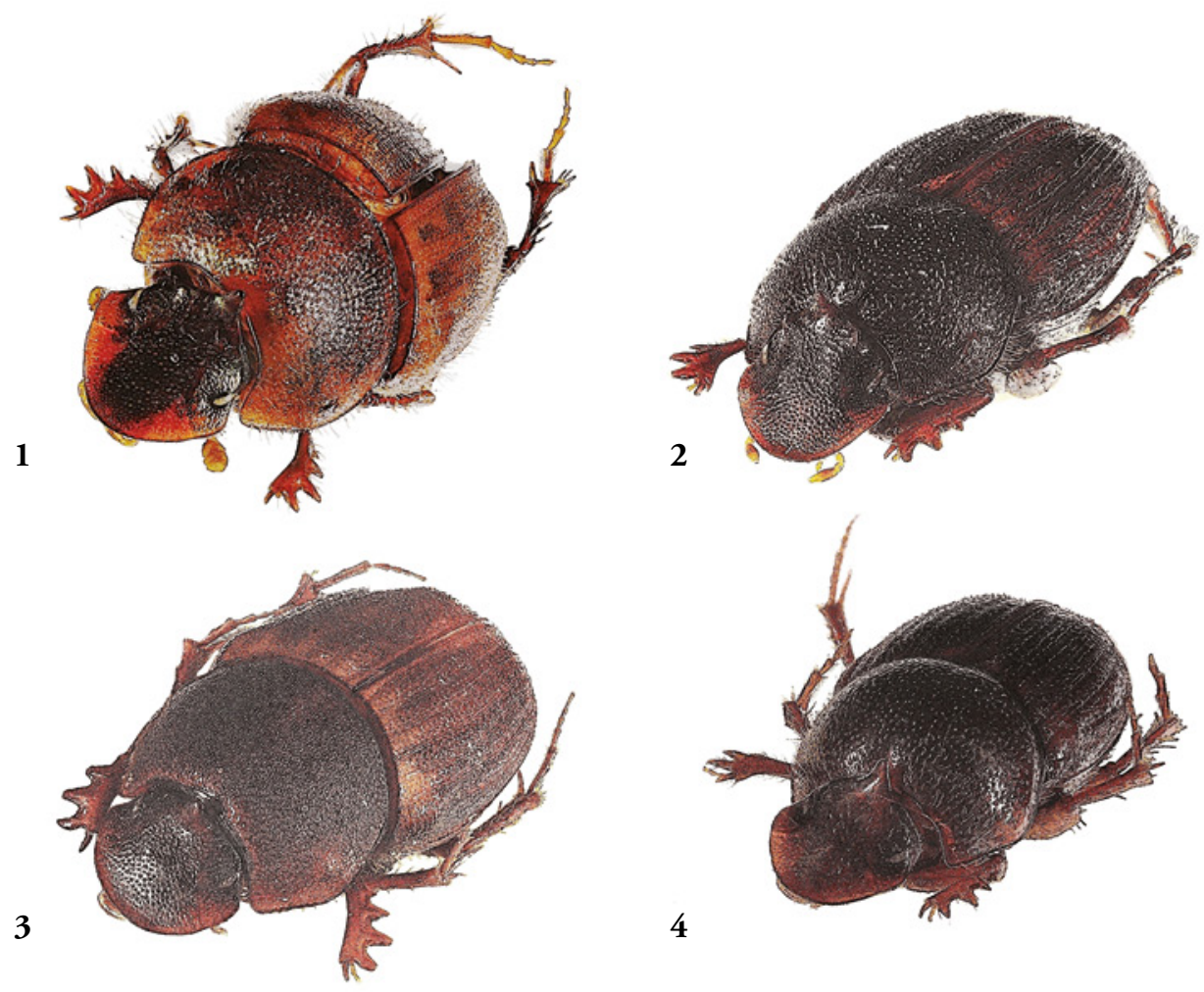

4
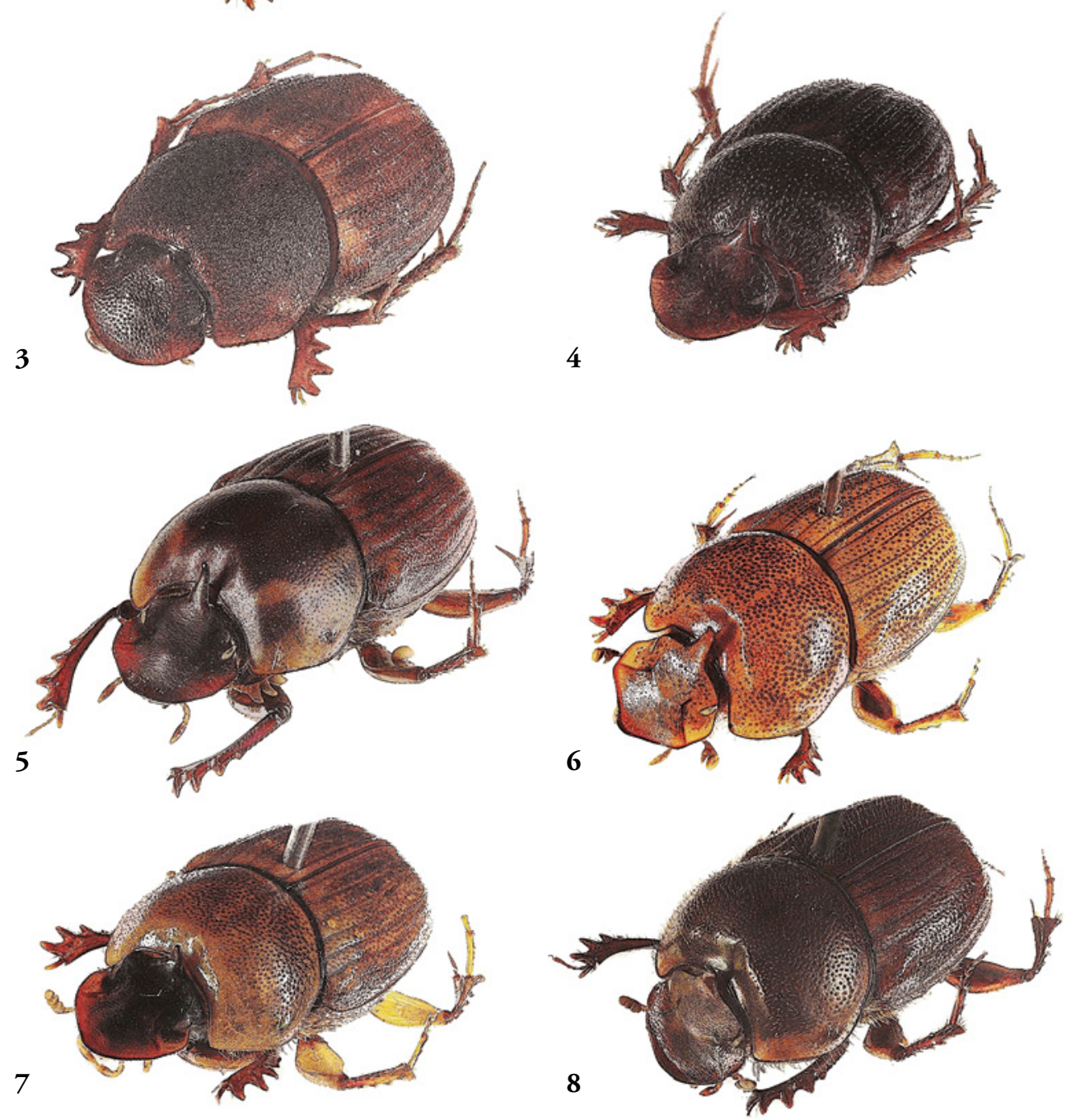

Figs 1-8. Habitus of Onthophagus species (oblique view), males, with indication of specimen status, locality, body length. - 1, O. tonywhitteni (holotype, $6.5 \mathrm{~mm}$ ); 2, ambang ambang (holotype, $5.5 \mathrm{~mm}$ ); 3, ambang morowali (holotype, $5.5 \mathrm{~mm}$ ); 4, toraut (holotype, $4 \mathrm{~mm}$ ); 5, gonipa (holotype, $8.5 \mathrm{~mm}$ ); 6, imbutus (Manado, $9 \mathrm{~mm}$ ); 7, sarasinorum (holotype, $8 \mathrm{~mm}$ ); griseoaeneus (Tawaeli, $7 \mathrm{~mm}$ ). 


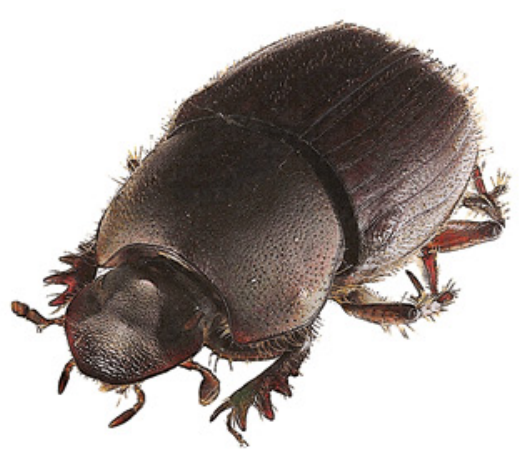

9
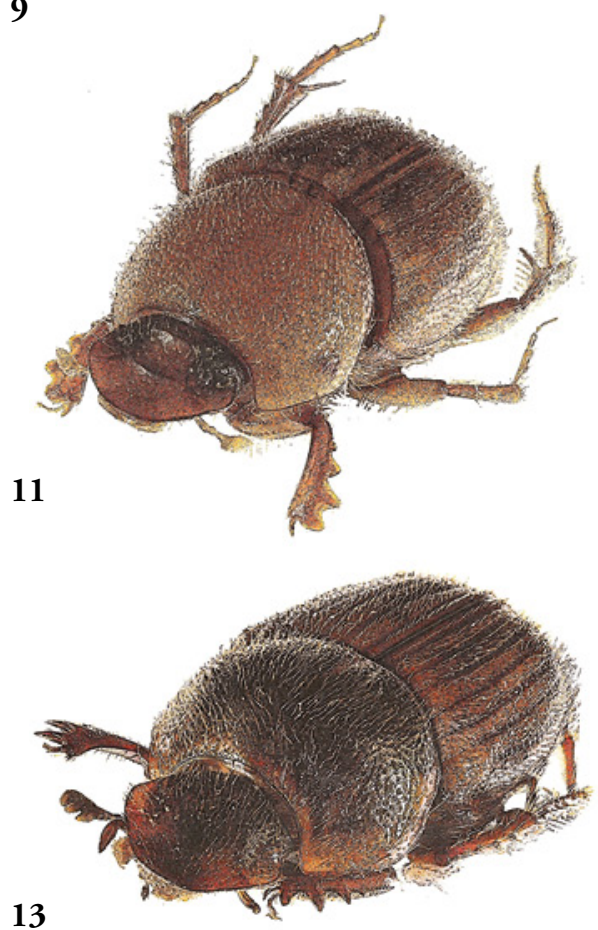

13

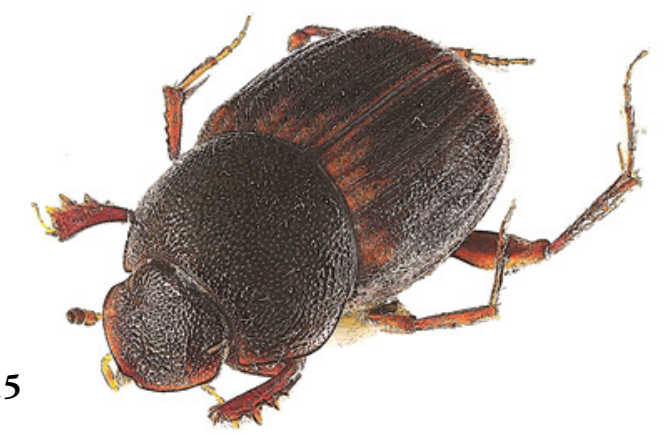

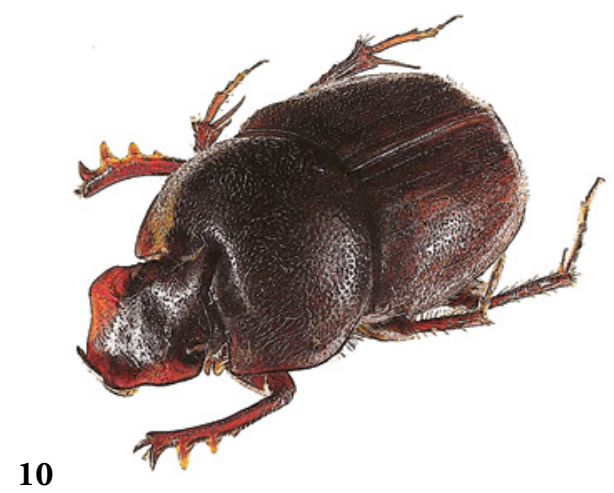

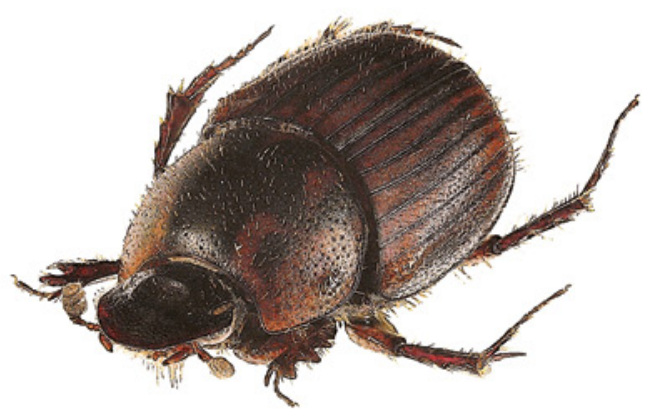

12

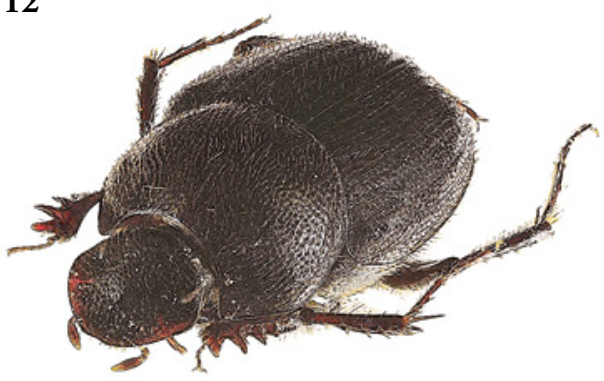

14

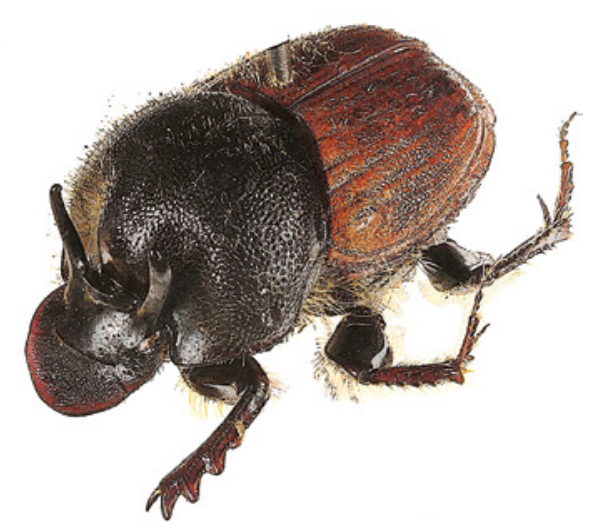

Figs 9-16. Habitus of Onthophagus species (oblique view), males, with indication of specimen status, locality, body length. -9 , O. tambing (paratype, Watuwila $8 \mathrm{~mm}$ ); 10, sulawesiensis (holotype, $7.5 \mathrm{~mm}$ ); 11, fulvus (Toraut, $5 \mathrm{~mm}$ ); 12, spiculatus (Tawaeli, $4.5 \mathrm{~mm}$ ); 13, fuscostriatus (Moramo, $6.5 \mathrm{~mm}$ ); 14, magnipygus (Batui, $6.5 \mathrm{~mm}$ ); 15 , rosenbergi rosenbergi (holotype, $5.5 \mathrm{~mm}$ ); 16, aureopilosus (Toraut, $11 \mathrm{~mm}$ ). 
ditto, or (partly) rufous; dorsum with much shorter setae and different microsculptural features. Further details of tonywhitteni as follows.

Dorsal setae very long, length locally up to about 7 times the diameter of associated annuli. Male clypeal apex slightly, narrowly lobate-reflexed. Clypeus with crowded, fine, double punctation; clypeogenal border virtually continuous, widely rounded. Clypeofrontal transition and frons lacking protrusions. Dentiform vertexal protrusion broad (strongly expanded at base, in this limited series not angulate laterad) in major males, obsolete in minor males and in females. Anterior declivity of major male pronotum distinct, impunctate, impressed behind vertexal protrusion. Apical edge of protibia (upper side view) not produced in any way, apico-external denticle oblique. Parameres with apex protruding beyond small distal paramerite, fig. 110. Most of dorsal side much lighter brown than in any ambang, and, although generally matt, under the microscope shiny between microsculpture (head with faint metallic lustre). Apparently larger than ambang, body up to ca $6.5 \mathrm{~mm}$ long.

\section{Description (holotype, male)}

Body length ca $6.5 \mathrm{~mm}$. Dorsal side generally deplanate. Colour generally light-brown, largely matt, partly infuscated; head with slight metallic lustre; metasternal disc and abdomen shiny yellowish, metasternal disc with symmetric dark markings; anterior margin of abdominal sternites infuscated. Pilosity pale-brownish, slender, dorsal side with very abundant, long, more or less erect, frequently recurved setae.

Clypeal margin slightly reflexed, apex with very short, broadly rounded lobe; clypeogenal transition very vaquely interrupted at border; head surface, except vertexal horn, with dense double punctation (diameter of secondary punctures mostly half the primary ones), primary punctures bearing seta, length of setae increasing from apex to frontovertex; clypeofrontal ridge absent. Genal border rounded. Postvertexal ridge distinct, with slight lateral angle on either side, medially with sharp, reclined denticle. Eye foramina narrow, with ca 7 facet rows across widest point. Ratio interocular distance / maximum (transverse, single) eye width ca 11.

Pronotum moderately convex, with anteromedian pair of approximated callosities, anterior declivity shallowly concave, impunctate; disc deplanate, midline impressed near base; anterior section of lateral border very slightly rounded (full-face view), anterolateral angle shortly rounded, subrectangular; posterior section of lateral border very slightly sinuate, posterolateral angle rounded off; base vaguely finely marginate, hardly angular medially; entire pronotal surface with large, crowded, seta-bearing, very distinct annulate punctures, intra-annular surface matt; setae very long, up to ca 7 annular diameters; puncture diameters mostly $0.06-0.09 \mathrm{~mm}$, some smaller mixed in.

Elytra uniformly brown, generally matt; shape of base and apex unmodified. Elytral striae all welldefined, with moderately distinct punctures, mostly separated by $2-4$ diameters, slightly crenulating interstrial edge. Interstrial surface at most very slightly convex, all with abundant, fine, seta-bearing granules, intergranular surface somewhat shiny; setae long, as on head and pronotum.

Antennal club brown-yellow, scapus unmodified. Propectus with lateral sides unmodified, with straight coxal-marginal ridge, surface punctatesetose. Metasternum with anteriorly abruptly declivous anteromedian lobe, surface along discal midline impression impunctate, remainder of disc with dense, fine, somewhat irregular but simple seta-bearing punctation; metasternal flanks densely subannulate-punctate; disc with symmetric blackish pattern. Yellowish abdominal sternites with narrow basal margin infuscated and with numerous setabearing subannulate punctures. Pygidium evenly slightly convex, uniformly yellow-brown; base with abrupt transition to different propygidial microsculpture; pygidial surface with dense seta-bearing, subannulate punctation, setal length up to ca 7 puncture diameters.

Legs brown. Protibia with 3+1 larger external denticles (apico-external denticle oblique), separated by fine serration; proximal serration consisting of 7-8 small denticles; tibial apex slightly convex (upper side view), without particular pilosity and apicointernal angle not produced; terminal spur elongateacuminate, slightly curved. Femoral undersides densely, unevenly, simply punctate-setose. Mesoand metatibiae relatively robust, strongly dilated distad, externally with ca 4 spine-bearing fossorial protrusions; apex with strongly transverse subelliptic apical, fringed largely with fine fossorial spines; mesotibial terminal spurs elongate-acuminate, metatibial spur long, tapering, distally feebly curved, apex somewhat blunted. Tarsi all long, slender, unmodified, with fine, sickle-shaped claws; metatarsomere slender, straight, almost as long as $2-5$ combined. Approximate length proportions metatibial spur // metatarsomeres 1-5: 15//20/8/5/3/7.

Parameres with protruding apex and small anteapical paramerite, fig. 110.

Measurements in mm. Maximum width of head 2.1. Median length of pronotum 1.9, maximum width 3.5. Sutural length of elytra 3.0, maximum width 3.8 . 


\section{Variation and sexual dimorphism}

Body length ca 6-6.5 mm. Known from male holotype and two paratypes only; the second male (ca 6 $\mathrm{mm}$ long) has no vertexal protrusion, and whether this is a normal morph in the total varietal range remains to be seen. Female has a slightly bisinuatetruncate clypeal apex and also lacks vertexal elevation, otherwise very similar to the male paratype. Clearly, more material is needed to fully characterize this species.

\section{Range and ecology}

Central upland of Sulawesi. In faeces traps, in upland forest.

\section{Etymology}

Dedicated to the indefatigable ecologist and helpful colleague Dr A.J. (Tony) Whitten (Flora and Fauna International, Cambridge UK, formerly World Bank, Washington DC), who, among other volumes, produced with his team a landmark monograph on the ecology of Sulawesi (Whitten et al. 1987).

\section{Onthophagus ambang sp.n.}

Figs 2-3, 24-30, 111

Onthophagus ambang ambang subsp.n. (key below) Onthophagus ambang morowali subsp.n. (key below)

Material examined. Holotype male of Onthophagus ambang ambang (RMNH) from N Sulawesi: Mt Ambang NR (20 km E of Kotamobagu), 1120 m, 09-13/ix/1985, J. Huijbregts \#HH443A, multistr evergreen forest, 2 human excr traps. Paratypes listed in Appendix.

Holotype male of Onthophagus ambang morowali (BMNH) from E Sulawesi: nr Morowali, Ranu River Area, 27/i-20/iv/1980, M.J.D. Brendell, BM1980280, lowland rainforest. Paratypes listed in Appendix.

\section{Diagnosis}

Onthophagus ambang is closely related to the preceding species, and in Central Sulawesi it was trapped together with tonywhitteni on an upland forest site (Lake Tambing). The latter species is distinguishable from the variable ambang by its finer elytral granulation, generally lighter colour, longer pilosity, different genitalia, and more. Our present concept of ambang is broad and includes two subspecies (see key below); the following set of attributes should aid in the identification of this species.

Dorsal pilosity whitish, shorter than in tonywhitteni, on pronotum up to about 3 puncture diameters long. Head with fine, dense to crowded, double puncta- tion, posteriorly more or less annulate (between eyes, up to protrusion in holotype). Clypeal apex rounded to truncate, margin slightly, narrowly reflexed; clypeogenal border virtually continuous, widely rounded. Clypeofrontal transition and frons lacking protrusions. Male vertexal protrusion varies from large, dentiform horn, with or without angular expansion on either side, to mere transverse swelling. Anterior declivity of pronotum medially slightly impressed in males with well developed vertexal protrusion, not distinctly smooth and shiny. Pronotum crowded with annulate punctation. Elytral interstriae distinctly granulate-setose, setae on discal interstriae serially arranged (in two rows from interstria 2 on). Ventral side and pygidium usually black-brown. Apical edge of protibia (upper side view) not produced, but may have short spiniform apico-internal angle (underside view); apico-external denticle oblique. Base of pygidium folded, but lacking discrete ridge. Parameres with apex protruding beyond small distal paramerite, fig. 111. Forebody, and usually most of dorsal side, dark brown to black, and generally matt (subsp. ambang); elytral base and apex may have distinct rufous markings (subsp. morowali, fig. 3), which may extend over entire elytron; pronotum not patterned. Specimens in series all smaller than tonywhitteni, up to ca $5.5 \mathrm{~mm}$ long.

\section{Description (holotype, male)}

Body length ca $5.5 \mathrm{~mm}$. Habitus deplanate. Colour generally black-brown, matt, due to dense microsculpture, but somewhat shiny between microsculptural units. Pilosity rather stout, pale-white, dorsum with very abundant, more or less erect setae, short on disc, longer on sides.

Clypeus black, margin brownish, with apex broadly rounded, slightly reflexed; clypeogenal transition not interrupted at border; clypeofrons finely, densely punctate, discally annulate-punctate, with few setae; clypeofrontal ridge absent. Genal border fully rounded. Postvertexal ridge distinct, with lateral angle on either side and with sharp, smooth, reclined median angle. Eye foramina narrow, with ca 6 facet rows across widest point. Ratio interocular distance / maximum (single, transverse) eye width ca 15 .

Pronotum black, moderately convex, anterior declivity slightly convex, medially slightly depressed; disc deplanate, midline slightly impressed near base; anterior section of lateral border virtually straight (full-face view), anterolateral angle shortly rounded, subrectangular; posterolateral section of lateral border very slightly sinuate, posterolateral angle rounded off; base vaguely finely marginate, hardly angular medially. Entire pronotal surface with crowded, setabearing, annulate punctures, intra-annular surface 


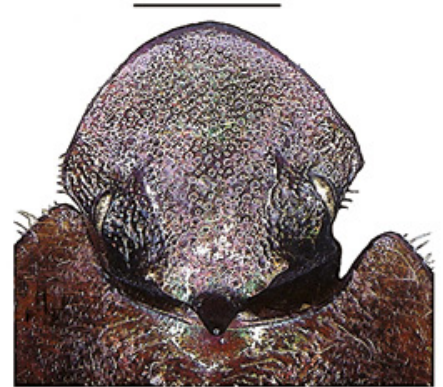

17

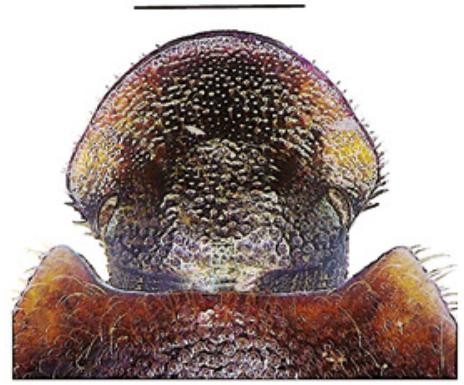

18

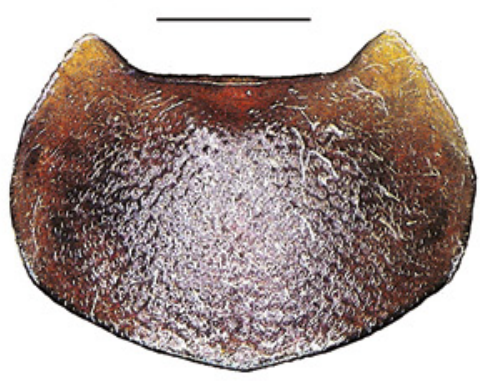

19

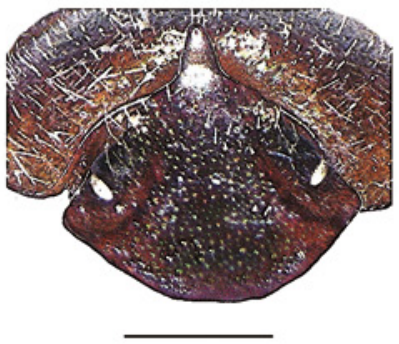

21

22
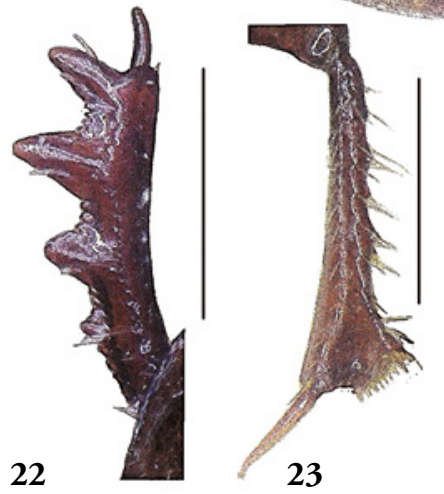

23

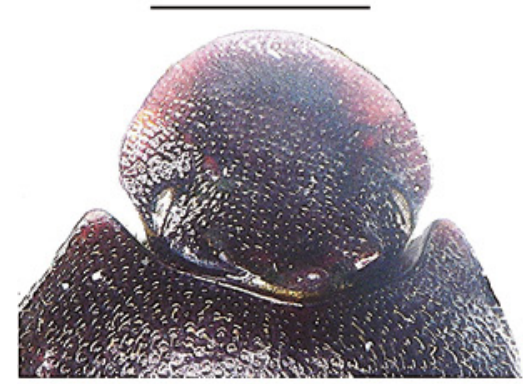

24

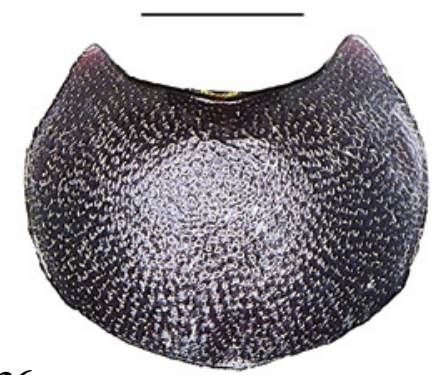

26

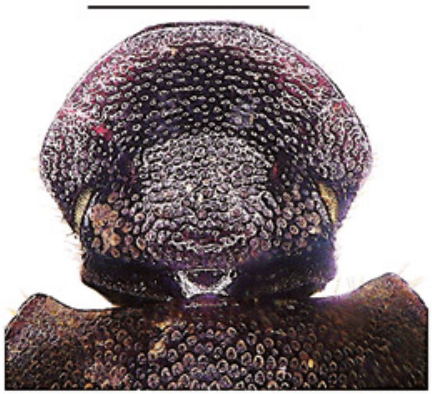

25

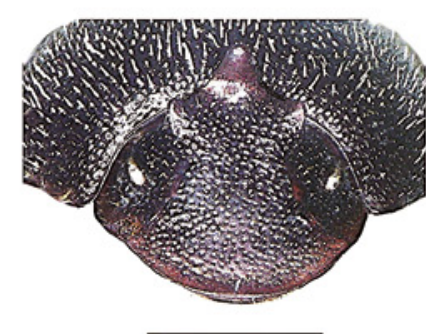

28

29
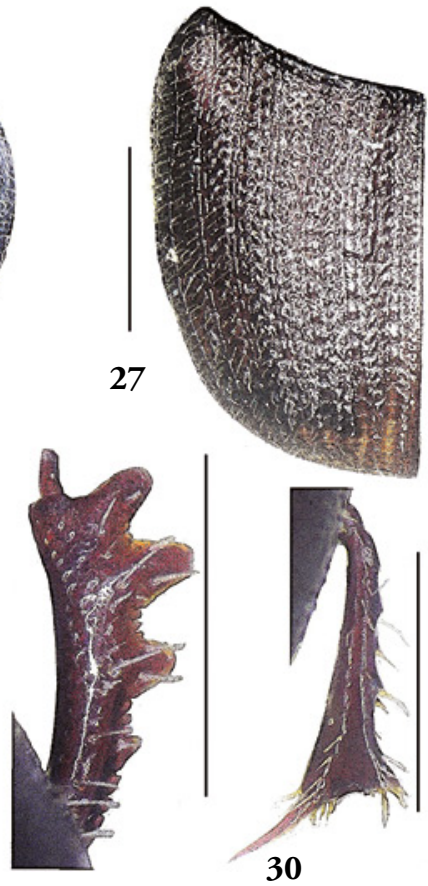

Figs 17-30. Contours of male head Onthophagus species (17, 24, full-face view, 21, 28, axial, with pronotal declivity), female head (18, 25, full-face); male pronotum (19, 26, dorsal), elytron (20, 27, dorsal), protibia (22, 29, upper side), metatibia (23, 30, upper side). - 17-23, O. tonywhitteni (holotype, 18 paratype female Tambing); 2430, ambang ambang (holotype, 25 paratype female Watuwila). - Scale lines $1 \mathrm{~mm}$. 

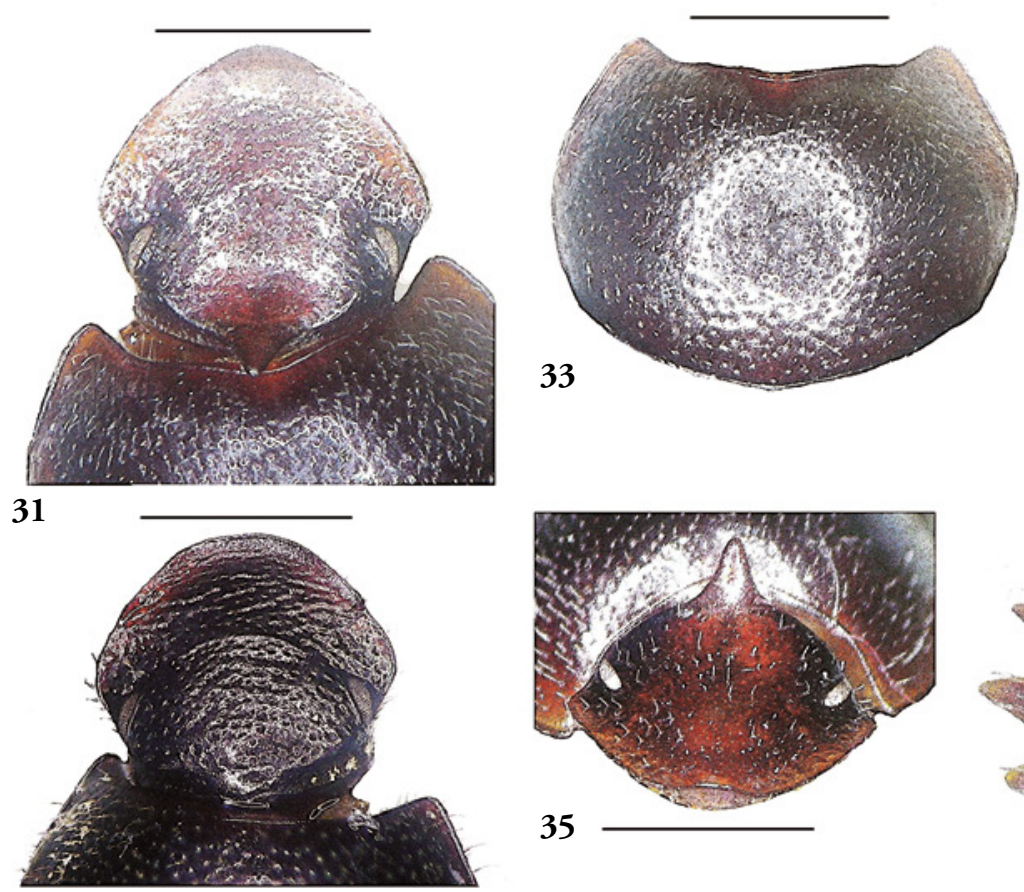

32

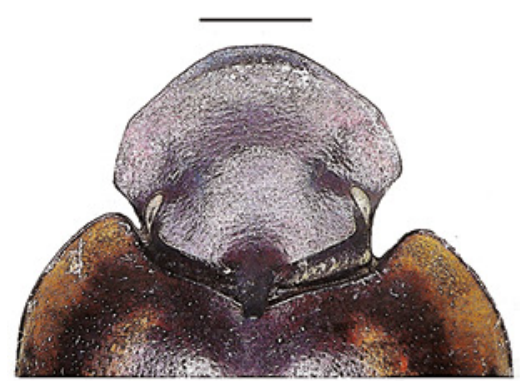

38
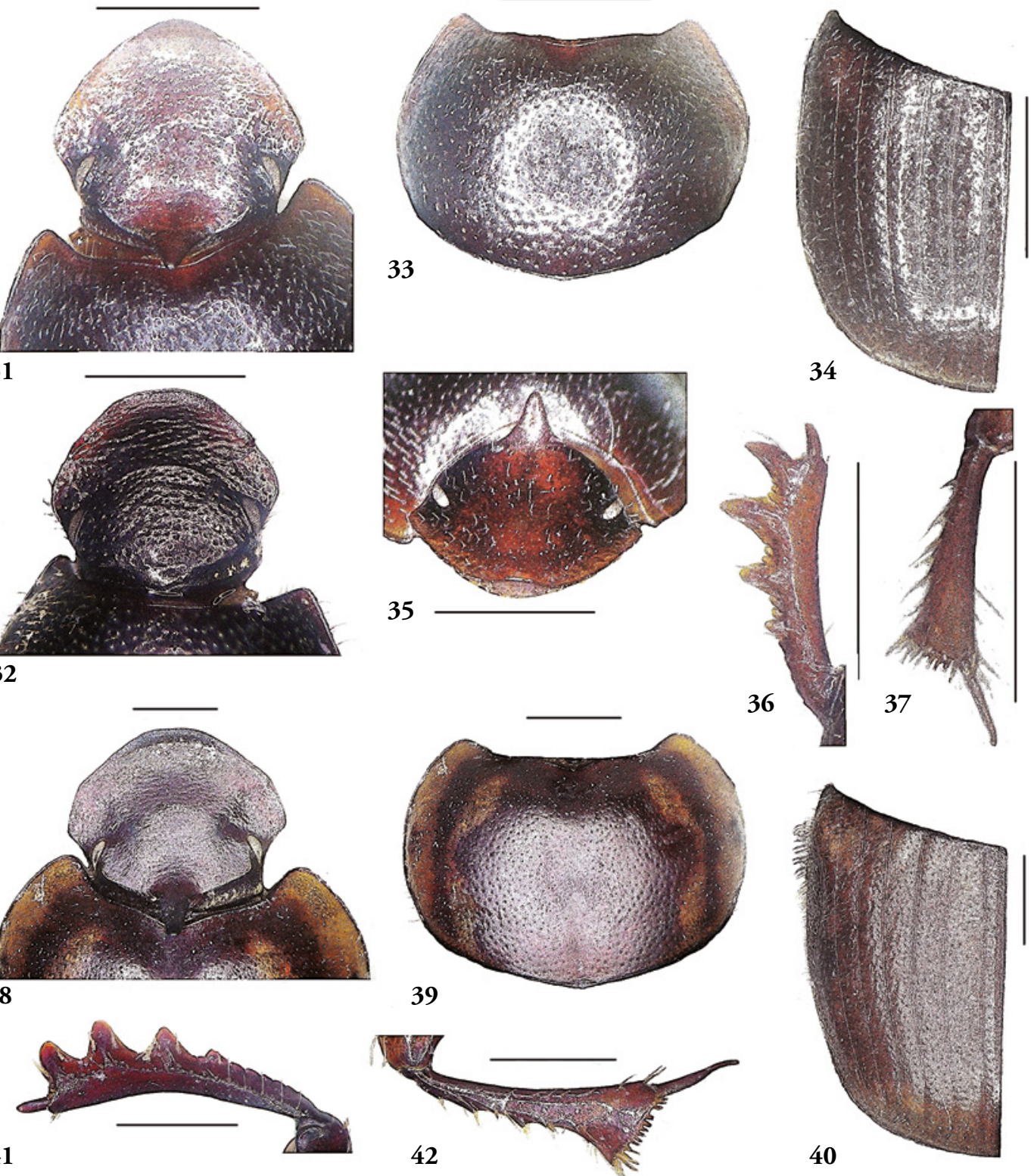

41

42

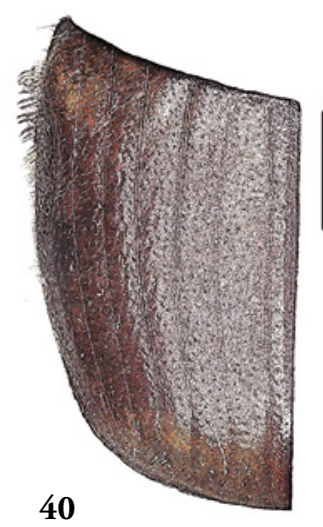

Figs 31-42. Contours of male head Onthophagus species (31, 38, full-face view, 35, axial, with pronotal declivity), female head (32, full-face); male pronotum $(33,39$, dorsal), elytron (34, 40, dorsal), protibia (36, 41, upper side), metatibia (37, 40, underside). -31-37, O. toraut (holotype, 32 paratype female Dongi-Dongi); 38-42, gonipa (holotype). - Scale lines $1 \mathrm{~mm}$. 
matt; setae short on disc, longer on sides up to ca 3 annular diameters long; puncture diameters mostly $0.04-0.07 \mathrm{~mm}$.

Elytra almost uniformly dark-brown (few lighter streaks on apex), slightly shiny; shape of base and apex unmodified. Elytral striae shiny, all welldefined, with moderately distinct punctures, mostly separated by 3-5 diameters, slightly crenulating interstrial edges. Interstrial surface at most slightly convex, with dense seta-bearing granules, intergranular surface somewhat shiny; lateral interstriae somewhat rugulate; setae on disc short, 2-3 times granular length, mostly arranged in 2 rows per interstria.

Antennal club brown-yellow, scapus unmodified. Propectus with unmodified coxal-marginal ridge, surface punctate-setose. Metasternum uniformly shiny dark-brown, locally with numerous punctures; anteromedian lobe slightly declivous in front; metasternal flanks densely subannulate-punctatesetose. Abdominal sternites dark-brown, basal zone with numerous seta-bearing, subannulate punctures. Pygidium dark-brown, slightly convex; base with abrupt transition to different propygidial microsculpture; pygidial surface with dense seta-bearing, annulate punctation, setal length up to ca 5 puncture diameters.

Legs brown. Protibia with 3+1 larger external denticles (apico-external denticle oblique), separated by fine serration; proximal serration consisting of 6 small denticles; tibial apex slightly convex (upper side view), with fine, spiniform apico-internal protrusion; terminal spur elongate-acuminate, slightly curved. Femoral undersides all densely, evenly, simply punctate-setose. Meso- and metatibiae relatively robust, strongly dilated to transversely subelliptic apical, which is largely fringed with short fossorial spines; external side with ca 4 sine-bearing fossorial protrusions; mesotibial terminal spurs elongateacuminate, metatibial spur long, tapering, distally feebly curved, apex somewhat blunted. Tarsi all long, slender, unmodified, with fine, sickle-shaped claws; metatarsomere 1 slender, straight, slightly longer than 2-5 combined. Approximate length proportions of metatibial spur // metatarsomeres 1-5: 25//30/11/7/6/10.

Parameres with protruding apex and small anteapical paramerite, fig. 111.

Measurements in mm. Maximum width of head 1.6. Median length of pronotum 1.8, maximum width 2.6. Sutural length of elytra 2.2 , maximum width 2.9.

\section{Variation and sexual dimorphism}

Body length 3.5-5.5 mm. Vertex of minor males may be unarmed; the holotype, with its angularly expanded vertexal denticle, seems to be a major male of this polytypic species. Females without vertexal ornamentation. Length of morowali type ca $5.5 \mathrm{~mm}$. Variation considerable, including the following characters:

- Development of male vertexal protrusion (from transverse median swelling to denticle with lateral angular expansion).

- Delimitation and median impression of anterior pronotal declivity in male (related to preceding character).

- Microsculpture of head surface (density, size, type of punctation).

- Granulation of elytral interstriae (granule shape and size, density, differences discal versus lateral interstriae).

- Light reflection on surface (on and between microsculptural units).

- Dorsal pilosity (density, setal length).

- Any dorsal colour pattern (uniform, elytra lighter than pronotum, presence of rufous markings).

- Any colour pattern of ventral side (symmetric, dark versus light).

- Apico-internal projection of male protibia.

Two subspecies may be recognized as follows:

1. Elytra (nearly) uniformly dark black-brown. Vertexal denticle with or without angular lateral expansion, or more or less reduced. N, C, SE Sulawesi upland

- Elytra symmetrically patterned, dark with (variably extensive) rufous markings. Vertexal denticle small, not laterally angularly expanded at base. E Sulawesi lowland

ambang morowali subsp.n.

\section{Range and ecology}

Sulawesi, apparently widespread and polytypic, not yet seen from the South. Mainly in faeces traps, in forest.

\section{Comments}

As implied in the Introduction, we struggled with the interpretation of the variation seen within and between series of ambang-like specimens and with any geographical or ecological correlation. For the time being we stick to the distinction of two subspecies, as indicated in the key above. Onthophagus ambang morowali appears to be a patterned East Sulawesi lowland form; the other specimens are here united in the nominotypical subspecies Onthophagus ambang ambang, an apparently upland dark subspecies ranging from $\mathrm{N}$ to $\mathrm{SE}$ Sulawesi. 


\section{Etymology}

Name ambang refers to an interesting North Sulawesi mountain area where the holotype of this species was first discovered; later we saw the species, as here conceived, from several other regions; name to be treated as masculine noun. Name morowali refers to the type locality of Onthophagus a. morowali on the eastern peninsula, also to be treated as masculine noun.

\section{The Onthophagus imbutus group}

\section{Group diagnosis}

Male clypeal apex expanded or simply rounded, truncate or bisinuate, more or less reflexed (apex not deeply emarginate, not bidentate). Male clypeofrontal ridge more or less effaced (at least in major males), frontovertex with variably developed, tapering median protrusion between (or between posterior border of) eyes, at least with indication of transverse ridge. Eye foramina narrow. Pronotal surface simply punctate (not annulate-punctate). Pronotum without protrusions other than (in some species) bluntly protuberant transverse ridge topping anterior declivity. Pronotal base subangular. Elytral interstriae simply punctate, or finely asperate (not distinctly granulate). Anterior intercoxal lobe of metasternum unmodified. Pygidial base without ridge. Antennae not conspicuously modified, 9-segmented. Mentum slightly concave in front. Propectoral sides unmodified, with simple coxal-marginal ridge. Protibia with 4 (3 larger +1 smaller) external denticles, apico-external denticle oblique; apex of male protibia may be more or less expanded (angular). Meso- and metatarsi slender, unmodified. Colour yellow to black, uniform or patterned, some species with numerous infuscated punctures on light background. Body length usually $4-10 \mathrm{~mm}$.

This group appears somewhat heterogeneous, as evident from Table 1. The Onthophagus imbutus-sarasinorum twin stands out by its yellowish colour with an infuscated punctation. Onthophagus sulawesiensis is remarkable by its shining, unicolour dark appearance with a conspicuously lobate clypeal apex in major males.

\section{Onthophagus toraut sp.n.}

Figs 4, 31-37, 112

Material examined. Holotype male (RMNH) from N Sulawesi: Dumoga Bone NP: Toraut R3, 245 m, 08-10/v/1985, J. Huijbregts \#HH311D, multistr evergr forest, 4 human excr traps. Paratypes listed in Appendix.

\section{Diagnosis}

The compact appearance, small size, and strongly reduced proximal protibial denticle of Onthophagus toraut are somewhat reminiscent of the species in the Onthophagus variolaris group (Sulawesi representatives of this group discussed in Krikken \& Huijbregts 2008), but toraut clearly lacks some decisive characters, and has, of course, no ridged pygidial base. Pronotal punctation relatively strong, dense to crowded, and simple, contrary to the members of the Onthophagus ambang group treated above, which have a conspicuously annulate, superficial punctation. Elytral interstriae of toraut finely punctate-setose (surface may be quite uneven, but not granulate or asperate); punctures on discal interstriae serially arranged.

Head with dense multi-sized punctation. Apical lobe of male clypeus rounded, narrow, short, distinctly reflexed; outline of clypeal apex of female simply rounded. Clypeofrontal transition and frons in both sexes lacking distinct elevations; clypeogenal border at suture widely, evenly rounded. Anterior declivity of male pronotum at most vaguely depressed behind small vertexal denticle; female without denticle. Pronotal base finely marginate. Pronotal surface with numerous setae in dense to crowded punctation. Apical edge of protibia not expanded, apico-external denticle slender, oblique, proximal external denticle very small. Parameres with apex hardly extended beyond distal-lateral paramerite, fig. 112. Dorsum black to brown, shiny (frequently with slight metallic lustre), elytral base and apex may have rufous markings. Small, body usually 3-5 mm long.

\section{Description (holotype, male)}

Body length ca $4.5 \mathrm{~mm}$. Habitus compact-convex. Colour generally black-brown, largely shiny; some parts rufous (base and apex of elytra) or yellowish (meso- and metafemora, parts of abdomen). Pilosity pale-white, dorsal side with numerous, moderately long, more or less erect setae.

Clypeal apex anteromedially produced into reflexed, subtriangular lobe, its apex rounded off; clypeogenal transition virtually continuous, thence widely rounded to apex; clypeofrontal ridge absent; head surface with abundant to dense double punctation (diameters of secondary punctures half the primary ones), most primary punctures with seta. Genal border rounded. Vertex with reclined median denticle, its apex acute, with distinct, evenly widely curved basolateral ridge. Eye foramina narrow, with ca 7 facet rows across widest point. Ratio interocular distance / maximum (transverse, single) eye width ca 17. 


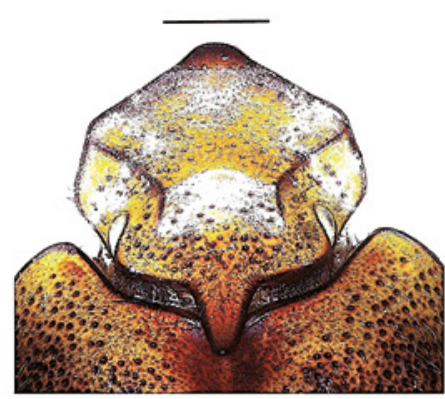

43

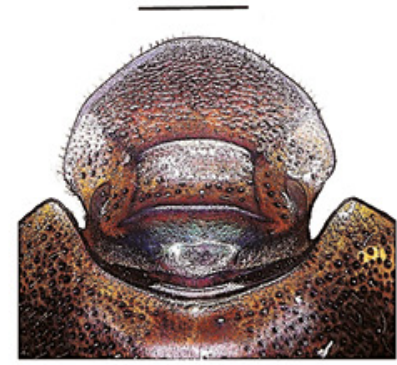

44

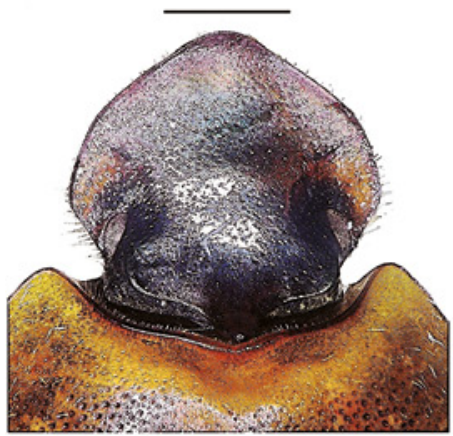

49

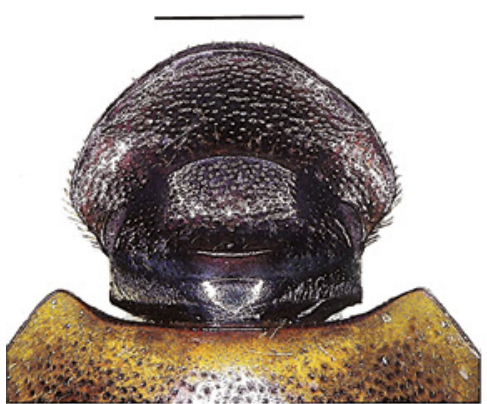

50

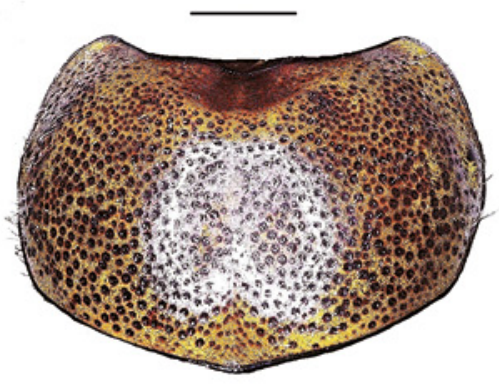

45

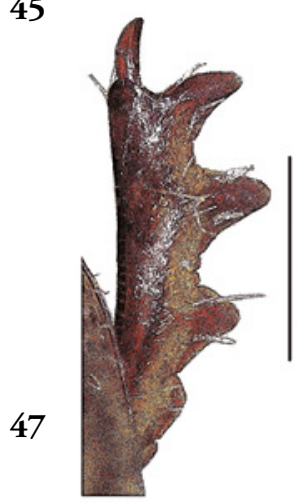

46
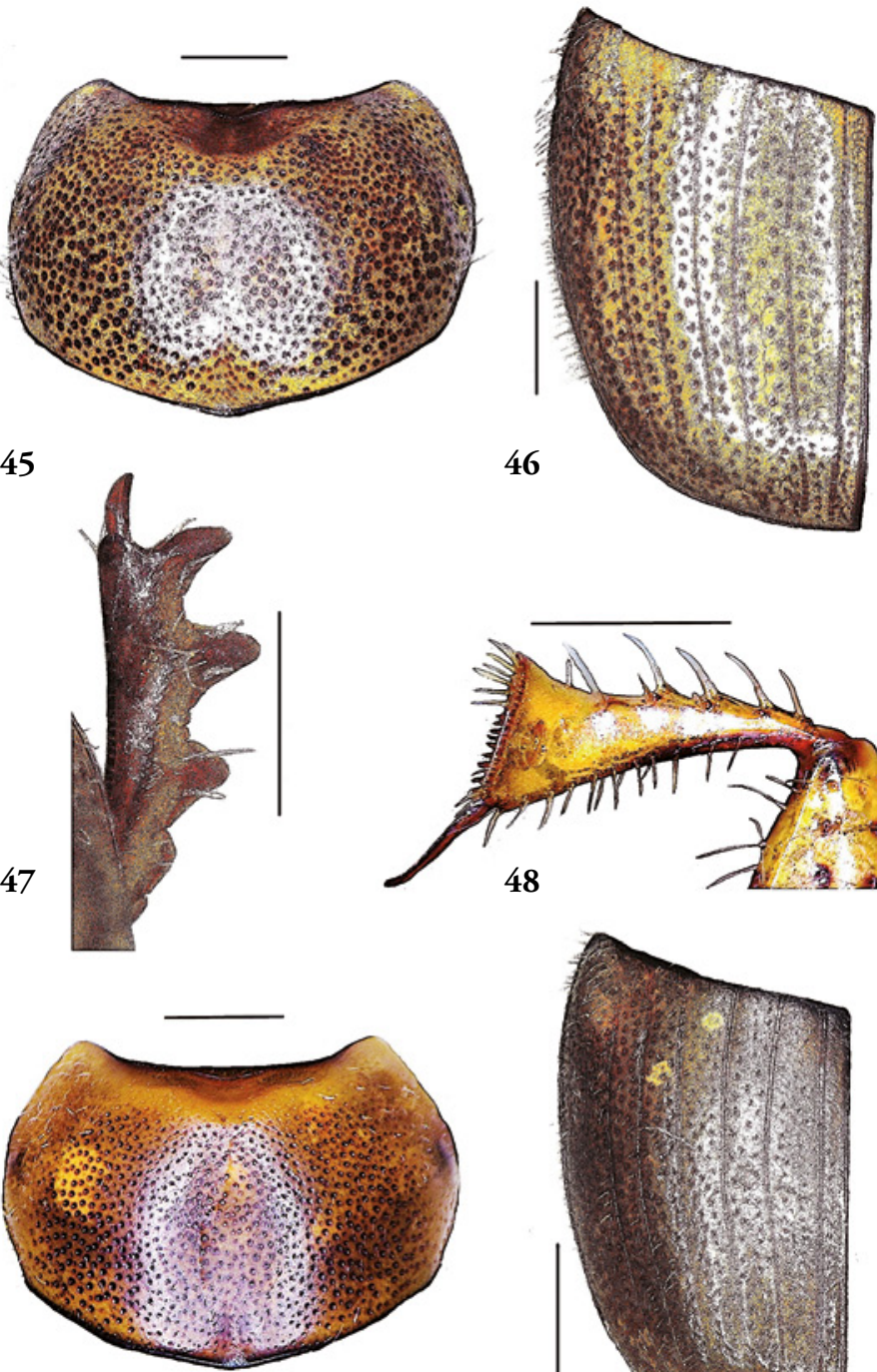

51

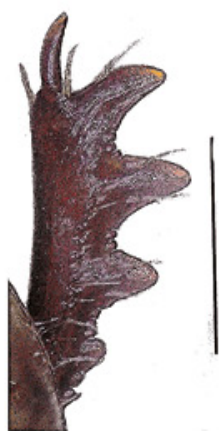

53

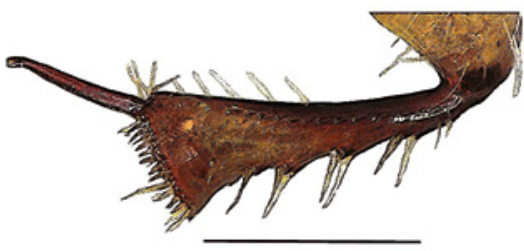

54

Figs 43-54. Contours of male head Onthophagus species (43, 49, full-face view), female head (44, 50, full-face); male pronotum $(45,51$, dorsal), elytron $(46,52$, dorsal), protibia $(47,53$, upper side), metatibia (48, 54, underside). - 43-48, O. imbutus (male Manado, 44 female Manado); 49-54, sarasinorum (holotype, 50 paratype female Mogogonipa). - Scale lines $1 \mathrm{~mm}$. 


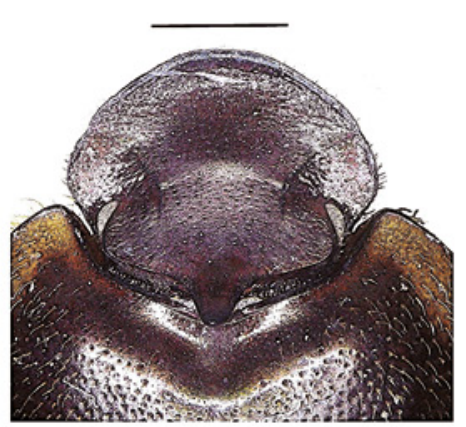

55

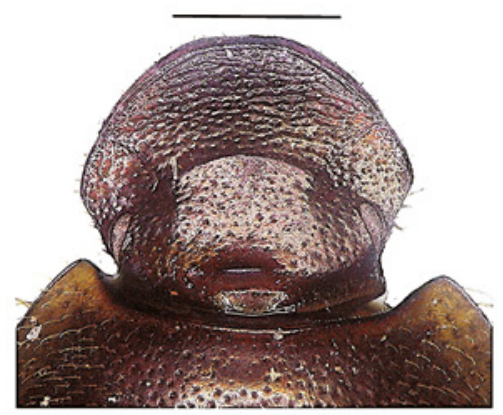

56

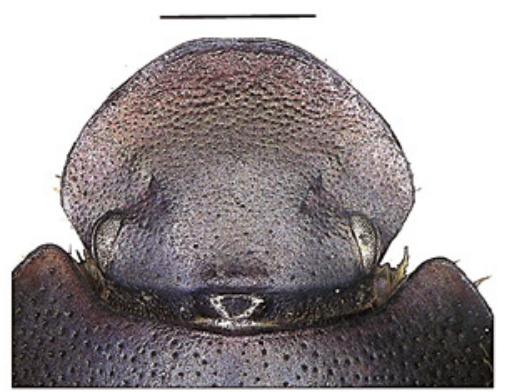

61

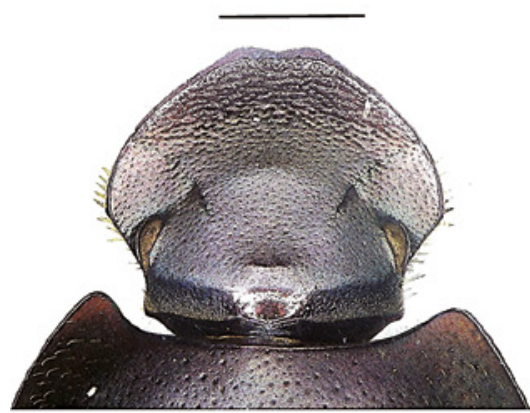

62

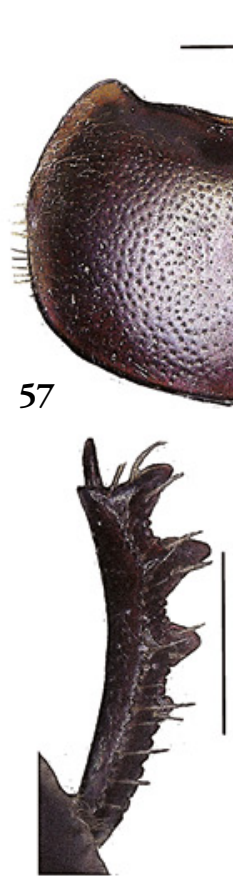

59

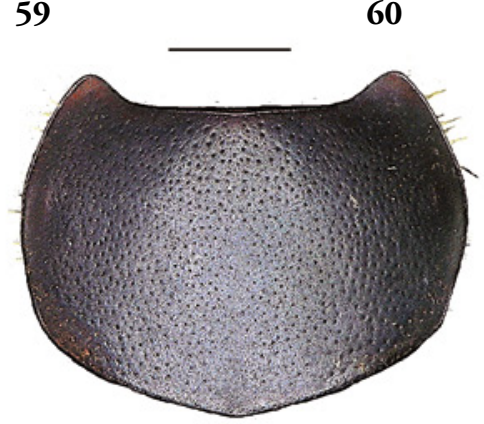

63

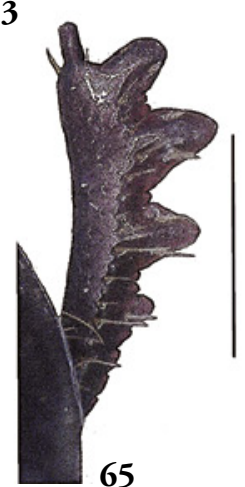

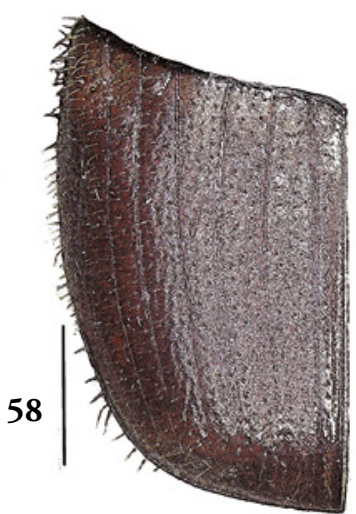

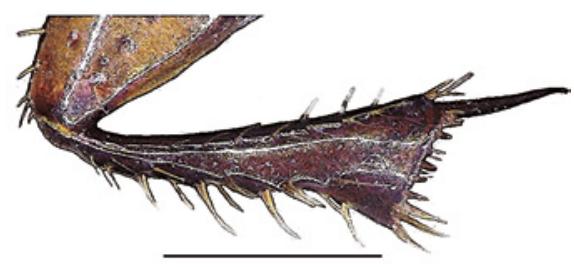

60

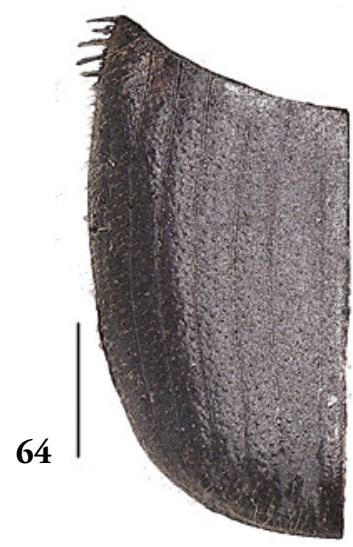

Figs 55-66. Contours of male head Onthophagus species (55,61, full-face view), female head (56, 62, full-face); male pronotum $(57,63$, dorsal), elytron $(58,64$, dorsal), protibia $(59,65$, upper side), metatibia $(60,66$, underside). - 55-60, O. griseoaeneus (male Tawaeli, 56 female Toraut); 61-66, tambing (holotype, 62 paratype female Watuwila). - Scale lines $1 \mathrm{~mm}$. 
Pronotum strongly convex, midline impressed near base; anterior declivity rather steep, with impression behind vertexal horn; anterior section of lateral border straight, anterolateral angle subrectangular, shortly rounded; posterior section of lateral border slightly sinuate, posterolateral angle rounded off; base widely rounded, hardly angular medially, finely marginate $(\times 60)$. Entire pronotal surface with very abundant to dense, rather evenly distributed setabearing punctation, setal length up to ca 5 puncture diameters; punctures simple, their diameters on disc 0.04-0.06 mm; secondary punctures minute, sparse. Elytra dark brown, shiny, base and apex lighter; shape of base and apex unmodified. Elytral striae discally well defined, with distinct punctures, mostly separated by $2-4$ times their diameter, slightly crenulating interstriae. Interstrial surface very slightly convex, with moderately abundant, minute, subserially arranged seta-bearing punctures (one longitudinal row on interstria 1 , two on 2-5).

Antennal club yellowish. Mentum shallowly emarginate in front. Propectus with scattered seta-bearing punctures on lateral surface, coxal ridge running straight to lateral border. Metasternum with vague midline impression, midline zone without primary punctures, remainder with abundant (disc) to dense (lateral lobe) seta-bearing punctation. Abdominal sternites with narrow basal zone of numerous simple seta-bearing punctures. Pygidial disc dark, remainder yellow-brown, with crowded, simple, seta-bearing punctation, length of most setae up to ca 4 puncture diameters; base non-ridged.

Protibia with $3+(1)$ external denticles (apico-external denticle oblique, proximal denticle very small), plus fine intervening serration; proximal serration consisting of ca 7 fine denticles; terminal spur long, slender, acuminate, slightly curved. Mesotibial terminal spurs long, acuminate, unmodified; metatibial spur long, acuminate, distally feebly sinuate, apex truncate. Femoral undersides with numerous scattered seta-bearing punctures. Meso- and metatibiae slender, dilated distad, with 4 or 5 slight, spinebearing external protrusions; apex with strongly transverse subelliptic crest, largely fringed with fine fossorial spines. Metatarsomere 1 long, slender, about as long as $2-5$ combined. Approximate length proportions metatibial spur // metatarsomeres 1-5: 20//24/10/6/4/6.

Parameres simple, with slight distal-lateral paramerite, fig. 112.

Measurements in mm. Maximum width of head 1.5. Median length of pronotum 1.5, maximum width 2.4. Sutural length of elytra 1.8 , maximum width 2.6.

\section{Variation and sexual dimorphism}

Body length 3-5 mm. The holotype seems to be a major male of this polymorphic species. We have not formally classified the variation, as in the previous species, Onthophagus ambang, the variation being less clear-cut. Females of toraut have clypeal margin slightly reflexed, evenly rounded, clypeal integument more or less rugulate, clypeofrontal transition with vague arcuate ridge, vertex lacking median protrusion, pronotal anterior declivity not impressed. The male from Morowali is lighter, largely rufous.

Variation observed in the following characters:

- Colour of head and pronotum (darker or lighter; with or without metallic lustre).

- Colour of elytra (predominantly similar to pronotum, darker or lighter; with or without rufous basal and/or apical markings).

- Development of male vertexal protrusion (from median swelling to sharp denticle).

- Delimitation and median impression of anterior pronotal declivity in male (related to preceding character).

- Development of reflexed anteromedian lobe of male clypeus (height/width).

- Colour of legs (yellow to black).

- Density and size of dorsal punctation, particularly on elytral interstriae.

Either this is a widespread, variable species, or some geographic subspecies (or allopatric species) are involved, not unlike the situation in Onthophagus ambang. Data based on samples from more localities are required to draw taxonomic conclusions, as indicated in the Introduction.

\section{Range and ecology}

Sulawesi, apparently widespread, but not yet seen from the South. In various traps, mainly those baited with faeces, in both forest and more open situations.

\section{Etymology}

Toraut is the name of the North Sulawesi lowland river near the Project Wallace $1985 \mathrm{HQ}$, on the banks of which the holotype of this species was trapped - subsequently it was found in various other localities; name to be treated as masculine noun.

\section{Onthophagus imbutus Sharp, 1875}

Figs 6, 43-49, 113

Material examined. Lectotype male from Sulawesi, syntype in $\mathrm{POb}$ here designated lectotype, labelled "Onthophagus $\backslash$ imbutus $\backslash \hat{\delta}$ type D.S", "Menado I Wallace", "Ex Musaeo \D. Sharp 1890". There is one female paralectotype in POb. More material examined listed in Appendix. 


\section{Diagnosis and comment}

Onthophagus imbutus is a robust, generally yellowbrown species, with a characteristically shaped head and a distinctly infuscated, simple primary punctation over most of its body and legs. Closely related to Onthophagus sarasinorum, diagnosed hereafter, but different in the shape (outline, vertexal elevation) and microsculpture of the head, and in the elytral interstrial punctation.

Clypeal apex of male lobate (strongly so in major males) and reflexed, with rounded tip. Clypeal margin slightly expanded-curved in front of clypeogenal suture, thence straight to apical lobe. Female clypeus with border more evenly rounded, both clypeofrontal transition and posterior part of frons with transverse elevation; postfrontal ridge longer than arcuate clypeofrontal ridge. Vertex of male with variably developed dentiform protrusion, its basolateral ridge low, arcuate forward near eye; clypeofrons of male lacking any transverse ridges. Male head with sparse primary punctation, puncture density increasing laterad and to frons, female clypeus punctate(rugulate). Pronotal disc deplanate, anteriorly limited by blunt (more or less protuberant) ridge topping steep declivity, medially impressed in males with well developed vertexal protrusion. Pronotal surface with evenly spaced, dense double punctation, secondary punctation sparse; numerous setae present; midline impression of pronotum distinct, basal border medially vaguely angular. All elytral interstriae very distinctly punctate-setose. Protibial apex slightly convex (upper side view), adjacent apico-external denticle oblique. Meso- and metatibiae strongly dilated to apex. Parameres with shortly protruding apex and distal-lateral paramerite, fig. 113. Punctural infuscation aside, no distinct dorsal colour patterns; dorsal surface largely shiny due to limited development of microreticulation. Body length usually 7.5-10 mm. Incorrectly included by Boucomont (1914) in his group 9, as the pygidial base, contrary to what is stated in his group diagnosis, is definitely non-ridged.

\section{Range and ecology}

Northern Sulawesi; southern: Selayer Island (Lansberge 1883 , record to be verified). No ecological data.

\section{Onthophagus sarasinorum sp.n.}

Figs 7, 49-54, 114

Material examined. Holotype male (RMNH) from C Sulawesi: Lore Lindu NP: Dongi-Dongi shelter, 940 m, 04-08/xii/1985, J. Krikken \#pw48a, multistr evergr forest 2 human excr traps. Paratypes listed in Appendix.

\section{Diagnosis}

Onthophagus sarasinorum is a generally matt, yellowbrown species, close to imbutus, with roughly similar head and ditto infuscated punctation, but it differs in details, like the punctation of the head and the elytral interstriae, the outline of the head, and the development of the basolateral ridge of the vertexal protrusion.

Clypeal apex of male lobate and reflexed, with rounded tip; lateral clypeal margin slightly expandedcurved in front of clypeogenal suture, thence straight to apical lobe. Female clypeus with border more evenly rounded; clypeofrontal transition and posterior part of frons both with low transverse elevation; postfrontal ridge shorter than arcuate clypeofrontal ridge. Vertex of male with variably developed dentiform protrusion, its basolateral ridge high, arcuate forward near eye; clypeofrons of male lacking transverse ridges. Male head with abundant to dense fine punctation throughout, female clypeus ditto. Pronotal disc deplanate, anteriorly limited by blunt ridge topping steep declivity, medially impressed in males with well developed vertexal protrusion; anterior pronotal declivity of female unmodified, simply convex. Pronotal surface with dense, infuscated primary punctation, secondary punctation sparse; numerous setae present; punctation on basomedian area finer and somewhat effaced; midline impression of pronotum distinct, basal border medially hardly angular. Elytral interstriae finely punctate-setose, punctation more or less effaced on base of interstriae 1-2. Protibial apex slightly convex (upper side view), adjacent apico-external denticle oblique. Parameres with shortly protruding apex and distal-lateral paramerite, different from imbutus; fig. 114. Punctural infuscation aside, no distinct dorsal colour patterns; dorsal surface matt due to microreticulation. Usually smaller than imbutus, 5.5-8.5 mm long.

\section{Description (holotype, male)}

Body length ca $8.5 \mathrm{~mm}$. Colour generally yellowbrown(-orange), locally more or less infuscated, tibiae darker brown; head with disc blackish (with a slight green lustre); punctures on pronotum and metasternum distinctly infuscated; surface partly more or less matt due to microreticulation. Pilosity pale-yellow, dorsal side with numerous long, recurved setae.

Clypeal tip slightly but distinctly expanded, slightly reflexed, apex evenly rounded; clypeogenal transition slightly convex at border (full-face view), continuing virtually straight to clypeal tip; clypeofrontal ridge absent. Clypeofrons generally shiny, surface with abundant fine punctation, sizes mixed, many larger ones with long seta. Genal border rounded. Vertex 

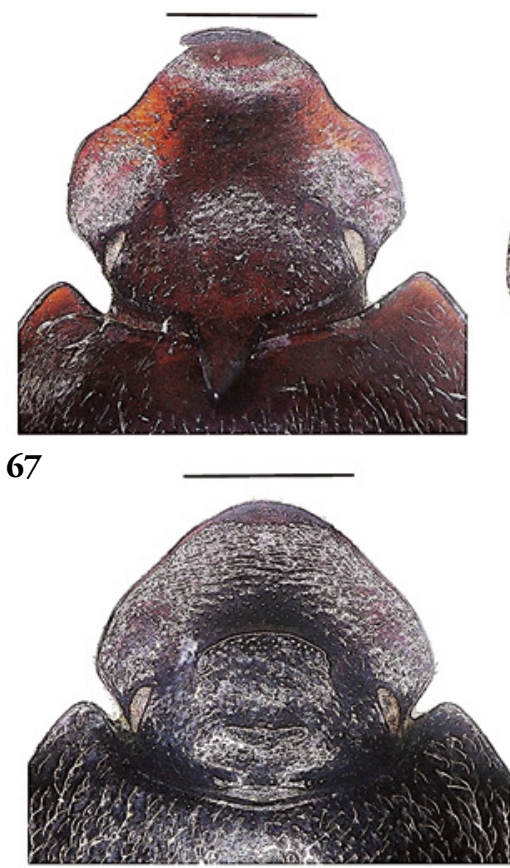

68

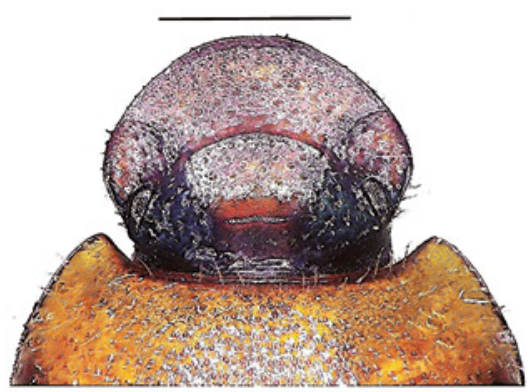

73

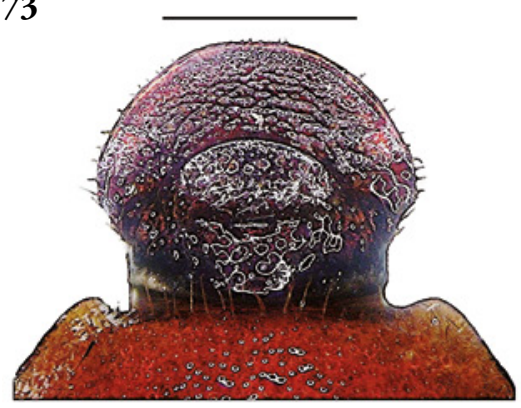

74
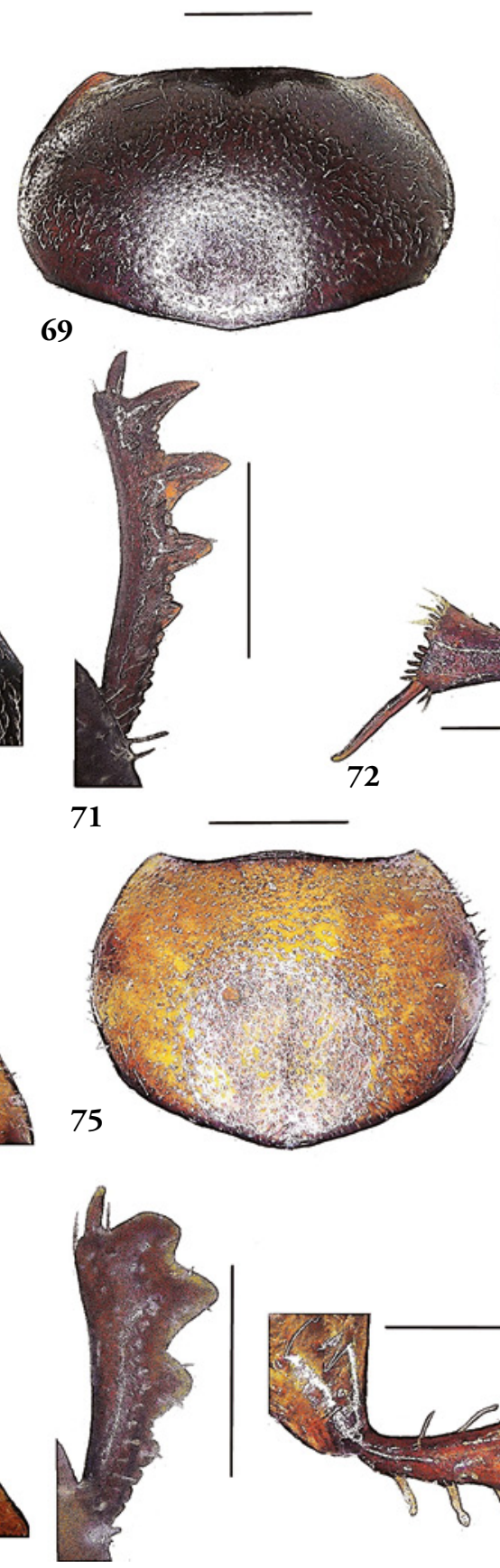

77

78
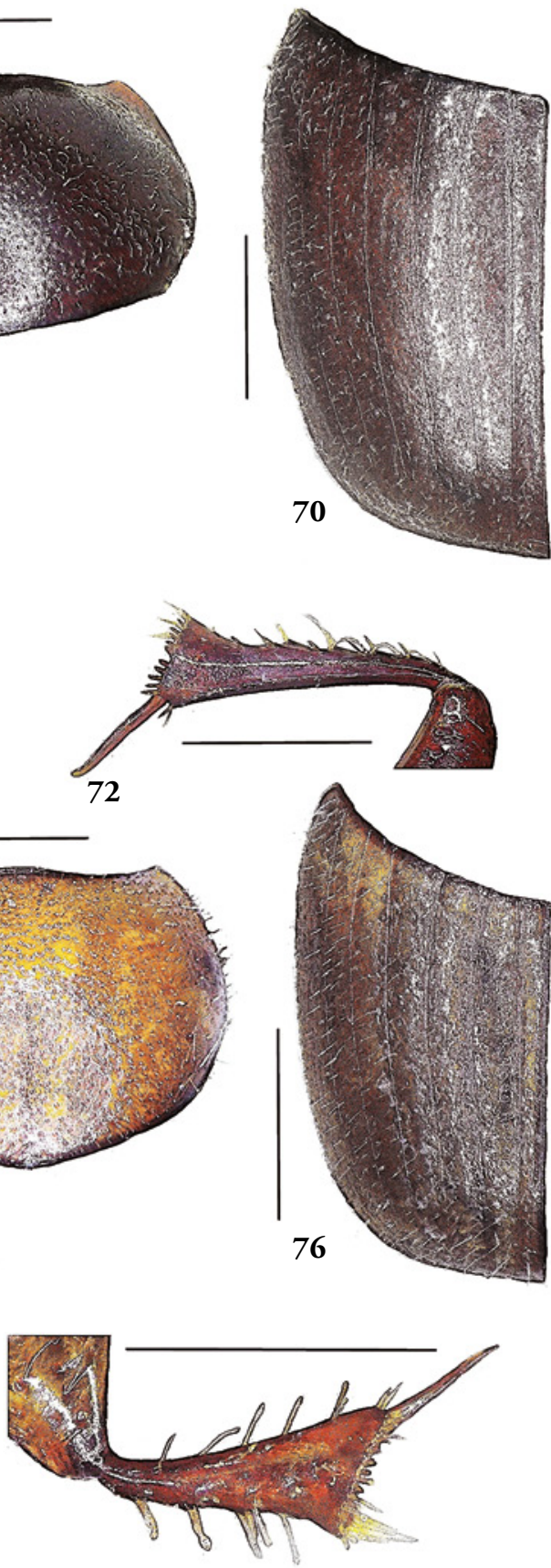

Figs 67-78. Contours of male head Onthophagus species (67, 73, full-face view), female head (68, 74, full-face); male pronotum $(70,76$, dorsal), elytron $(70,76$, dorsal), protibia $(71,77$, upper side), metatibia $(72,78$, underside), female head (full-face). - 67-72, O. sulawesiensis (holotype, 68 paratype female Mogogonipa); 73-78, fulvus (male Toraut, 74 female Marena). - Scale lines $1 \mathrm{~mm}$. 

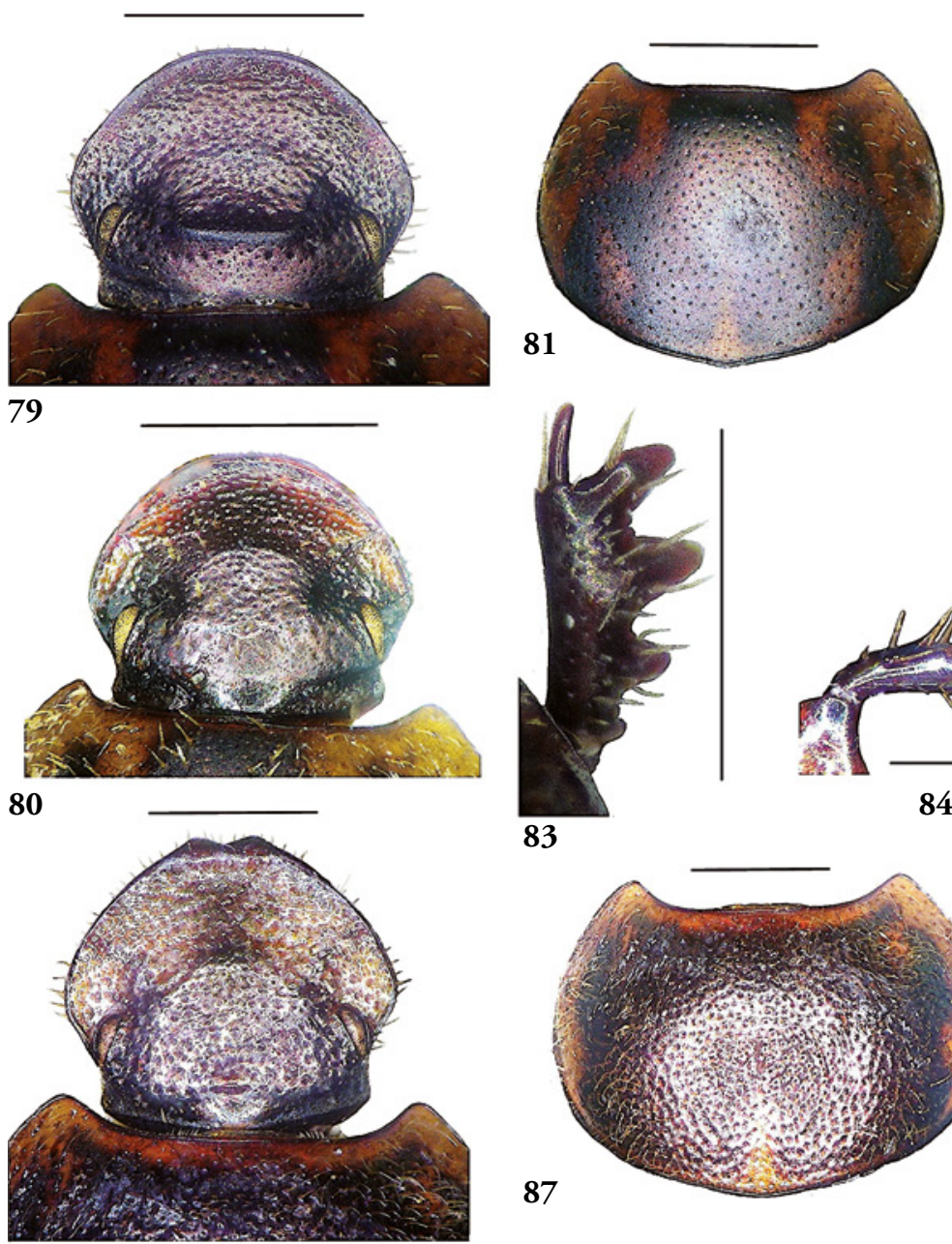

83

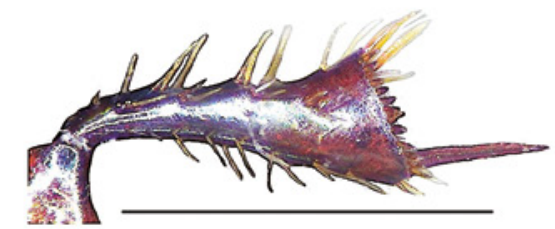

84
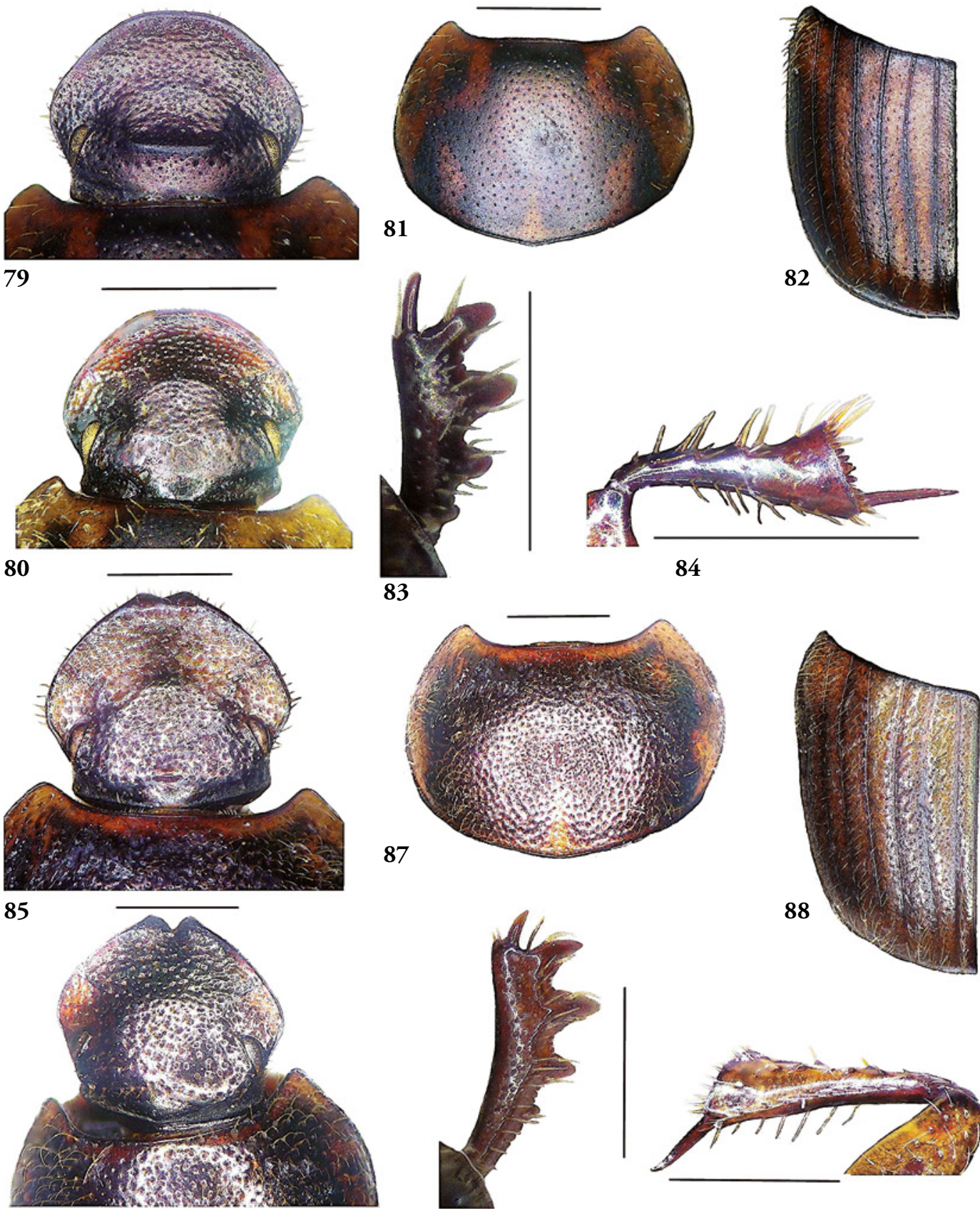

Figs 79-90. Contours of male head Onthophagus species (79, 85, full-face view), female head (80, 86, full-face); male pronotum $(81,87$, dorsal), elytron $(82,88$, dorsal), protibia $(83,89$, upper side), metatibia (84, 90 , underside) - 79-84, O. spiculatus (male Tawaeli, 80 female Tawaeli); 85-90, fuscostriatus (male Moramo, 86 female Page Subcamp). - Scale lines $1 \mathrm{~mm}$. 
with well-developed lamina, laterally strongly projecting, basolateral ridge arcuate near eyes, medially with broad, tapering, reclined denticle. Eye foramina narrow, with ca 8 facet rows across widest point. Ratio interocular distance / maximum (transverse, single) eye width ca 8.5 .

Pronotum moderately convex, midline distinctly impressed near base; anterior declivity short, steep, with median depression, surface finely, sparsely punctate; pronotal disc matt, sides shiny. Anterior section of lateral border straight (full-face view), anterolateral angle shortly rounded, subrectangular; posterior section of lateral border moderately sinuate, posterolateral angle rounded off; base very finely marginate, hardly angular medially. Most of pronotal surface with abundant, well-defined, double punctation; primary punctures infuscated, with long seta, their density on disc $20-30 / 0.25$ sq.mm, diameters mostly $0.05-0.06 \mathrm{~mm}$; secondary punctures sparse, their diameters ca 0.2 or less of primary ones; discal microreticulation distinct at magnification $\times 60$.

Elytra predominantly light-brown, disc matt (microreticulate), sides shiny; shape of base and apex unmodified. Elytral striae well-defined, with distinct punctures, mostly separated by 4-8 diameters, slightly crenulating interstrial surface. Interstriae almost flat, with sparse, fine (disc) to dense, coarser seta-bearing punctures (sides); setal length ca 9 puncture diameters; interstrial punctures finely asperate, at most slightly infuscated.

Antennal club yellow-brown. Propectoral sides yellow, shiny, with slightly curved coxal-marginal ridge not reaching border; prosternum brown. Metasternum with anteromedian lobe distinctly declivous in front; disc shiny, median zone yellow, impunctate, not impressed; vague symmetric dark markings, and scattered, infuscated seta-bearing punctures present, metasternal flanks matt, also punctate-setose. Abdominal sternites with narrow zone of seta- bearing punctures along more or less infuscated base. Pygidium convex, shiny, yellow-brown, with dark central patch, and with numerous, scattered setabearing punctures, setal length up to ca 8 puncture diameters; base non-ridged.

Protibia brown, with 3+1 larger denticles separated by fine serration (apico-external denticle oblique), proximal serration consisting of 5-6 fine denticles; tibial apex medially slightly protruding (upper side view), terminal spur elongate, slightly acuminate and curved. Femora yellowish; profemoral underside posteriorly strongly punctate-setose; underside of meso- and metafemora abundantly punctate-setose. Meso- and metatibiae dilated to transversely subelliptic apex, its crest largely fringed with fine spines; external side of tibiae with 3 slight fossorial protru- sions; mesotibial terminal spur simply elongateacuminate, metatibial spurs elongate-acuminate, longer one distally feebly curved, apex somewhat truncate. Tarsi all unmodified, slender, claws fine, sickle-shaped; metatarsomere 1 almost as long as 2-5 combined; approximate length proportions metatibial spur // metatarsomeres 1-5: 16//20/7/5/3/7.

Parameres with short apex beyond distal-lateral paramerites, fig. 114 .

Measurements in mm. Maximum width of head 2.4. Median length of pronotum 2.5, maximum width 4.2. Sutural length of elytra 3.4, maximum width 4.4.

\section{Variation and sexual dimorphism}

Body length $5.5-8.5 \mathrm{~mm}$. Colours variable, especially with respect to degree of infuscation of punctures.

Female with clypeal apex simply evenly rounded, clypeal punctation coarser than in male, clypeofrontal transition with distinct slightly arcuate ridge, vertex with transverse, low ridge. Vertexal protrusion may be almost completely reduced in minor males. Pronotum without medially impressed anterior declivity.

\section{Range and ecology}

Northern, central and southeastern parts of Sulawesi. Mainly in faeces traps, usually in forest.

\section{Etymology}

The cousins K.F. \& P.B. Sarasin (1859-1942 and 1856-1929, respectively) were famous Swiss zoologists, and explorers of Sulawesi and other regions. More on the Sarasins, including portraits, in van Steenis-Kruseman (1948-1954).

\section{Onthophagus gonipa sp.n.}

Figs 5, 38-42, 116

Material examined. Holotype male only (RMNH) from N Sulawesi: Dumoga Bone NP: Mt Mogogonipa, $1000 \mathrm{~m}, 22-26 /$ viii/1985, J. Huijbregts \#HH427A, multistr evergr forest, 2 human excr traps.

\section{Diagnosis}

Onthophagus gonipa seems best characterized by its symmetrically patterned parts, including a black(ish) versus yellow-brown pronotum. Dorsal punctation generally fine, relatively sparse; interstrial punctation of elytra finely but distinctly asperate-setose. Dorsum generally less setose than in related species, particularly on head and pronotum. Male protibia very slender, slightly expanded apico-internally, as in griseoaeneus, diagnosed hereafter; apico-external denticle oblique as usual. 
Clypeal apex slightly truncate-bisinuate, margin narrowly, slightly reflexed. Clypeogenal margin in front of suture vaguely angular, thence continuing straight to clypeal apex. Head merely with tapering median vertexal protrusion, its basolateral ridge low, arcuate forward near eyes. Most of head surface very superficially, finely, abundantly punctate(-rugulate). Anterior declivity of pronotum steep, medially depressed. Pronotal surface simply, sparsely, finely punctate, with numerous very short setae. Dorsum deplanate, and, apart from darker head and pronotal pattern, generally light-brown, matt. Parameres high (in lateral view), with distinct (in upper side view rounded) distal-inferior paramerites, Figs 116, 129. Metasternum also has symmetric black versus yellow-brown pattern. Body length of single known male ca $8.5 \mathrm{~mm}$.

\section{Description (holotype, male)}

Body length ca $8.5 \mathrm{~mm}$. Colour generally yellowbrown, pronotum symmetrically patterned with darker markings; locally more or less infuscated, head and tibiae darker brown; dorsum largely matt, due to vague microreticulation. Pilosity pale-white, dorsum with numerous more or less erect setae.

Head dark-brown, matt. Clypeal tip slightly expanded, reflexed, apex evenly rounded; clypeogenal transition very slightly angular just in front of suture, thence continuing straight to rounded clypeal tip; clypeofrontal ridge absent. Clypeofrontal surface matt, with abundant fine punctation, more or less effaced and sparse on frons. Genal border subangular, tip rounded off. Vertex laterally with low ridge, arcuate near eyes, medially with broad, tapering, reclined, apically blunted denticle. Head virtually entirely glabrous. Eye foramina narrow, with ca 10 facet rows across widest point. Ratio interocular distance / maximum (transverse, single) eye width ca 14 .

Pronotum moderately convex, midline shallowly impressed near base; anterior declivity short, steep, with median depression. Anterior section of lateral border very widely rounded (full-face view), anterolateral angle shortly rounded, subrectangular; posterior section of lateral border moderately sinuate, posterolateral angle rounded off; base widely rounded, very finely marginate. Most of pronotal surface with sparse, fine, well-defined, simple punctation, punctures slightly larger on lateral declivity, some with seta, disc with stubbles; puncture diameters mostly $0.02-0.03 \mathrm{~mm}$, separated by ca 5 diameters; interspersed with micropunctation, distinct at ca $\times 60$. Pronotum patterned, dark, with distinct, lighter sublateral and lateral longitudinal zone.
Elytra predominantly light-brown, matt; shape of base and apex unmodified. Elytral striae narrow, welldefined, with distinct punctures, mostly separated by 3-6 diameters, slightly crenulating interstrial edges. Interstrial surface slightly uneven, generally flat, with fine, evenly spaced, sparse, finely asperate, seta-bearing punctures, puncture depressions indistinct; setae short, up to 3 strial puncture diameters long; surface slightly rugulate around humeral umbone.

Antennal club yellow-brown, scapus unmodified. Propectoral sides partly yellowish, shiny, with straight coxal-marginal ridge not reaching border, locally with punctures bearing long seta. Metasternum with anteromedian lobe slightly declivous in front; disc shiny, median zone yellow, on either side with distinct dark marking; metasternal flanks matt, with abundant punctures bearing long seta. Abdominal sternites each with narrow zone of seta-bearing punctures along strongly infuscated base. Pygidium yellow, convex, somewhat uneven, with abundant, scattered punctures, many bearing a long seta; base non-ridged; propygidium infuscated.

Protibia with $3+1$ robust external denticles (apicoexternal denticle oblique), separated by fine serration; proximal serration consisting off ca 7 fine denticles; tibial apex internally protruding, subangular (upper side view); terminal spur elongate-acuminate, hardly curved. Femora yellowish, with dark patches, their undersides all with numerous punctures bearing long seta. Meso- and metatibiae dilated to transversely subelliptic apical crest, which is largely fringed with fossorial spines; external side of tibiae with 3-4 slight fossorial protrusions; mesotibial terminal spurs simply elongate-acuminate; metatibial spur also elongate-acuminate, apex slightly curved, somewhat blunted. Tarsi all unmodified, slender, claws fine, sickle-shaped; metatarsomere 1 straight; approximate proportions of metatibial spur // metatarsomeres 1-2: 17//20/7 (some tarsomeres lost).

Parameres high, with distinct distal-lateral paramerite, Figs 116, 129.

Measurements in mm. Maximum width of head 2.8. Median length of pronotum 2.9, maximum width 4.7. Sutural length of elytra 3.7 , maximum width 4.8.

\section{Variation and sexual dimorphism}

Only holotype seen.

\section{Range and ecology}

Northern Sulawesi, from faeces trap, in upland forest.

\section{Etymology}

Name derived from Gunung Mogogonipa, an isolated mountain in North Sulawesi where the single 


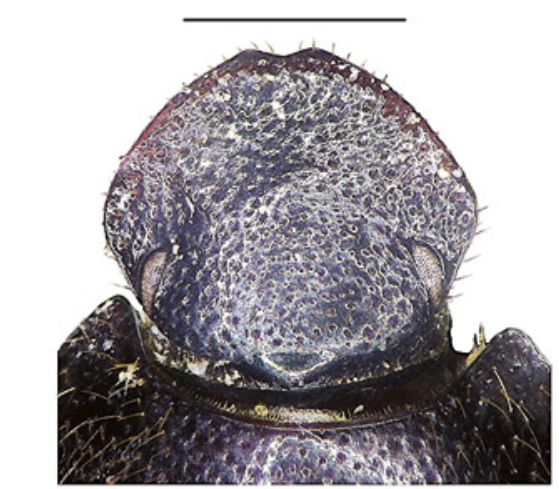

91

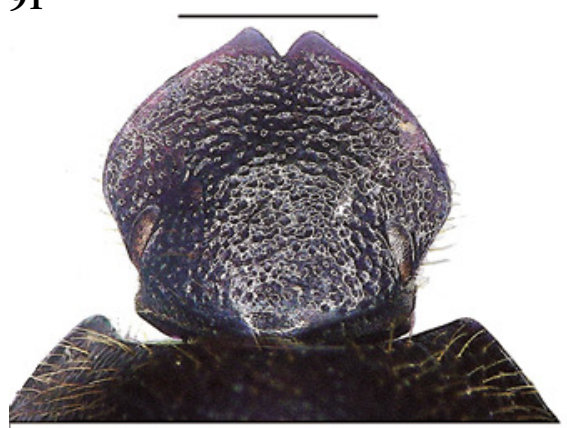

92

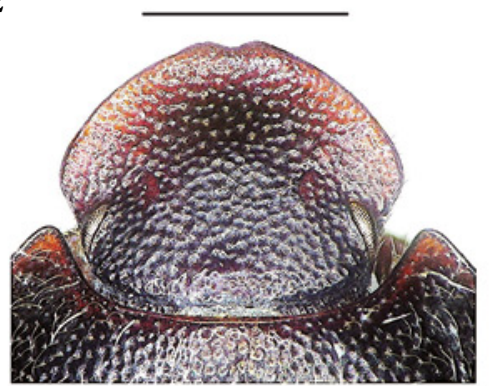

97

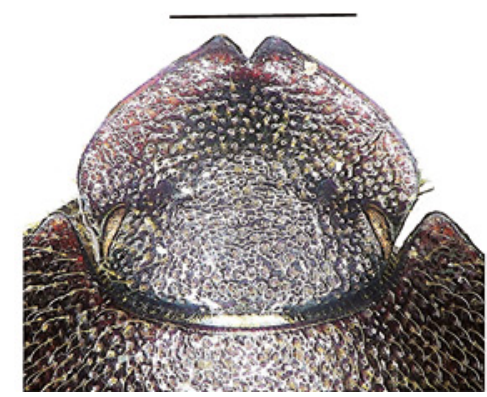

98
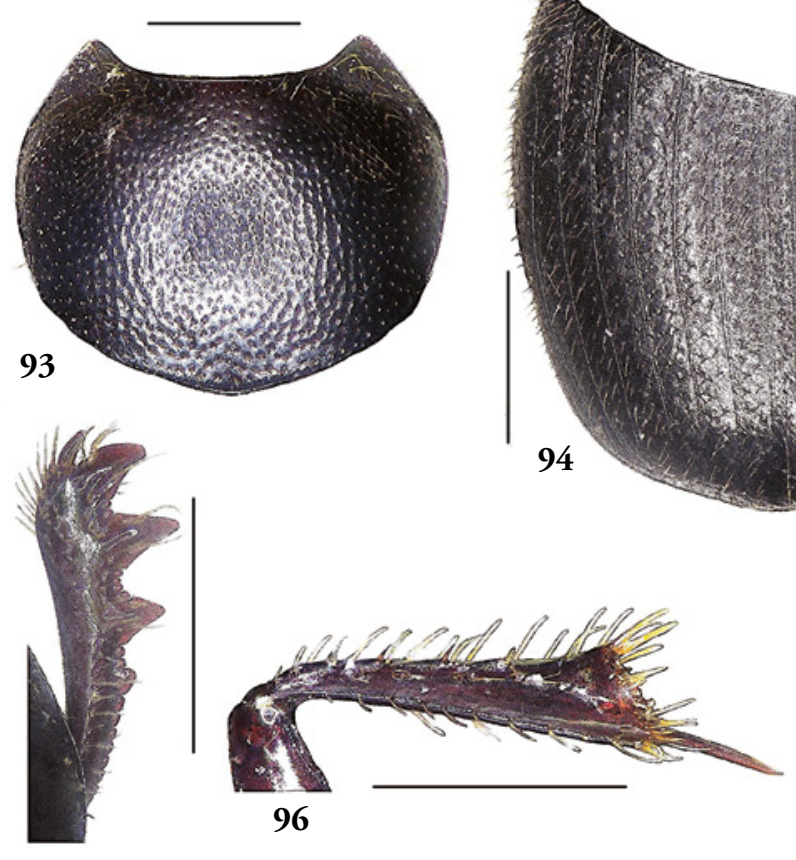

96

95
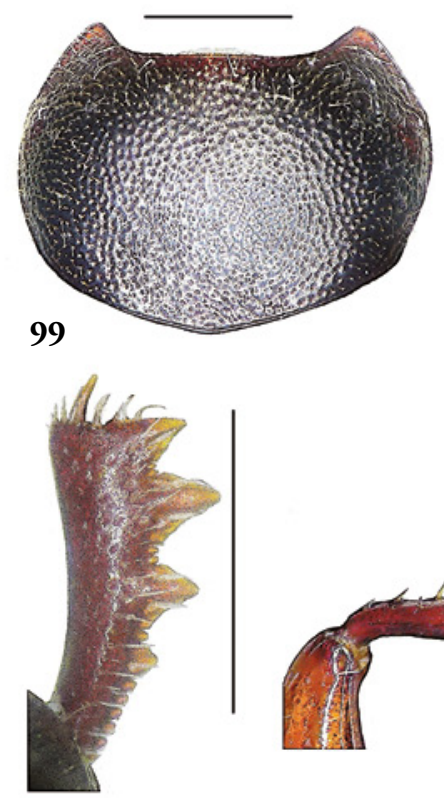

101
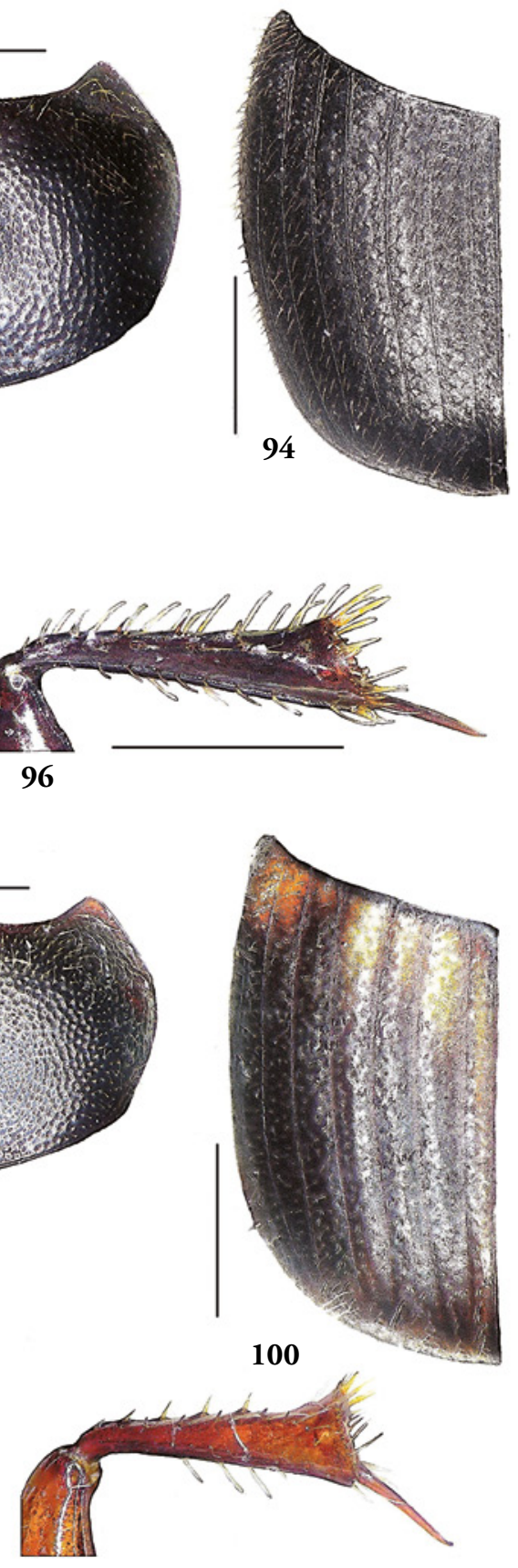

102

Figs 91-102. Contours of male head Onthophagus species (91, 97, full-face view, axial), female head (92, 98, full-face); male pronotum $(93,99$, dorsal), elytron $(94,100$, dorsal), protibia $(95,101$, upper side), metatibia (96, 102, underside). - 91-96, O. magnipygus (male Batui, 92 female Toraut); 97-102, rosenbergi rosenbergi (holotype, 98 Marena). - Scale lines $1 \mathrm{~mm}$. 

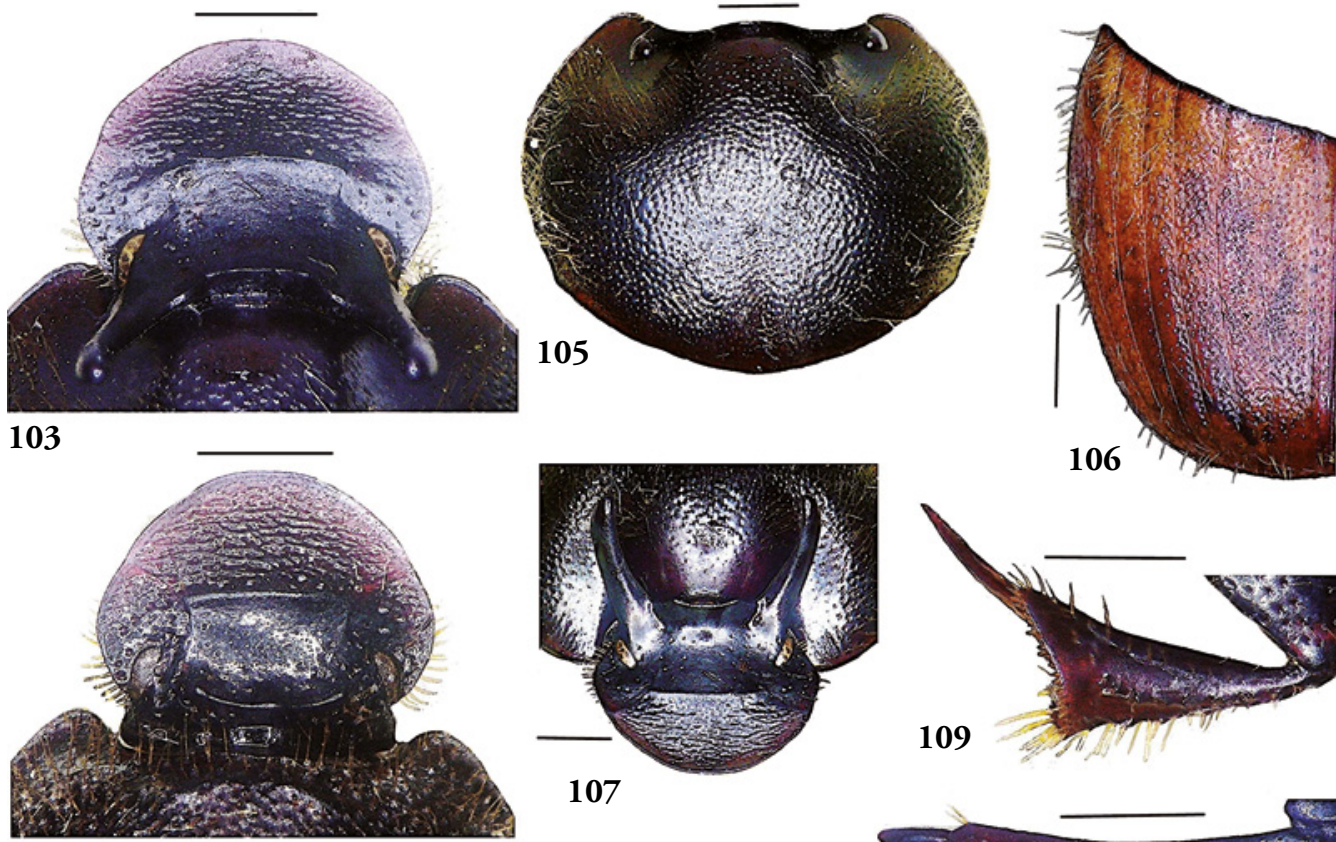

104

108

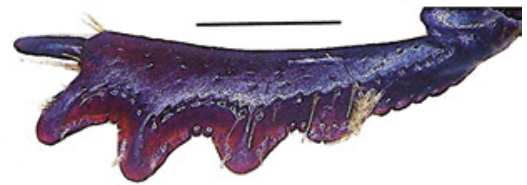

Figs 103-109. Contours of parts of Onthophagus aureopilosus, male (103, 105-109) and female (104) Toraut. - 103-104, 107, head (full-face view, 107, axial, with pronotal declivity); 105, pronotum (dorsal), 106, elytron (dorsal), 109, protibia (upper side), 108, metatibia (underside). - Scale lines $1 \mathrm{~mm}$.

known individual of this species was trapped; name to be treated as masculine noun.

Onthophagus griseoaeneus Lansberge, 1885 Figs 8, 55-60, 115

Onthophagus forsteni Lansberge, 1887 syn.n.

Material examined. Lectotype male, syntype of Onthophagus griseoaeneus Lansberge (MCGD) here designated lectotype, labelled "Celebes \Kandari \ III.74. \ O. Beccari”, "Typus” (red print), "O. Griseoae- \neus Lansbge \o "; female paralectotype from same locality, same label. Holotype of Onthophagus forsteni from Sulawesi: Tondano (RMNH). Other material examined listed in Appendix.

\section{Diagnosis and comments}

Onthophagus griseoaeneus is close to gonipa, the male protibia also having a slightly protruding internal apex, the vertex a distinct, tapering median protrusion, and the elytral interstriae a finely asperate, seta-bearing punctation. Pronotal disc may be dark- ish, only lateral margins brown, but otherwise lacking a distinct pattern. Primary pronotal punctation abundant to dense, simple, bearing long setae; secondary punctation sparse. Head finely, superficially punctate(-rugulate), sparsely setose. Parameres with high, arcuate crest (in lateral view) and distal-lateral paramerite, fig. 115 .

Clypeal apex rounded-truncate, margin narrowly reflexed over much of its width. Clypeogenal transition of male very shallowly excised at margin, thence widely rounded to clypeal apex. Vertexal protrusion in major male reclined; basolateral ridge of vertexal protrusion arcuate forward near eyes. If correctly associated with male sex, female head densely punctate; vertex medially with low, short, transverse ridge, clypeofrontal transition with arcuate ridge (which is absent in male). Anterior declivity of male pronotum depressed (medially more strongly so), largely impunctate and shiny. Elytra brown to black, more or less uniform. Dorsum deplanate, matt (microreticulate), locally with slight metallic lustre. Ventral side, including metasternum, with black/ yellow-brown pattern. Pygidium almost flat, yellow 
with central infuscation, densely punctate-rugulatesetose. Apico-external denticle of protibia oblique. Body length usually $5.5-8 \mathrm{~mm}$.

The type of Onthophagus griseoaeneus is extremely similar to forsteni, and the latter name is here considered a junior synonym. Onthophagus forsteni was incorrectly included by Boucomont (1914) in his group 9, as the pygidial base of the type, contrary to what is stated in his group diagnosis, is definitely non-ridged.

\section{Range and ecology}

Widespread on Sulawesi, no records from the South. Mainly in faeces traps, in both lowland forest and more open situations.

\section{Onthophagus tambing sp.n.}

Figs 9, 61-66, 117

Material examined. Holotype male (RMNH) from C Sulawesi: Lore Lindu NP: Danau Tambing forest, 1600 m, 05-09/xii/1985, J. Krikken \#pw51a, multistr evergr forest, 4 human excr traps. Paratypes listed in Appendix.

\section{Diagnosis}

Onthophagus tambing is close to gonipa and griseoaeneus, differing in the hardly protruding apex of the male protibia and the male vertex having a very short, blunt to slightly tapering median protrusion. Pronotum deplanate, without distinct impressions or protrusions, uniformly darkish (to black). Dorsal punctation discally very fine, simple, not distinctly asperate on discal elytral interstriae. Punctation of head and pronotal disc finer than in griseoaeneus and gonipa.

Clypeal apex bisinuate(-truncate), anteromedially narrowly, slightly reflexed. Margin in front of clypeogenal transition very slightly expanded. Head of male with basolateral vertexal ridge indistinct and not arcuate near eyes. Head of female only with slight, transverse vertexal swelling. Most of head superficially, finely, abundantly to densely punctate(rugulate), glabrous. Anterior declivity of pronotum evenly slightly convex, lacking depression. Pronotal disc away from midline abundantly punctate, laterally with numerous longer setae. Elytral interstriae very finely punctate, laterally also with numerous longer setae. Dorsum generally black-brown, microreticulate, remarkably matt. Apico-external denticle of protibia oblique. Parameres distally high (in lateral view), with large, reflexed distal-inferior paramerite, fig. 117. Ventral side partly lighter, metasternum with symmetric black versus yellow-brown pattern. Body length usually $8-9 \mathrm{~mm}$.

\section{Description (holotype, male)}

Body length ca $9 \mathrm{~mm}$. Colour generally yellowbrown, head and pronotum darker brown than elytra; Profemur and tibiae darker brown; ventral side patterned, partly yellow; surface largely more or less matt, due to vague microreticulation. Pilosity pale-white, dorsal side with numerous more or less erect setae; disc of pronotum and elytra with inconspicuous stubbles.

Clypeal tip slightly expanded, reflexed, border evenly rounded (apex somewhat truncate); margin in front of clypeogenal transition very slightly expanded, continuing virtually straight to clypeal tip; clypeofrontal transition without ridge; clypeal surface slightly shiny in front, clypeal sides as well as genae with abundant fine punctation. Genal border rounded. Vertex with low ridge, arcuate near eyes, medially with small, tapering, reclined denticle; frontovertex largely finely, sparsely punctate. Virtually entire head glabrous. Eye foramina narrow, with ca 9 facet rows across widest point. Ratio interocular distance / maximum (transverse, single) eye width ca 9.

Pronotum nearly evenly matt brown, moderately convex, disc deplanate, midline shallowly impressed near base; anterior declivity evenly, slightly convex. Anterior section of lateral border straight (full-face view), anterolateral angle shortly rounded, subrectangular; posterolateral border almost straight, posterolateral angle rounded off; base virtually immarginate. Most of pronotum with abundant, fine, well-defined punctation, very fine discal punctures at most with stubble; punctures on lateral declivity larger, several with long seta, mixed with inconspicuous, sparse, scattered micropunctation; midline sparsely punctate, puncture diameters away from midline mostly 0.02-0.04 mm.

Elytra predominantly light brown, matt; shape of base and apex unmodified. Elytral striae well-defined, narrow, with distinct punctures, mostly separated by 3-6 diameters, slightly crenulating interstrial edges. Interstrial surface almost flat, with sparse, fine (disc), to more abundant, coarser, seta-bearing punctures (lateral interstriae), setae on disc short, up to ca 3 puncture diameters long; interstrial punctures simple (not asperate, not infuscated).

Antennal club brown. Mentum shallowly emarginate in front. Propectoral sides partly yellowish, shiny, unmodified, with straight coxal-marginal ridge. Prosternum dark brown. Metasternum with anteromedian lobe very slightly declivous in front; disc shiny, median zone yellow, very shallowly impressed, with symmetric dark markings; metasternal flanks shiny, with numerous punctures, bearing long setae. Abdominal sternites each with narrow basal zone of seta-bearing punctures along strongly infuscated 
base. Pygidium convex, yellow, with central infuscation, generally matt, with numerous scattered setabearing punctures, setal length varies strongly, up to ca 10 puncture diameters; base non-ridged.

Protibia wit 3+1 larger external denticles, separated by fine serration; proximal serration consisting of ca 7 fine denticles; tibial apex medially very slightly protruding (upper side view), terminal spur elongate-acuminate, hardly curved. Profemur largely brown, meso- and metafemora yellowish; profemoral underside strongly punctate-setose, meso- and metafemoral undersides less strongly punctatesetose. Meso- and metatibiae dilated to apical crest, which is largely fringed with fine fossorial spines; external side with 3-4 slight, spine-bearing fossorial protrusions. Mesotibial spurs elongate-acuminate, metatibial spur also elongate-acuminate, tip feebly curved, blunted. Tarsi all unmodified, slender, claws fine, sickle-shaped; metatarsomere 1 straight, almost as long as $2-5$ combined; approximate length proportions of metatibial spur // metatarsomeres 1-5: 15//20/7/5/4/7.

Upper side with high, rounded parameral crest (in lateral view), inferior paramerite very distinct, reflexed, fig. 117.

Measurements in mm. Maximum width of head 2.6. Median length of pronotum 2.7, maximum width 4.1. Sutural length of elytra 3.9, maximum width 4.5 .

\section{Variation and sexual dimorphism}

Body length 8-9 mm. Minor male with slight transverse vertexal ridge. Female with clypeus rugulatepunctate, vertex with minimal transverse median swelling.

\section{Range and ecology}

Central and southeastern parts of Sulawesi. Mainly in faeces traps, in upland forest.

\section{Etymology}

Named after the upland Danau (= lake) Tambing in Lore Lindu NP, Central Sulawesi, on the forested banks of which this Onthophagus was first trapped, along with other interesting congeners; name to be treated as masculine noun.

\section{Onthophagus sulawesiensis sp.n.}

Figs 10, 67-72, 118

Material examined. Holotype male (RMNH) from N Sulawesi: Dumoga Bone NP: Mt Mogogonipa, 1000 m, 22-26/viii/1985, J. Huijbregts \#HH427B, multistr evergr forest, 2 fish traps. Paratypes listed in Appendix.

\section{Diagnosis}

The long, upright, more or less spatuliform, parallelsided clypeal protrusion and other head shape characters give the identity of major males of Onthophagus sulawesiensis immediately away. Their vertex has a tapering median denticle and the apico-internal angle of the protibia is distinctly expanded. Colour virtually uniformly black-brown, very shiny, in spite of abundant to dense dorsal punctation.

Lateral margin of male clypeus more or less concave, slightly so in minor males. Head abundantly finely punctate (somewhat rugulate-punctate in females). Major males without clypeofrontal ridge. Females and minor males with arcuate ridge on clypeofrontal transition and straight transverse ridge between posterior part of eyes, lacking complete vertexal denticle. Anterior declivity of pronotum depressed in major males, not topped by transverse ridge. Both pronotum and elytra abundantly to densely, simply punctate-setose, setae may be reduced to mere stubbles. Protibia of males long and slender, with apicoexternal denticle oblique. Parameres distally high (in lateral view), with distal-lateral paramerite, fig. 118 . Body length usually $5-8 \mathrm{~mm}$.

\section{Description (holotype, male)}

Body length ca $7 \mathrm{~mm}$. Colour generally blackbrown, elytra lighter uniformly brown, largely shiny. Pilosity pale-white, dorsal side with numerous long, fine, recurved setae.

Clypeus anteromedially produced into strongly reflexed, long, almost spatuliform lobe; lateral border of clypeus with sinuate-concave, shortly expanded just in front of vague clypeogenal suture; clypeofrontal ridge absent; clypeofrontal surface with abundantly punctation of mixed sizes, many larger punctures with long seta. Genal border rounded, tip somewhat shifted backwards. Vertex with long reclined, median denticle, its apex acute, adjacent ridge issuing laterad to eye border low. Eye foramina narrow, with ca 8 facet rows across widest point. Ratio interocular distance / maximum (transverse, single) eye width ca 11 .

Pronotum strongly convex, midline shallowly impressed near base; anterior declivity glabrous, steep, with broad median depression; anterior section of lateral border virtually straight (full-face view), anterolateral shortly rounded, ca $85^{\circ}$ adjacent surface slightly deplanate; posterior section of lateral border slightly sinuate, Posterolateral angle rounded off; base very finely marginate, hardly angular medially. Entire pronotal surface with dense double punctation; primary punctures dense, simple, their density on disc ca 35-45/0.25 sq.mm, diameters 0.02$0.05 \mathrm{~mm}$; most primary punctures with seta, length 
110
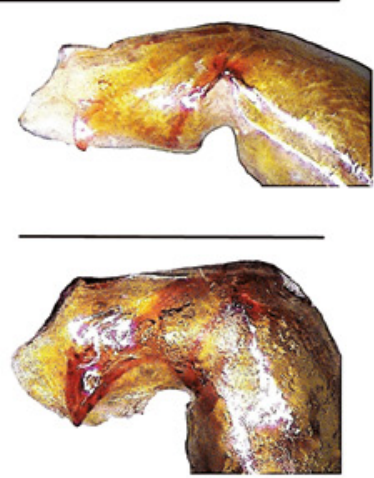

113

116

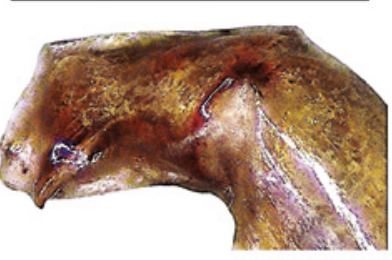

119

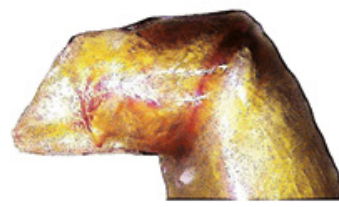

117

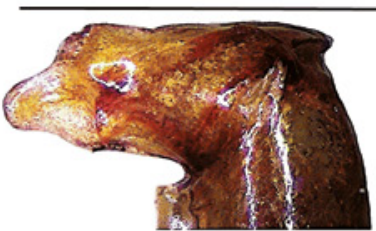

111

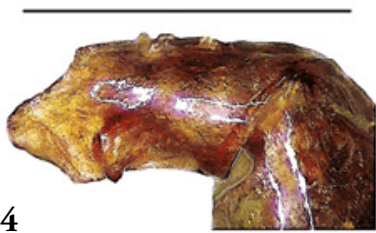

114
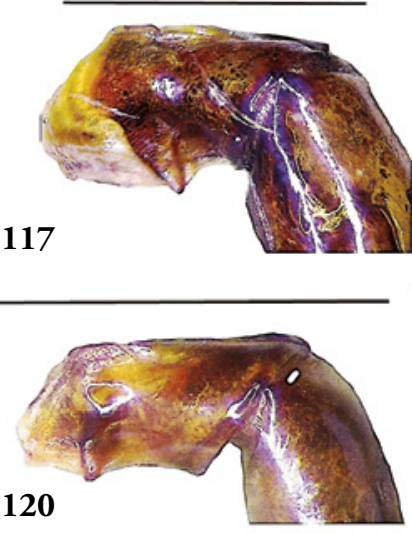

120

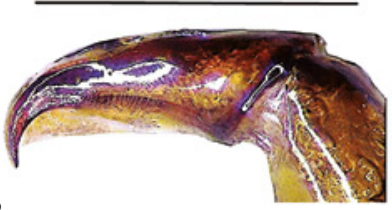

122
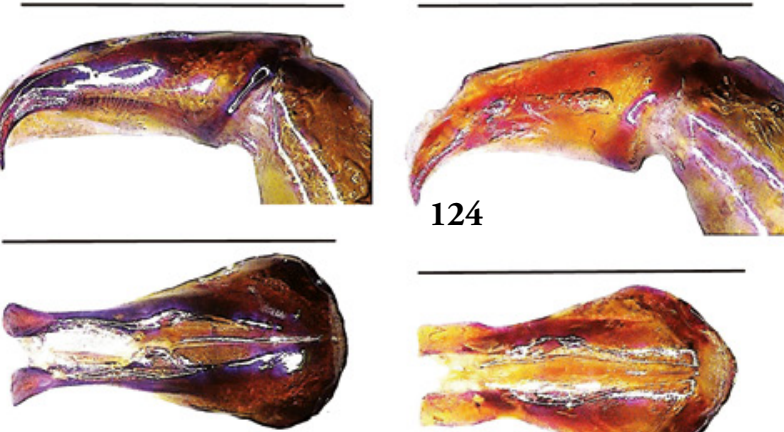

123

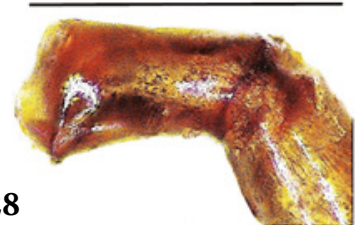

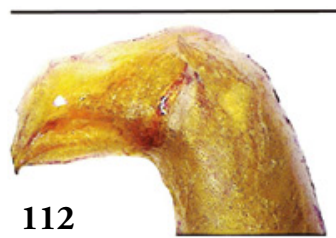

112

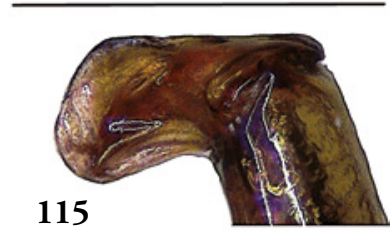

115

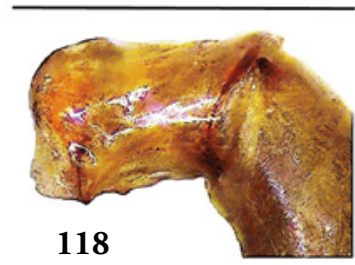

118
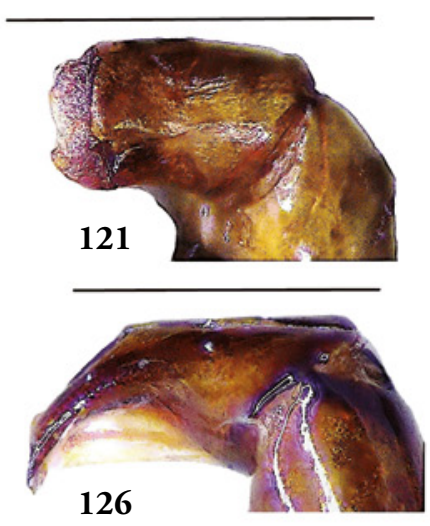

126

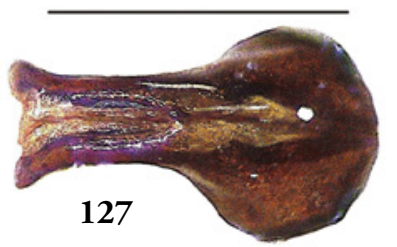

Figs 110-129. Parameres of Onthophagus species (lateral view, except 123, 125, 127, upper side, 129, tip only). - 110, O. tonywhitteni (holotype); 111, ambang ambang (holotype); 112, toraut (holotype); 113, imbutus (Manado); 114, sarasinorum (holotype); 115, griseoaeneus (Tawaeli); 116, gonipa (holotype); 117, tambing (holotype); 118, sulawesiensis (holotype); 119, fulvus (Toraut); 120, spiculatus (Tawaeli); 121, fuscostriatus (Moramo); 122 123, magnipygus (Batui); 124-125, rosenbergi rosenbergi (holotype); 126-127, rosenbergi divergens (holotype); 128, aureopilosus (Toraut); 129, gonipa (holotype). - Scale lines (on top of corresponding parameres) $1 \mathrm{~mm}$. 
on disc mostly ca 5 puncture diameters; secondary punctures minute, very sparse, inconspicuous.

Elytra unmodified, light brown. Elytral striae welldefined, with indistinct punctures, mostly separated by $2-4$ times their diameter, scarcely crenulating interstrial surface. Interstriae almost flat, with dense, discally more or less serially arranged seta-bearing punctures and scattered, indistinct micropunctures. Antennal club yellow-brown. Mentum shallowly emarginate in front. Propectoral sides shiny, with sinuate coxal-marginal ridge, abundantly punctatesetose. Metasternum slightly but distinctly raised anteromedially, medial surface smooth, glabrous, remainder abundantly punctate-setose. Abdominal sternites with basal, laterally broad zone of somewhat scabrous seta-bearing punctures. Pygidium uniformly brown, convex, with dense seta-bearing punctation, setal length up to ca 4 puncture diameters; base non-ridged.

Legs all long and slender, brown. Protibia with 3+1 larger external denticles, separated by fine serration; proximal serration extensive, consisting of numerous fine denticles; tibial apex internally angular (upper side view); terminal spur elongate-acuminate, slightly curved. Femoral undersides all abundantly punctate-setose. Meso- and metatibiae strongly dilated from slender base to transversely subelliptic apical crest, which is largely fringed with fine fossorial spines; external side of tibiae with ca 4 very slight spine-bearing protrusions; mesotibial terminal spurs unmodified, elongate-acuminate, metatibial spur long, distally feebly curved, apex somewhat truncate. Tarsi all slender, with fine, sickle-shaped claws; metarsomere 1 slender, straight, as long as $2-5$ combined. Approximate length proportions metatibial spur // metatarsomeres 1-5: 17//20/7/4/3/6.

Parameres with distal-lateral paramerites, upper side with high crest, fig. 118.

Measurements in mm. Maximum width of head 2.3. Median length of pronotum 2.5, maximum width 3.9. Sutural length of elytra 3.0, maximum width 4.1 .

\section{Variation and sexual dimorphism}

Body length 5-8 $\mathrm{mm}$. Variation in male head shape considerable (length of apical projection, presence and size of vertexal denticle, degree of lateral sinuation of clypeus, protrusions on clypeofrons). General colour (brown to black), density of elytral punctation, and length of setae on pronotal and elytral disc also variable. Apex of male clypeal projection short, rounded, to long, dilated-truncate (in major males). Female with head shorter, clypeal margin slightly reflexed, evenly rounded, clypeal surface more rugulate-punctate; clypeofrontal transition with distinct arcuate ridge, posterior part of frons with straight transverse ridge, vertex lacking distinct median protrusion. Pronotum less strongly convex, always without medially depressed anterior declivity. Protibial apex not angularly expanded. Minor males have a short, rounded clypeal lobe, two cephalic ridges as just mentioned for females, and a less expanded protibial apex.

\section{Range and ecology}

Northern and central parts of Sulawesi. Apparently upland forest species, in fish traps.

\section{Etymology}

Named after the island of Sulawesi.

\section{The Onthophagus fuscostriatus group}

\section{Group diagnosis}

Clypeal apex emarginate(-bidentate) or roundedtruncate, never strongly produced. Vertex usually at most with vague protrusion, one species with transverse ridge on both clypeofrontal transition and between eyes. Eye foramina narrow. Pronotal microsculpture may be dense, but never crowded with annulate punctures. Pronotal base medially virtually rounded. Elytral interstriae simply punctate or asperate-punctate, usually strongly setose. Antennae not conspicuously modified, 9-segmented. Mentum slightly concave in front. Propectoral sides unmodified, with simple coxal-marginal ridge. Anterior intercoxal lobe of metasternum unmodified. Pygidial base without ridge. Protibia with 4 (3 larger +1 smaller) external denticles, apico-external denticle oblique or perpendicular to tibial axis; apico-internally never broadly, angularly expanded, not penicillate. Meso- and metatarsi slender, unmodified. Colour varying from yellow to black, elytra uniform, or more or less patterned (unicolour light versus infuscated, or (rufous-)brown versus black). Body length usually $3.5-6.5 \mathrm{~mm}$.

The group is distinctly heterogeneous (see Table 1). For instance, Onthophagus fulvus has two ridges on the head, in both sexes, and Onthophagus rosenbergi and magnipygus may be joined by their similar parameres, bidentate clypeal apex, and large pygidium (note also the modified protibial apex of rosenbergi males).

\section{Onthophagus fulvus Sharp, 1875}

Figs 11, 73-78, 119

Material examined. Lectotype male from Sulawesi, syntype in $\mathrm{POb}$ here designated lectotype, labelled "Onthophagus \fulvus \ô Type. D.S.", "Menado 
I Wallace", "Ex Musaeo \D. Sharp 1890"; paralectotypes, 3 males, 1 female from Menado, 1 female from Celebes, leg. Wallace, with darker head. Other material examined listed in Appendix.

\section{Diagnosis and comment}

Within the group both sexes of Onthophagus fulvus are immediately recognizable from the presence of two distinct ridges on the head, its generally orange colour, and conspicuously asperate-granulate pronotum and elytra. Colour varies slightly from yellowbrown to orange, somewhat matt due to asperate microsculpture; some parts may be more or less infuscated (head, elytra, ventral parts); pronotum lacking discrete black pattern.

Clypeal apex simply, widely rounded. Clypeogenal transition at margin continuous, widely, evenly rounded to apex. Clypeofrontal ridge strongly, evenly arcuate, distinctly raised. Frons between eyes with short, straight transverse ridge, not reaching eyes. Gena widely rounded. Head with double punctation and numerous long setae. Anterior declivity of pronotum evenly convex, unmodified. Pronotal surface densely to crowdedly asperate-punctate, with numerous long setae; base immarginate. Elytral interstriae asperate-punctate, also with numerous long setae. Pygidium densely punctate-setose. Protibial apex not particularly modified, apico-external denticle broad, oblique; terminal spur small, fine. Parameres simply tapering, short (in lateral view), distal paramerite slight, fig. 119. Body length usually $4.5-6.5 \mathrm{~mm}$.

Contrary to its arrangement in Boucomont (1914, group 8 , followed by Balthasar 1963), the pygidial base is definitely non-ridged.

\section{Range and ecology}

Widespread on Sulawesi. Mainly in faeces traps, in both forest and open situations.

\section{Onthophagus spiculatus Boucomont, 1914}

Figs 12, 79-84, 120

Material examined. Lectotype male, syntype in PBouc here designated lectotype, labelled "Nord-Celebes $\backslash$ Toli-Toli \ Nov.-Dez. $1895 \backslash$ H.Fruhstorfer", "Ex Musaeo \N. van de Poll", "Museum Paris \1936 \ Coll. A. Boucomont", "Typus" (red label), "Boucomont det. $1914 \backslash$ Onthophagus \spiculatus n.sp."; paralectotypes, 2 females from same locality. Other material examined listed in Appendix.

\section{Diagnosis}

Onthophagus spiculatus is a generally matt, yellowish to light brown species, which, in the male sex, has a slight transverse ridge between the eyes. Pronotum with usually very distinct dark symmetric pattern; elytral striae infuscated. Clypeal apex simply, widely rounded.

Clypeogenal transition at margin continuous, widely, evenly rounded to apex. Genal edge also widely rounded. Head black-brown, densely punctate, with several setae; punctures fine, multi-sized. Ridge on male head between anterior half of eye foramina straight, low, not reaching eyes; female head with strongly curved, vague clypeofrontal ridge, interocular ridge effaced. Pronotal surface with sparse, fine, double punctation, many primary punctures with erect seta; base immarginate. Elytral interstriae microreticulate, asperate, most asperities bearing fine seta, sparse on basal part of elytral disc, more abundant elsewhere. Pygidium abundantly punctate-setose. Protibia unmodified, apico-external denticle oblique. Parameres with distinct distal-inferior paramerite, parameral apex protruding, poorly sclerotized, fig. 120. Some ventral parts infuscated. Small, body length usually $3.5-5.5 \mathrm{~mm}$.

\section{Range and ecology}

Apparently widespread on Sulawesi. In both lowland forest and more open situations, various collecting methods, most specimens associated with dung.

\section{Onthophagus fuscostriatus Boucomont, 1914}

Figs 13, 85-90, 121

Material examined. Lectotype male, syntype in PBouc here designated lectotype, labelled "NordCelebesıToli-TolilNov.-Dez. 1895\H. Fruhstorfer", "Ex Musaeo \N. van de Poll”, " $\$$ " ”, "Museum Paris \1936 \Coll. A. Boucomont”, “Typus” (red label), "Boucomont det. $1914 \backslash$ Onthophagus ô \ fuscostriatus n.sp."; male and female paralectotype from the same locality. Other material examined listed in Appendix.

\section{Diagnosis}

Onthophagus fuscostriatus is a variable yellow-brown to brown-black, more or less patterned, shiny species, with a shortly but distinctly bidentate clypeus, and with unmodified slender protibiae. Pronotal disc as well as elytra may be very dark (at least pronotal margins remaining yellow-brown), and elytral striae may be infuscated on a yellow-brown background. Head without distinct elevations. The somewhat similar magnipygus is unicolour black, more robust, has a different dorsal microsculpture, and very different parameres. Parameres of Onthophagus fuscostriatus with distal paramerite, apex hardly protruding, almost truncate (in lateral view), fig. 121. 
Margin of head at clypeogenal transition continuous, widely, evenly rounded to clypeal apex. Head surface abundantly to densely, simply punctate-setose, punctures multi-sized. Anterior declivity of pronotum evenly convex, unmodified. Pronotal surface simply, densely punctate-setose; base finely marginate. Elytral interstriae discally shiny, finely punctate-setose, punctures at most very slightly asperate. Pygidium densely punctate-setose, not enlarged and strongly convex. Male protibia with apico-external denticle oblique, acuminate. Body length usually $4.5-6 \mathrm{~mm}$.

\section{Range and ecology}

Northern, central and southeastern parts of Sulawesi. Mainly in faeces traps, up to ca $1000 \mathrm{~m}$ altitude, in both forest and more open situations.

\section{Onthophagus magnipygus Boucomont, 1914}

Figs 14, 91-96, 122-123

Material examined. Holotype in PBouc, a male from $S$ Sulawesi: Bantimurung. Other material examined listed in Appendix.

\section{Diagnosis}

Onthophagus magnipygus is an entirely black, more or less matt (shagreened) species with a distinctly bidentate clypeus and robust but unmodified protibiae. Onthophagus rosenbergi, judged from the shape of the parameres its closest relative, has patterned or brownish elytra, and the males have a conspicuously transverse protibial apex. Onthophagus fuscostriatus is shinier due to a different dorsal microsculpture, and its colour pattern and parameres are different. Head of magnipygus without any distinct elevations. Male protibia with apico-external denticle oblique, acuminate. Contrary the next species, rosenbergi, bristle-bearing asperities on elytral interstriae serially arranged (two rows from interstria 2 on).

Margin of head at clypeogenal transition continuous, widely, evenly rounded to clypeal apex. Head surface with abundant to dense, seta-bearing primary punctures, interspersed with numerous finer secondary punctures. Female clypeal denticles more prominent, intervening excision deeper; clypeofrontal surface rugulate- punctate. Anterior declivity of pronotum evenly convex, unmodified; base marginate, medially with very obtuse angle. Pronotal surface simply, crowdedly punctate-setose. Elytral interstriae discally matt, finely asperate-setose. Pygidium very large, strongly convex. Parameres well sclerotized, long, slender, without paramerites (in profile curved, tapering; apex more strongly curved downward than in rosenbergi, and dilated-rounded in upper side view), Figs 122-123. Habitus plump, with relatively slender middle and hind legs. Body length usually 6-6.5 mm.

\section{Range and ecology}

Widespread on Sulawesi, no records from central parts. Only in faeces traps, in lowland forest.

\section{Onthophagus rosenbergi sp.n.}

Figs 15, 97-102, 124-127

Onthophagus rosenbergi rosenbergi subsp.n. (key below) Onthophagus rosenbergi divergens subsp.n. (key below)

Material examined. Holotype male of Onthophagus rosenbergi rosenbergi (RMNH) from $\mathrm{N}$ Sulawesi: Dumoga Bone NP: Mt Mogogonipa, $1000 \mathrm{~m}$, 22-26/viii/1985, J. Huijbregts \#HH427A, multistr evergr forest, 2 human excr traps. Paratypes listed in Appendix.

Holotype male of Onthophagus rosenbergi divergens (RMNH) from SE Sulawesi: Kolaka: Watuwila Mosquito Camp, 1150 m, 13-15/x/1989, J. Krikken $\&$ K. van der Blom \#sw10a, multistr evergr forest, 2 human excr traps. Paratypes listed in Appendix.

\section{Diagnosis}

Onthophagus rosenbergi is within the fuscostriatus group one of the more characteristic species, on account of the combination of an aberrant male protibial apex, a heavy (almost rugulate) pronotal punctation, and distinct rufous brown elytral colour markings, which frequently extend over the entire surface. The general shape of the parameres (size and curvature) agrees with Onthophagus magnipygus. In Onthophagus rosenbergi the shape of the parameres varies geographically, supporting the recognition of two subspecies (see key below).

Head relatively broad compared to magnipygus. Clypeal apex excised, obtusely bidentate-reflexed in males, sharper in females. Head surface without any protrusions. Clypeogenal margin continuous at suture, evenly, widely rounded to apex. Dorsal side of body deplanate, both head and pronotum entirely crowded with very distinct seta-bearing punctures, setae rather long. Anterior declivity of pronotum evenly convex, unmodified; base marginate, medially with very obtuse angle. Discal elytral interstriae abundantly, scatteredly asperate-punctatesetose or more simply punctate-setose (setae not serially arranged, as in Onthophagus magnipygus). Ventral side as well as large, convex pygidium with black versus (yellow-)brown pattern. Male protibial apex remarkably transverse, straight, with relatively short apico-external denticle subperpendicular to tibial axis; terminal spur fine. Parameres strongly 
sclerotized, long, slender, without paramerites (in profile evenly curved, tapering; tip variably dilated in upper side view, cf. two subspecies), Figs 124-127. Habitus plump, with relatively slender middle and hind legs. Body length usually $4.5-6.5 \mathrm{~mm}$.

\section{Description (holotype, male)}

Body length ca $5.5 \mathrm{~mm}$. Habitus compact. Blackbrown, some parts lighter brown, including legs; elytra distinctly patterned (rufous brown on black); dorsal side matt (shagreened), due to crowded punctation and closely micropunctate surface. Pilosity pale-white(-yellow), dorsal side with numerous fine, mostly long, recurved setae.

Head broad. Clypeus anteromedially slightly reflexed, shortly, obtusely bidentate-emarginate, emargination shallow; clypeogenal border widely rounded to equally rounded genal tip, transition at suture continuous; clypeofrontal ridge absent. Head surface densely covered with distinct isodiametric, subannulate punctures, many with long seta. Vertex lacking any protrusions. Eye foramina very narrow, with ca 6 facet rows across widest point. Ratio interocular distance / maximum (transverse, single) eye width ca 20 .

Pronotum slightly convex, disc deplanate, midline not impressed; anterior section of lateral border straight (full-face view), anterolateral angle shortly rounded, subrectangular; posterior section of lateral border virtually straight, posterolateral angle rounded off; base finely, distinctly marginate, medially very obtusely angular. Nearly entire pronotal surface with crowded, almost rugulate punctation; puncture diameters on disc mostly $0.04-0.07 \mathrm{~mm}$; most punctures with long seta, setal length up to 8 puncture diameters.

Elytra with juxtasutural interstria, base of interstriae 2-4, 6-7, apex of all interstriae, epipleuron, orange-brown; basal markings well defined; disc closely micropunctate, matt, sides more shiny; shape of elytral base and apex unmodified. Elytral striae well-defined, with indistinct punctures, mostly separated by $2-4$ diameters, slightly crenulating interstrial edges. Interstrial surface very slightly convex, with numerous more or less serially arranged, fine, irregular seta-bearing asperate punctures, punctation on lateral interstriae (5-8) dense, larger, somewhat rugulate.

Antennal club dark grayish-brown; scapus unmodified. Propectoral sides brown, matt (microstriolate), densely punctate-setose. Metasternum dark brown, shiny (microreticulation vague), disc with vague midline impression, most of metasternal surface with dense seta-bearing punctation. Abdominal sternites with row of seta- bearing simple punctures laterally along base; sternites brown, shiny (microreticulation vague), basal margins infuscated. Pygidium convex, large, matt, with crowded, coarse, seta-bearing punctures, setal length up to ca 8 puncture diameters; disc and base dark, sides orange-brown; base non-ridged. Protibia broad, apex very abundantly setose; apical border transverse, straight, with 3 broad triangular external denticles, plus small proximal one, all separated by fine serration; proximal serration consisting of 8-9 fine denticles; terminal spur small, elongateacuminate. Femoral undersides all densely punctatesetose. Meso- and metatibiae slender, dilated from narrow base to transversely subelliptic apical crest, which is fringed largely with long pale-white setae and short fossorial spines; external side of tibiae with ca 4 very slight spine-bearing fossorial protrusions; mesotibial terminal spurs elongate-acuminate, unmodified; metatibial spur long, distally feebly curved, apex blunted. Tarsi all long and slender, unmodified, with fine, sickle-shaped claws; metatarsomere 1 straight, slender, about as long as $2-5$ combined. Approximate length proportions metatibial spur // metatarsomeres 1-5: 15//20/6/4/3/7.

Parameres without paramerites, elongate-tapering in lateral view; apex plate-like, parallel-sided in upper side view; Figs 124-125.

Measurements in mm. Maximum width of head 1.7. Median length of pronotum 1.9, maximum width 3.0. Sutural length of elytra 2.5 , maximum width 3.8 .

\section{Variation and sexual dimorphism}

Body length $4.5-6.5 \mathrm{~mm}$. Female with clypeus always strongly excised-bidentate. Female pygidium smaller, and legs different, protibia with oblique apico-external denticle (but less oblique than in related species), terminal spur longer, elongate-acuminate.

Variable in colouration, microsculpture, clypeal apex, protibial spur, and particularly parameral shape, as follows:

Elytra with brown (to rufous) markings (particularly distinct on base), but this lighter colour may extend over entire elytra.

Punctation on head more simple or annulate.

Microsculpture on (discal) elytral interstriae consisting of either fine setiferous punctures or superficial asperities.

Length of denticles on clypeal apex varies (particularly in male).

Length of male protibial spur varies (longer in some male paratypes, tip may be worn off in some specimens).

Parameral tips elongate-dilated, but in different ways (compare Figs 122-127).

The parameres of the Kolaka males and the males of the central and northern populations appear 
quite different, but to rank them as two full species requires an evaluation of intervening populations. Here we recognize two subspecies:

1. Parameres distally constricted, thence more or less parallel-sided, plate-like (upper side view, fig. 125), tips approximated. Discal interstriae usually asperate-setose. Elytra usually with light basal and apical markings. N, C Sulawesi ... rosenbergi rosenbergi subsp.n.

- Parameres with evenly curved external outline (upper side view, fig. 127), tips divergent. Discal interstriae usually finely punctate-setose. Elytra usually more extensively brownish. SE Sulawesi rosenbergi divergens subsp.n.

\section{Range and ecology}

Northern, central and southeastern parts of Sulawesi, apparently polytypic. Both subspecies mainly in faeces traps, in forest, divergens from one upland locality only.

\section{Etymology}

Named after C.B.H. Baron von Rosenberg (18171888), of German extraction, who enlisted in the Dutch East Indian military and civil service, and explored many parts of the archipelago, particularly Sulawesi and other eastern islands. Made collections for the Leiden museum. More on Rosenberg in Van Steenis-Kruseman (1948-1954), in Fransen et al. (1997), with portraits. The subspecific name divergens refers to the divergent appearance of the parameral tips.

\section{The Onthophagus orientalis group}

\section{Group diagnosis and comment}

Male vertex with pair of horns connected by medially more strongly elevated lamella. Clypeal edge widely rounded. Clypeofrontal ridge distinct. Eye foramina narrow. Pronotum with bulbous anteromedian protrusion; base medially subangular. Elytral interstriae asperate-punctate-setose. Antennae not conspicuously modified, 9-segmented. Mentum slightly concave in front. Propectoral sides unmodified, with simple coxal-marginal ridge. Intercoxal lobe of metasternum unmodified. Pygidial base without distinct ridge. Protibia unmodified, with 4 (3 larger +1 smaller) external denticles. Meso- and metatarsi slender, unmodified. Colour predominantly brown and black. Dorsum strongly setose, with coarse microsculpture. May be large, up to ca $13 \mathrm{~mm}$ long.
Another member of the orientalis group, Onthophagus vulpes Harold, 1877, appears incorrectly reported from Sulawesi (Krikken \& Huijbregts 2007). The group as such, including four or five SundalandSulawesi species, is part of Boucomont's (1914) more broadly conceived group 11 . More group members occur on the islands to the East, cf. Onthophagus hirtuosus Gillet, 1930 from New Guinea (type in Brussels IRSNB).

\section{Onthophagus aureopilosus Boucomont, 1914}

Figs 16, 103-109, 128

Material examined. Lectotype male, syntype in PBouc here designated lectotype, labelled "S.-Celebes \Patunuang \Jan.1896 \H. Fruhstorfer", "Ex Musaeo \N. van de Poll", "Museum Paris \1936", "Coll. A.Boucomont", "Typus" (red label), "Boucomont det. $1914 \backslash$ Onthophagus \aureopilosus nov. spec.”. Other material examined listed in Appendix.

\section{Diagnosis}

Onthophagus aureopilosus is a robust species, with a characteristic set of elevations on the male head, and with a generally black forebody and rufous brown elytra. It has no direct relatives among other Sulawesi Onthophagus.

Clypeal apex simply, widely rounded, margin narrowly, slightly reflexed; margin at clypeogenal suture virtually continuous, evenly, widely rounded to apex. Clypeofrontal transition with slightly arcuate ridge. Vertex of males with paraocular protrusions and intervening lamina - medially usually higher, and crest angular on either side (axial view); female with transverse ridge only (which may be tridentate). Clypeus transversely rugulate-punctate, frons and vertex more sparsely punctate; setae on head virtually absent. Anterior declivity of males distinctly bulbous in front, concave on either side, lower surface largely impunctate, shiny; females with transverse ridge topping anterior declivity. Pronotal surface crowdedly punctate to rugulate-punctate, with numerous setae; discal midline distinctly impressed. Basomedian border of pronotum immarginate, very widely rounded. Elytral interstrial surface uneven, abundantly punctate-setose. Narrow basal margin of brown elytra infuscated. Appearance generally matt, due to heavy microsculpture and pilosity. Setae on dorsum abundant to dense, long, yellow-brown. In addition to elytra, sides of abdomen, legs, and other ventral parts may also be brown. Tibiae robust, protibia with apico-external denticle oblique, middle and hind tibiae strongly dilated distad. Parameres with truncate apex (lateral view), without paramerites, sclerotized parameral tips distinctly spatuliform 
(axial view), fig. 128. Body length varying strongly, $6.5-13 \mathrm{~mm}$.

\section{Range and ecology}

Widespread on Sulawesi. Mainly in faeces traps, in forest.

\section{Acknowledgements}

Thanks are due to the colleagues in The Natural History Museum, London, the Muséum National d'Histoire Naturelle, Paris, and the Museo Civico di Storia Naturale Giacomo Doria, Genoa, for their continued support to our studies of the Southeast Asian scarab fauna. A. Drumont recently assisted with access to Gillet specimens in the Institut Royal des Sciences Naturelles de Belgique, Brussels.

We are greatly indebted to the organizers and field team of Project Wallace (Royal Entomological Society of London) for facilitating our 1985 participation in the North Sulawesi campaign. With pleasure we also recall the support during 1985-1989 by local Indonesian teams from UNSRAT (Universitas Sam Ratulangi), Manado, UNHALU (Universitas Haluoleu), Kendari, and PHPA (Directorate-General of Forest Protection and Nature Conservation), Palu - all on Sulawesi. LIPI (Indonesian Institute of Science), Jakarta, kindly supplied the necessary permits. Colleagues in the National Museum of Natural History Naturalis, Leiden who supported our scarab work, each in their own way, include J. van Tol, K. van der Blom, and A. van Assen. Our colleague in Copenhagen, S. Tarasov, gave useful suggestions. The field work of Huijbregts was financially supported by the Uyttenboogaart-Eliasen Stichting (Amsterdam).

\section{References}

Balthasar, V., 1963. Monographie der Scarabaeidae und Aphodiidae der palaearktischen und orientalischen Region (Coleoptera Lamellicornia). Vol. 2. - Prague, Tschechoslowakische Akademie der Wissenschaften, $1-627$.

Balthasar, V., 1969. Neue Onthophagus-Arten von NeuGuinea and den benachbarten Inseln. - Acta Entomologica Musaei Nationalis Pragae 38: 361-408.

Boucomont, A., 1914. Les Coprophages de l'Archipel malais (Coléopt.). - Annales de la Société Entomologique de France 73: 238-350.
Fransen, C.H.J.M., L.B. Holthuis \& J.P.H.M. Adema, 1997. Type-catalogue of the Decapod Crustacea in the collections of the Nationaal Natuurhistorisch Museum, with appendices of pre-1900 collectors and material. - Zoologische Verhandelingen Leiden 311: i-xvi, 1-344.

Huijbregts, J. \& J. Krikken, 2009. Sulawesi Onthophagus with paraocular protrusions: ten new species, with a key (Coleoptera: Scarabaeidae: Scarabaeinae). - Tijdschrift voor Entomologie 152: 209-236.

Huijbregts, J. \& J. Krikken, 2011. Taxonomy of Onthophagus javanensis and its closest relatives in Sundaland (Coleoptera: Scarabaeidae: Scarabaeinae). - Tijdschrift voor Entomologie 154: 33-59.

Krikken, J. \& J. Huijbregts, 2007. Taxonomic diversity of the genus Ochicanthon in Sundaland (Coleoptera: Scarabaeidae: Scarabaeinae). - Tijdschrift voor Entomologie 150: 421-479.

Krikken, J. \& J. Huijbregts, 2008. Sulawesi large-eyed Onthophagus and their relatives: seven new species, with a key (Coleoptera: Scarabaeidae: Scarabaeinae). Tijdschrift voor Entomologie 151: 155-171.

Lansberge, J.W. van, 1883. Revision des Onthophagus de l'Archipel indo-néerlandais, avec description des espèces nouvelles. - Notes from the Leyden Museum 5: 41-82.

Lansberge, J.W. van, 1885. Description d'espèces nouvelles de Coléopteres appartenant au Musée civique de Gènes. - Annali del Museo Civico di Storia Naturale di Genova (2)2: 375-400.

Lansberge, J.W. van, 1887. Description de quatre espèces nouvelles de Coprophages appartenant au Musée de Leyde. - Notes from the Leyden Museum 7: 17-20.

Sharp, D., 1875. Description of some new genera and species of Scarabaeidae from tropical Asia and Malasia. Part II. - Coleopterologische Hefte 14: 47-66.

Steenis-Kruseman, M.J. van, 1948-1954. Malaysian plant collectors and collections, being a cyclopaedia of botanical exploration. - Flora Malesiana (1)1, i-clii, 1-639

Whitten, A.J., M. Mustafa, M. \& G.S. Henderson, 1987. The ecology of Sulawesi. - Yokyakarta, Gadjah Mada University Press, i-xxi, 1-778 [+ corrections].

Received: 29 August 2011

Accepted: 9 September 2011 


\section{Appendix 1. Material examined}

\section{Species in alphabetical order}

multistr evergr forest $=$ multistratal evergreen forest (Fosberg vegetation classification)

\section{Onthophagus ambang ambang}

Sulawesi: Dumoga Bone NP: Mt Moajat, x.1985, Hornabrook, 1780 m, 1 ex., in RMNH; Kolaka Distr: Watuwila Mosquito Camp, 13-15.x.1989, Krikken \& van der Blom \#sw10a, $1150 \mathrm{~m}$, multistr evergr forest, human excr trap, 97 exx., in RMNH; Kolaka Distr: Watuwila Mosquito Camp, 13-15.x.1989, Krikken \& van der Blom \#sw10b, 1150 m, multistr evergr forest, fish trap, 2 exx., in RMNH; Kolaka Distr: Watuwila Mosquito Camp, 13-15.x.1989, Krikken \& van der Blom \#sw11a, 1150 m, multistr evergr forest, human excr trap, 109 exx., in RMNH; Lore Lindu NP: Danau Tambing forest, 5-9.xii.1985, Krikken \#pw51a, 1600 m, multistr evergr forest, human excr trap, 18 exx., in RMNH; Mt Ambang NR: Kotamobagu, 20km E of, 9-13.ix.1985, Huijbregts \#hh443a, 1120 m, multistr evergr forest, human excr trap, 5 exx. incl. holotype, in RMNH; Mt Ambang NR: Kotamobagu, 20km E of, 48.xi.1985, Krikken \#pw13a, 1340 m, multistr evergr forest, human excr trap, 1 ex., in RMNH.

Total 233 exx., holotype and paratypes, 7 records, in RMNH.

\section{Onthophagus ambang morowali}

Sulawesi: Morowali: Ranu river area, 27-20.i-iv.1980, Brendell, lowland rain forest, at light, 3 exx. incl. holotype, in BMNH, RMNH.

Total 3 exx., holotype and paratypes, 1 record, in $\mathrm{BMNH}$ RMNH.

\section{Onthophagus aureopilosus}

Sulawesi: Banggai Distr: Batui: Seseba Estate, 69.xi.1989, Krikken \& van der Blom \#sw30a, 80 m, multistr evergr forest, human excr trap, 5 exx.; Banggai Distr: Matanyo Forest, N of Kayutanyo, 30-4.xi.1989, Krikken \& van der Blom \#sw16a, $120 \mathrm{~m}$, multistr evergr forest, human excr trap, 19 exx.; Banggai Distr: Matanyo Forest, N of Kayutanyo, 30-4.xi.1989, Krikken \& van der Blom \#sw17a, 120 m, multistr evergr forest, human excr trap, 6 exx.; Banggai Distr: Matanyo Forest, $\mathrm{N}$ of Kayutanyo, 30-4.xi.1989, Krikken \& van der Blom \#sw18a, $170 \mathrm{~m}$, multistr evergr forest, human excr trap, 11 exx.; Banggai Distr: Matanyo Forest, $\mathrm{N}$ of Kayutanyo, 304.xi.1989, Krikken \& van der Blom \#sw18b, 170 m, multistr evergr forest, fish trap, 8 exx.; Banggai Distr: Salodik: Luwuk-Poh rd (km23-24), 31-5.xi.1989, Krikken \& van der Blom \#sw22a, 390 m, multistr evergr forest, human excr trap, 4 exx.; Dumoga Bone NP: Edwards Subcamp, 2-6.vi.1985, Huijbregts \#hh352, 664 m, multistr evergr forest, human excr trap, 4 exx.; Dumoga Bone NP: Mt Mogogonipa, 22-26.viii.1985, Huijbregts \#hh427a, $1000 \mathrm{~m}$, multistr evergr forest, human excr trap, 79 exx.; Dumoga Bone NP: Mt Mogogonipa, 23-26.viii.1985, Huijbregts \#hh431, $1000 \mathrm{~m}$, multistr evergr forest, rat excr trap, 2 exx.; Dumoga Bone NP: Page Subcamp, 38.ix.1985, Huijbregts \#hh439, 302 m, multistr evergr forest, human excr bbc trap 0m, 2 exx.; Dumoga Bone NP: Toraut, 9-11.v.1985, Huijbregts \#hh313, 217 m, multistr evergr forest edge, human excr trap, 9 exx.; Dumoga Bone NP: Toraut, 11-18.v.1985, Huijbregts \#hh321, $217 \mathrm{~m}$, multistr evergr forest edge, human excr trap, 5 exx.; Dumoga Bone NP: Toraut, 18-22.v.1985, Huijbregts \#hh329, $217 \mathrm{~m}$, multistr evergr forest edge, human excr trap, 4 exx.; Dumoga Bone NP: Toraut, 27-31.v.1985, Huijbregts \#hh344, 234 m, multistr evergr forest, flight interception trap, 1 ex.; Dumoga Bone NP: Toraut, 31-8.vvi.1985, Huijbregts \#hh356, 234 m, multistr evergr forest, flight interception trap, 1 ex.; Dumoga Bone NP: Toraut, 15-21.viii.1985, Huijbregts \#hh416, 234 m, multistr evergr forest, flight interception trap, 1 ex.; Dumoga Bone NP: Toraut R3, 8-10.v.1985, Huijbregts \#hh311, 245 m, multistr evergr forest, human excr trap, 26 exx.; Dumoga Bone NP: Toraut R3, 16-20.viii.1985, Huijbregts \#hh422, $245 \mathrm{~m}$, multistr evergr forest, human excr bbc trap $0 \mathrm{~m}, 8$ exx.; Dumoga Bone NP: Toraut: Maze, 9-15.xi.1985, Krikken \#pw23, 220 m, multistr evergr forest, human excr trap, 2 exx.; Kendari Distr: Mekara, $7 \mathrm{~km}$ S of Lambuya, 1518.xi.1989, Krikken \& van der Blom \#sw34a, 70 m, Pinus-Acacia forest plantation, human excr trap, 2 exx.; Kolaka Distr: Sanggona Base Camp, 9-12.x.1989, Krikken \& van der Blom \#sw01a, 200 m, second-growth forest, human excr trap, 6 exx.; Kolaka Distr: Sanggona Base Camp, 13-17.x.1989, Krikken \& van der Blom \#sw05a, $200 \mathrm{~m}$, multistr evergr forest, human excr trap, 1 ex.; Kolaka Distr: Sanggona Base Camp, 13-17.x.1989, Krikken \& van der Blom \#sw06a, 200 m, multistr evergr forest, human excr trap, 3 exx.; Kolaka Distr: Watuwila Mosquito Camp, 13-15.x.1989, Krikken \& van der Blom \#sw11a, $1150 \mathrm{~m}$, multistr evergr forest, human excr trap, 1 ex.; Lore Lindu NP: Dongi Dongi (garage), 4-9.xii.1985, Krikken \#pw55a, 950 m, multistr evergr forest, dung trap, 7 exx.; Lore Lindu NP: Dongi Dongi Shelter, 3-9.xii.1985, Krikken \#pw45, $940 \mathrm{~m}$, clearing in multistr evergr forest, hand coll, 4 exx.; Lore Lindu NP: Dongi Dongi Shelter, 48.xii.1985, Krikken \#pw48a, 940 m, multistr evergr forest, human excr trap, 10 exx.; Lore Lindu NP: Marena Shelter, 14-17.xii.1985, Krikken \#pw65a, 600 m, second-growth forest, human excr trap, 3 exx.; Lore Lindu NP: Marena forest (hill crest), 14-17.xii.1985, Krikken \#pw63a, $650 \mathrm{~m}$, multistr evergr forest, human excr trap, 2 exx.; Lore Lindu NP: Marena forest (nr river), 14-17.xii.1985, Krikken \#pw64a, 600 m, multistr evergr forest, human excr trap, 16 exx.; Lore Lindu NP: Marena forest (nr river), 1417.xii. 1985, Krikken \#pw64b, 600 m, multistr evergr forest, fish trap, 2 exx.; Mt Ambang NR: Kotamobagu, $20 \mathrm{~km}$ E of, 9-13.ix.1985, Huijbregts \#hh443a, 1120 m, multistr evergr forest, human excr trap, 3 exx.; Palu region: Tawaeli-Toboli rd (km34), 20-22.xii.1985, Krikken \#pw69a, $500 \mathrm{~m}$, multistr evergr forest, degraded, human excr trap, 1 ex.; Todjambu, viii.1939, Doesburg, 9 exx.

Total 267 exx., 34 records, in RMNH. 


\section{Onthophagus fulvus}

Sulawesi: Banggai Distr: Batui: Seseba Estate, 6-9.xi.1989, Krikken \& van der Blom \#sw30a, 80 m, multistr evergr forest, human excr trap, 32 exx.; Banggai Distr: Kamunu: Luwuk-Poh rd (km21-22), 31-5.xi.1989, Krikken \& van der Blom \#sw21a, $220 \mathrm{~m}$, Pinus forest plantation, human excr trap, 3 exx.; Banggai Distr: Luwuk-Kayutanyo rd (km17-18), 30-4.xi.1989, Krikken \& van der Blom \#sw15a, 40 m, limestone forest remnant, human excr trap, 1 ex.; Banggai Distr: Matanyo Forest, $\mathrm{N}$ of Kayutanyo, 24.xi.1989, Krikken \& van der Blom \#sw19a, 110 m, multistr evergr forest, river beach, human excr trap, 1 ex.; Banggai Distr: Matanyo Forest, N of Kayutanyo, 30-4.xi.1989, Krikken \& van der Blom \#sw16a, 120 m, multistr evergr forest, human excr trap, 9 exx.; Banggai Distr: Matanyo Forest, N of Kayutanyo, 30-4.xi.1989, Krikken \& van der Blom \#sw17a, $120 \mathrm{~m}$, multistr evergr forest, human excr trap, 5 exx.; Banggai Distr: Matanyo Forest, N of Kayutanyo, 30-4.xi.1989, Krikken \& van der Blom \#sw18a, $170 \mathrm{~m}$, multistr evergr forest, human excr trap, 13 exx.; Banggai Distr: Salodik: Luwuk-Poh rd (km23-24), 315.xi.1989, Krikken \& van der Blom \#sw22a, 390 m, multistr evergr forest, human excr trap, 6 exx.; Dumoga Bone NP: Edwards Subcamp, 2-6.vi.1985, Huijbregts \#hh352, $664 \mathrm{~m}$, multistr evergr forest, human excr trap, 6 exx.; Dumoga Bone NP: Mt Mogogonipa, 22-25.viii.1985, Huijbregts \#hh430, $1000 \mathrm{~m}$, multistr evergr forest, hand coll, 1 ex.; Dumoga Bone NP: Mt Mogogonipa, 22-26. viii.1985, Huijbregts \#hh427a, $1000 \mathrm{~m}$, multistr evergr forest, human excr trap, 4 exx.; Dumoga Bone NP: Page Subcamp, 3-8.ix.1985, Huijbregts \#hh439, 302 m, multistr evergr forest, human excr bbc trap 0m, 1 ex.; Dumoga Bone NP: Toraut, 9-11.v.1985, Huijbregts \#hh313, $217 \mathrm{~m}$, multistr evergr forest edge, human excr trap, 51 exx.; Dumoga Bone NP: Toraut, 11-18.v.1985, Huijbregts \#hh321, $217 \mathrm{~m}$, multistr evergr forest edge, human excr trap, 41 exx.; Dumoga Bone NP: Toraut, 18-22.v.1985, Huijbregts \#hh329, $217 \mathrm{~m}$, multistr evergr forest edge, human excr trap, 20 exx.; Dumoga Bone NP: Toraut, 31-8.vvi.1985, Huijbregts \#hh356, $234 \mathrm{~m}$, multistr evergr forest, flight interception trap, 3 exx.; Dumoga Bone NP: Toraut, 15-21.viii.1985, Huijbregts \#hh416, $234 \mathrm{~m}$, multistr evergr forest, flight interception trap, 2 exx.; Dumoga Bone NP: Toraut R3, 8-10.v.1985, Huijbregts \#hh311, 245 m, multistr evergr forest, human excr trap, 43 exx.; Dumoga Bone NP: Toraut R3, 16-20.viii.1985, Huijbregts \#hh422, 245 $\mathrm{m}$, multistr evergr forest, human excr bbc trap $0 \mathrm{~m}, 18$ exx.; Kendari Distr: Aopa, 30km S of Lambuya, 15-18.xi.1989, Krikken \& van der Blom \#sw33a, $40 \mathrm{~m}$, sago palm forest, human excr trap, 2 exx.; Kendari Distr: Mekara, $7 \mathrm{~km}$ $S$ of Lambuya, 15-18.xi.1989, Krikken \& van der Blom \#sw34a, 70 m, Pinus-Acacia forest plantation, human excr trap, 14 exx.; Kendari Distr: Moramo Falls Forest, 1617.xi.1989, Krikken \& van der Blom \#sw35a, 200 m, multistr evergr forest, human excr trap, 1 ex.; Kolaka Distr: Sanggona Base Camp, 9-12.x.1989, Krikken \& van der Blom \#sw01a, $200 \mathrm{~m}$, second-growth forest, human excr trap, 12 exx.; Kolaka Distr: Sanggona Base Camp, 9-12.x.1989, Krikken \& van der Blom \#sw01b, 200 m, second-growth forest, fish trap, 1 ex.; Kolaka Distr: Sanggona Base Camp, 13-17.x.1989, Krikken \& van der Blom \#sw03a, $200 \mathrm{~m}$, second-growth forest margin, human excr trap, 9 exx.; Kolaka Distr: Sanggona Base Camp, 13-17.x.1989, Krikken \& van der Blom \#sw04a, 200 m, second-growth forest, open space, human excr trap, 8 exx.; Kolaka Distr: Sanggona Base Camp, 13-17.x.1989, Krikken \& van der Blom \#sw05a, 200 m, multistr evergr forest, human excr trap, 2 exx.; Kolaka Distr: Sanggona Base Camp, 13-17.x.1989, Krikken \& van der Blom \#sw06a, $200 \mathrm{~m}$, multistr evergr forest, human excr trap, 1 ex.; Lore Lindu NP: Dongi Dongi (garage), 4-9.xii.1985, Krikken \#pw55a, $950 \mathrm{~m}$, multistr evergr forest, dung trap, 2 exx.; Lore Lindu NP: Dongi Dongi Shelter, 3-9.xii.1985, Krikken \#pw45, $940 \mathrm{~m}$, clearing in multistr evergr forest, hand coll, 1 ex.; Lore Lindu NP: Dongi Dongi Shelter, 48.xii.1985, Krikken \#pw48a, 940 m, multistr evergr forest, human excr trap, 9 exx.; Lore Lindu NP: Marena Shelter, 14-17.xii.1985, Krikken \#pw65a, 600 m, second-growth forest, human excr trap, 3 exx.; Lore Lindu NP: Marena forest (hill crest), 14-17.xii.1985, Krikken \#pw63a, $650 \mathrm{~m}$, multistr evergr forest, human excr trap, 2 exx.; Lore Lindu NP: Marena forest (nr river), 14-17.xii.1985, Krikken \#pw64a, $600 \mathrm{~m}$, multistr evergr forest, human excr trap, 13 exx.; Mt Ambang NR: Kotamobagu, 20km E of, 29-30.v.1985, Huijbregts \#hh342, $1200 \mathrm{~m}$, coffea plantation, human excr trap, 5 exx.; Mt Ambang NR: Kotamobagu, 20km E of, 9-13.ix.1985, Huijbregts \#hh443a, $1120 \mathrm{~m}$, multistr evergr forest, human excr trap, 1 ex.; Palu region: Tawaeli-Toboli rd (km29), 20-22.xii.1985, Krikken \#pw68a, $250 \mathrm{~m}$, second-growth forest/coffea, $\mathrm{nr}$ rivulet, human excr trap, 5 exx.; Palu region: TawaeliToboli rd (km34), 20-22.xii.1985, Krikken \#pw69a, $500 \mathrm{~m}$, multistr evergr forest, degraded, human excr trap, 2 exx.; Rantepao: Nanggala, xi.1937, Drescher, 900 m, 1 ex.

Total 354 exx., 39 records, in MBBJ, RMNH.

\section{Onthophagus fuscostriatus}

Sulawesi: Dumoga Bone NP: Edwards Subcamp, 26.vi.1985, Huijbregts \#hh352, $664 \mathrm{~m}$, multistr evergr forest, human excr trap, 33 exx.; Dumoga Bone NP: Edwards Subcamp, 3-5.vi.1985, Huijbregts \#hh348, 664 m, multistr evergr forest, hand coll, 3 exx.; Dumoga Bone NP: Mt Mogogonipa, 22-26.viii.1985, Huijbregts \#hh424, $400 \mathrm{~m}$, multistr evergr forest, fish trap, 3 exx.; Dumoga Bone NP: Mt Mogogonipa, 22-26.viii.1985, Huijbregts \#hh427a, $1000 \mathrm{~m}$, multistr evergr forest, human excr trap, 1 ex.; Dumoga Bone NP: Page Subcamp, 3-6.ix.1985, Huijbregts \#hh438, $302 \mathrm{~m}$, multistr evergr forest, at light, 1 ex.; Dumoga Bone NP: Page Subcamp, 3-8.ix.1985, Huijbregts \#hh439, $302 \mathrm{~m}$, multistr evergr forest, human excr bbc trap 0m, 184 exx.; Dumoga Bone NP: Toraut, 7.v.1985, Huijbregts \#hh308, 230 m, multistr evergr forest, dung, cf monkey, 57 exx.; Dumoga Bone NP: Toraut, 9-11.v.1985, Huijbregts \#hh313, $217 \mathrm{~m}$, multistr evergr forest edge, human excr trap, 68 exx.; Dumoga Bone NP: Toraut, 11-18.v.1985, Huijbregts \#hh321, 217 m, multistr evergr forest edge, human excr trap, 23 exx.; Dumoga Bone NP: Toraut, 18-22.v.1985, Huijbregts \#hh329, $217 \mathrm{~m}$, multistr evergr forest edge, human excr trap, 10 exx.; 
Dumoga Bone NP: Toraut, 27-31.v.1985, Huijbregts \#hh344, 234 m, multistr evergr forest, flight interception trap, 10 exx.; Dumoga Bone NP: Toraut, v-vi.1985, Huijbregts \#hh312, $250 \mathrm{~m}$, multistr evergr forest, hand coll, 1 ex.; Dumoga Bone NP: Toraut, 31-8.v-vi.1985, Huijbregts \#hh356, $234 \mathrm{~m}$, multistr evergr forest, flight interception trap, 31 exx.; Dumoga Bone NP: Toraut, 1521.viii.1985, Huijbregts \#hh416, 234 m, multistr evergr forest, flight interception trap, 7 exx.; Dumoga Bone NP: Toraut, 18-23.ix.1985, Huijbregts \#hh456, 234 m, multistr evergr forest, flight interception trap, 1 ex.; Dumoga Bone NP: Toraut R3, 8-10.v.1985, Huijbregts \#hh311, $245 \mathrm{~m}$, multistr evergr forest, human excr trap, 570 exx.; Dumoga Bone NP: Toraut R3, 10-18.v.1985, Huijbregts \#hh320, 245 m, multistr evergr forest, human excr canopy trap 0m, 42 exx.; Dumoga Bone NP: Toraut R3, 8.vi.1985, Huijbregts \#hh354, 245 m, multistr evergr forest, dung, cf monkey, 29 exx.; Dumoga Bone NP: Toraut R3, 15-19.viii.1985, Huijbregts \#hh415, 245 m, multistr evergr forest, papaya trap, 1 ex.; Dumoga Bone NP: Toraut: Maze, 2-9.xi.1985, Krikken \#pw16a, 220 m, multistr evergr forest, human excr trap, 339 exx.; Kendari Distr: Moramo Falls Forest, 16-17.xi.1989, Krikken \& van der Blom \#sw35a, 200 m, multistr evergr forest, human excr trap, 26 exx.; Kolaka Distr: Sanggona Base Camp, 9-12.x.1989, Krikken \& van der Blom \#sw01a, $200 \mathrm{~m}$, second-growth forest, human excr trap, 52 exx.; Kolaka Distr: Sanggona Base Camp, 9-12.x.1989, Krikken \& van der Blom \#sw01b, 200 m, second-growth forest, fish trap, 15 exx.; Kolaka Distr: Sanggona Base Camp, 10-21.x.1989, Krikken \& van der Blom \#sw08, $200 \mathrm{~m}$, second-growth forest, hand collected, 15 exx.; Kolaka Distr: Sanggona Base Camp, 13-17.x.1989, Krikken \& van der Blom \#sw03a, 200 m, second-growth forest margin, human excr trap, 190 exx.; Kolaka Distr: Sanggona Base Camp, 13-17.x.1989, Krikken \& van der Blom \#sw03b, $200 \mathrm{~m}$, second-growth forest margin, fish trap, 1 ex.; Kolaka Distr: Sanggona Base Camp, 13-17.x.1989, Krikken \& van der Blom \#sw04a, 200 m, second-growth forest, open space, human excr trap, 13 exx.; Kolaka Distr: Sanggona Base Camp, 1317.x.1989, Krikken \& van der Blom \#sw05a, 200 m, multistr evergr forest, human excr trap, 25 exx.; Kolaka Distr: Sanggona Base Camp, 13-17.x.1989, Krikken \& van der Blom \#sw05b, 200 m, multistr evergr forest, fish trap, 1 ex.; Kolaka Distr: Sanggona Base Camp, 1317.x.1989, Krikken \& van der Blom \#sw06a, 200 m, multistr evergr forest, human excr trap, 24 exx.; Kolaka Distr: Sanggona Base Camp, 13-17.x.1989, Krikken \& van der Blom \#sw06b, $200 \mathrm{~m}$, multistr evergr forest, fish trap, 15 exx.; Kolaka Distr: Sanggona Base Camp, 1421.x.1989, Krikken \& van der Blom \#sw09b, 200 m, second-growth forest, combi-trap, bottom, 2 exx.; Palu, Osella, 1 ex.; Palu region: Tawaeli-Toboli rd (km29), 20-22.xii.1985, Krikken \#pw68a, 250 m, second-growth forest/coffea, nr rivulet, human excr trap, 1 ex.; Palu region: Tawaeli-Toboli rd (km34), 20-22.xii.1985, Krikken \#pw69a, 500 m, multistr evergr forest, degraded, human excr trap, 11 exx.; Tangkoko NR: Pantai Trail, 2729.xi.1985, Krikken \#pw41b, 100 m, multistr evergr forest, fish trap, 1 ex.

Total 1807 exx., 36 records, in RMNH.

\section{Onthophagus gonipa}

Sulawesi: Dumoga Bone NP: Mt Mogogonipa, 2226.viii.1985, Huijbregts \#hh427a, 1000 m, multistr evergr forest, human excr trap, 1 ex. holotype, in RMNH.

Total 1 ex., holotype, 1 record, in RMNH.

\section{Onthophagus griseoaeneus}

Sulawesi: Banggai Distr: Batui: Seseba Estate, 6-9.xi.1989, Krikken \& van der Blom \#sw30a, 80 m, multistr evergr forest, human excr trap, 2 exx.; Banggai Distr: Kamunu: Luwuk-Poh rd (km21-22), 31-5.xi.1989, Krikken \& van der Blom \#sw21a, $220 \mathrm{~m}$, Pinus forest plantation, human excr trap, 14 exx.; Banggai Distr: Luwuk-Kayutanyo rd (km1718), 30-4.xi.1989, Krikken \& van der Blom \#sw15b, $40 \mathrm{~m}$, limestone forest remnant, fish trap, 1 ex.; Banggai Distr: Luwuk-Poh rd (km17-18), 31-5.xi.1989, Krikken \& van der Blom \#sw20a, 220 m, multistr evergr forest, degraded, human excr trap, 1 ex.; Banggai Distr: Matanyo Forest, N of Kayutanyo, 2-4.xi.1989, Krikken \& van der Blom \#sw16c, 120 m, multistr evergr forest, cattle dung trap, 1 ex.; Banggai Distr: Matanyo Forest, $\mathrm{N}$ of Kayutanyo, 30-4.xi.1989, Krikken \& van der Blom \#sw16a, $120 \mathrm{~m}$, multistr evergr forest, human excr trap, 15 exx.; Banggai Distr: Matanyo Forest, $N$ of Kayutanyo, 304.xi.1989, Krikken \& van der Blom \#sw17a, 120 m, multistr evergr forest, human excr trap, 2 exx.; Banggai Distr: Matanyo Forest, N of Kayutanyo, 30-4.xi.1989, Krikken \& van der Blom \#sw18a, 170 m, multistr evergr forest, human excr trap, 13 exx.; Banggai Distr: Matanyo Forest, N of Kayutanyo, 30-4.xi.1989, Krikken \& van der Blom \#sw18b, $170 \mathrm{~m}$, multistr evergr forest, fish trap, 1 ex.; Banggai Distr: Salodik, 4-5km E of, 31-5.xi.1989, Krikken \& van der Blom \#sw23a, 450 m, grassland, human excr trap, 2 exx.; Banggai Distr: Salodik: Luwuk-Poh rd (km23-24), 315.xi.1989, Krikken \& van der Blom \#sw22a, 390 m, multistr evergr forest, human excr trap, 3 exx.; Dumoga Bone NP: Sungei Moynakom, N. of Siniung, 28..1983, Rozendaal \#fr54, 600 m, multistr evergr forest, human excrements, 1 ex.; Dumoga Bone NP: Toraut, 11-18.v.1985, Huijbregts \#hh321, $217 \mathrm{~m}$, multistr evergr forest edge, human excr trap, 1 ex.; Dumoga Bone NP: Toraut R3, 8-10.v.1985, Huijbregts \#hh311, 245 m, multistr evergr forest, human excr trap, 2 exx.; Dumoga Bone NP: Toraut R3, 16-20.viii.1985, Huijbregts \#hh422, 245 m, multistr evergr forest, human excr bbc trap 0m, 3 exx.; Dumoga Bone NP: Toraut: Maze, 9-15.xi.1985, Krikken \#pw23, $220 \mathrm{~m}$, multistr evergr forest, human excr trap, 4 exx.; Kendari Distr: Aopa, $30 \mathrm{~km} \mathrm{~S} \mathrm{of} \mathrm{Lam-}$ buya, 15-18.xi.1989, Krikken \& van der Blom \#sw33a, $40 \mathrm{~m}$, sago palm forest, human excr trap, 20 exx.; Kendari Distr: Mekara, $7 \mathrm{~km}$ S of Lambuya, 15-18.xi.1989, Krikken \& van der Blom \#sw34a, 70 m, Pinus-Acacia forest plantation, human excr trap, 24 exx.; Kolaka Distr: Sanggona Base Camp, 9-12.x.1989, Krikken \& van der Blom \#sw01a, 200 m, second-growth forest, human excr trap, 3 exx.; Kolaka Distr: Sanggona Base Camp, 9-12.x.1989, Krikken \& van der Blom \#sw01b, 200 m, second-growth forest, fish trap, 1 ex.; Kolaka Distr: Sanggona Base Camp, 13-17.x.1989, Krikken \& van der Blom \#sw03a, 200 m, 
second-growth forest margin, human excr trap, 27 exx.; Kolaka Distr: Sanggona Base Camp, 13-17.x.1989, Krikken \& van der Blom \#sw04a, 200 m, second-growth forest, open space, human excr trap, 1 ex.; Kolaka Distr: Sanggona Base Camp, 13-17.x.1989, Krikken \& van der Blom \#sw05a, $200 \mathrm{~m}$, multistr evergr forest, human excr trap, 5 exx.; Kolaka Distr: Sanggona Base Camp, 13-17.x.1989, Krikken \& van der Blom \#sw06a, 200 m, multistr evergr forest, human excr trap, 5 exx.; Palu region: TawaeliToboli rd (km34), 20-22.xii.1985, Krikken \#pw69a, $500 \mathrm{~m}$, multistr evergr forest, degraded, human excr trap, 7 exx.

Total 159 exx., 25 records, in RMNH.

\section{Onthophagus imbutus}

Sulawesi: loc. unspecified, Rolle, 4 exx.; North: Kuandang, x.[1863], Rosenberg, 1 ex.; Manado, vii.1906, Koller, 3 exx.

Total 8 exx., 3 records, in RMNH, ZMAN.

\section{Onthophagus magnipygus}

Sulawesi: Banggai Distr: Batui: Seseba Estate, 69.xi.1989, Krikken \& van der Blom \#sw30a, 80 m, multistr evergr forest, human excr trap, 15 exx.; Banggai Distr: Matanyo Forest, N of Kayutanyo, 30-4.xi.1989, Krikken \& van der Blom \#sw16a, 120 m, multistr evergr forest, human excr trap, 2 exx.; Dumoga Bone NP: Page Subcamp, 3-8.ix.1985, Huijbregts \#hh439, $302 \mathrm{~m}$, multistr evergr forest, human excr bbc trap $0 \mathrm{~m}$, 1 ex.; Dumoga Bone NP: Toraut R3, 10-18.v.1985, Huijbregts \#hh320, $245 \mathrm{~m}$, multistr evergr forest, human excr canopy trap 0m, 2 exx.; Dumoga Bone NP: Toraut R3, 16-20.viii.1985, Huijbregts \#hh422, 245 m, multistr evergr forest, human excr bbc trap 0m, 1 ex.; Kolaka Distr: Sanggona Base Camp, 13-17.x.1989, Krikken \& van der Blom \#sw06a, 200 m, multistr evergr forest, human excr trap, 1 ex.

Total 22 exx., 6 records, in RMNH.

\section{Onthophagus rosenbergi divergens}

Sulawesi: Kolaka Distr: Watuwila Mosquito Camp, 1315.x.1989, Krikken \& van der Blom \#sw10a, 1150 m, multistr evergr forest, human excr trap, 115 exx. incl. holotype, in RMNH; Kolaka Distr: Watuwila Mosquito Camp, 13-15.x.1989, Krikken \& van der Blom \#sw11a, $1150 \mathrm{~m}$, multistr evergr forest, human excr trap, 176 exx., in $\mathrm{RMNH}$.

Total 291 exx., holotype and paratypes, 2 records, in RMNH.

\section{Onthophagus rosenbergi rosenbergi}

Sulawesi: Dumoga Bone NP: Mt Mogogonipa, 2226.viii.1985, Huijbregts \#hh427a, 1000 m, multistr evergr forest, human excr trap, 8 exx. incl. holotype, in RMNH; Lore Lindu NP: Dongi Dongi Shelter, 4-8.xii.1985, Krikken \#pw48a, $940 \mathrm{~m}$, multistr evergr forest, human excr trap, 37 exx., in RMNH; Lore Lindu NP: Marena Shelter, 13-17.xii.1985, Krikken \#pw60, 600 m, second-growth forest, clearing, hand coll, 1 ex., in RMNH; Lore Lindu NP: Marena Shelter, 14-17.xii.1985, Krikken \#pw65a, $600 \mathrm{~m}$, second-growth forest, human excr trap, 16 exx., in RMNH; Lore Lindu NP: Marena forest (hill crest), 1417.xii.1985, Krikken \#pw63a, 650 m, multistr evergr forest, human excr trap, 18 exx., in RMNH; Lore Lindu NP: Marena forest (nr river), 14-17.xii.1985, Krikken \#pw64a, $600 \mathrm{~m}$, multistr evergr forest, human excr trap, 120 exx., in RMNH; Lore Lindu NP: Sopu River forest, 7-9.xii.1985, Krikken \#pw52, 940 m, multistr evergr forest, human excr trap, 1 ex., in RMNH; Lore Lindu NP: Sopu River pools, 6.xii.1985, Krikken \& van Tol \#pw50a, 930 m, multistr evergr forest vicinity, vegetated pools, 1 ex., in RMNH; Palu region: Tawaeli-Toboli rd (km34), 20-22.xii.1985, Krikken \#pw69a, 500 m, multistr evergr forest, degraded, human excr trap, 9 exx., in RMNH.

Total 211 exx., holotype and paratypes, 9 records, in RMNH.

\section{Onthophagus sarasinorum}

Sulawesi: Dumoga Bone NP: Mt Mogogonipa, 2226.viii.1985, Huijbregts \#hh427a, $1000 \mathrm{~m}$, multistr evergr forest, human excr trap, 6 exx., in RMNH; Dumoga Bone NP: Mt Mogogonipa, 22-26.viii.1985, Huijbregts \#hh428, $1000 \mathrm{~m}$, multistr evergr forest, flight interception trap, 1 ex., in RMNH; Dumoga Bone NP: Mt Mogogonipa, 23-26.viii.1985, Huijbregts \#hh431, 1000 m, multistr evergr forest, rat excr trap, 1 ex., in RMNH; Kendari Distr: Moramo Falls Forest, 16-17.xi.1989, Krikken \& van der Blom \#sw35a, $200 \mathrm{~m}$, multistr evergr forest, human excr trap, 7 exx., in RMNH; Kolaka Distr: Sanggona Base Camp, 13-17.x.1989, Krikken \& van der Blom \#sw03a, $200 \mathrm{~m}$, second-growth forest margin, human excr trap, 1 ex., in RMNH; Kolaka Distr: Watuwila Mosquito Camp, 13-15.x.1989, Krikken \& van der Blom \#sw10a, 1150 m, multistr evergr forest, human excr trap, 85 exx., in RMNH; Kolaka Distr: Watuwila Mosquito Camp, 13-15.x.1989, Krikken \& van der Blom \#sw11a, 1150 m, multistr evergr forest, human excr trap, 91 exx., in RMNH; Lore Lindu NP: Danau Tambing forest, 5-9.xii.1985, Krikken \#pw51a, 1600 m, multistr evergr forest, human excr trap, 2 exx., in RMNH; Lore Lindu NP: Dongi Dongi (garage), 4-9.xii.1985, Krikken \#pw55a, 950 m, multistr evergr forest, dung trap, 4 exx., in RMNH; Lore Lindu NP: Dongi Dongi Shelter, 4-8.xii.1985, Krikken \#pw48a, 940 m, multistr evergr forest, human excr trap, 16 exx. incl. holotype, in RMNH; Lore Lindu NP: Sopu River forest, 79.xii.1985, Krikken \#pw52, 940 m, multistr evergr forest, human excr trap, 2 exx., in RMNH; Lore Lindu NP: Sopu River pools, 6.xii.1985, Krikken \& van Tol \#pw50a, 
$930 \mathrm{~m}$, multistr evergr forest vicinity, vegetated pools, 2 exx., in RMNH.

Total 218 exx., holotype and paratypes, 12 records, in RMNH.

\section{Onthophagus spiculatus}

Sulawesi: Banggai Distr: Batui: Seseba Estate, 6-9.xi.1989, Krikken \& van der Blom \#sw30a, 80 m, multistr evergr forest, human excr trap, 17 exx.; Banggai Distr: Kamunu: Luwuk-Poh rd (km21-22), 31-5.xi.1989, Krikken \& van der Blom \#sw21a, $220 \mathrm{~m}$, Pinus forest plantation, human excr trap, 11 exx.; Banggai Distr: Matanyo Forest, $\mathrm{N}$ of Kayutanyo, 2-4.xi.1989, Krikken \& van der Blom \#sw16c, $120 \mathrm{~m}$, multistr evergr forest, cattle dung trap, 5 exx.; Banggai Distr: Matanyo Forest, $\mathrm{N}$ of Kayutanyo, 30-4.xi.1989, Krikken \& van der Blom \#sw16a, 120 m, multistr evergr forest, human excr trap, 18 exx.; Banggai Distr: Matanyo Forest, N of Kayutanyo, 30-4.xi.1989, Krikken \& van der Blom \#sw17a, 120 m, multistr evergr forest, human excr trap, 15 exx.; Banggai Distr: Matanyo Forest, N of Kayutanyo, 30-4.xi.1989, Krikken \& van der Blom \#sw18a, 170 m, multistr evergr forest, human excr trap, 28 exx.; Banggai Distr: Salodik: Luwuk-Poh rd (km23-24), 31-5.xi.1989, Krikken \& van der Blom \#sw22a, $390 \mathrm{~m}$, multistr evergr forest, human excr trap, 9 exx.; Dumoga Bone NP: Edwards Subcamp, 26.vi.1985, Huijbregts \#hh352, $664 \mathrm{~m}$, multistr evergr forest, human excr trap, 5 exx.; Dumoga Bone NP: Edwards Subcamp, 3-5.vi.1985, Huijbregts \#hh348, 664 m, multistr evergr forest, hand coll, 1 ex.; Dumoga Bone NP: Page Subcamp, 3-8.ix.1985, Huijbregts \#hh439, 302 m, multistr evergr forest, human excr bbc trap 0m, 5 exx.; Dumoga Bone NP: Toraut, 9-11.v.1985, Huijbregts \#hh313, $217 \mathrm{~m}$, multistr evergr forest edge, human excr trap, 4 exx.; Dumoga Bone NP: Toraut, 11-18.v.1985, Huijbregts \#hh321, $217 \mathrm{~m}$, multistr evergr forest edge, human excr trap, 4 exx.; Dumoga Bone NP: Toraut, 18-22.v.1985, Huijbregts \#hh329, 217 m, multistr evergr forest edge, human excr trap, 1 ex.; Dumoga Bone NP: Toraut, 31-8.vvi.1985, Huijbregts \#hh356, 234 m, multistr evergr forest, flight interception trap, 1 ex.; Dumoga Bone NP: Toraut R3, 8-10.v.1985, Huijbregts \#hh311, 245 m, multistr evergr forest, human excr trap, 8 exx.; Dumoga Bone NP: Toraut R3, 16-20.viii.1985, Huijbregts \#hh422, 245 m, multistr evergr forest, human excr bbc trap 0m, 9 exx.; Dumoga Bone NP: Toraut: Maze, 9-15.xi.1985, Krikken \#pw23, $220 \mathrm{~m}$, multistr evergr forest, human excr trap, 27 exx.; Kendari Distr: Moramo Falls Forest, 1617.xi.1989, Krikken \& van der Blom \#sw35a, 200 m, multistr evergr forest, human excr trap, 2 exx.; Kolaka Distr: Sanggona Base Camp, 9-12.x.1989, Krikken \& van der Blom \#sw01a, 200 m, second-growth forest, human excr trap, 5 exx.; Kolaka Distr: Sanggona Base Camp, 10-21.x.1989, Krikken \& van der Blom \#sw08, 200 m, second-growth forest, hand collected, 3 exx.; Kolaka Distr: Sanggona Base Camp, 13-17.x.1989, Krikken \& van der Blom \#sw03a, $200 \mathrm{~m}$, second-growth forest margin, human excr trap, 16 exx.; Kolaka Distr: Sanggona Base Camp, 13-17.x.1989, Krikken \& van der Blom \#sw05a, $200 \mathrm{~m}$, multistr evergr forest, human excr trap, 8 exx.; Kolaka Distr: Sanggona Base Camp, 13-17.x.1989,
Krikken \& van der Blom \#sw06a, 200 m, multistr evergr forest, human excr trap, 5 exx.; Kolaka Distr: Sanggona Base Camp, 14-21.x.1989, Krikken \& van der Blom \#sw09b, 200 m, second-growth forest, combi-trap, bottom, 1 ex.; Lore Lindu NP: Marena forest (hill crest), 14-17.xii.1985, Krikken \#pw63a, 650 m, multistr evergr forest, human excr trap, 12 exx.; Lore Lindu NP: Marena forest (hill crest), 14-17.xii.1985, Krikken \#pw63b, 650 $\mathrm{m}$, multistr evergr forest, fish trap, 1 ex.; Lore Lindu NP: Marena forest (nr river), 14-17.xii.1985, Krikken \#pw64a, $600 \mathrm{~m}$, multistr evergr forest, human excr trap, 15 exx.; Palu region: Tawaeli-Toboli rd (km29), 20-22.xii.1985, Krikken \#pw68a, 250 m, second-growth forest/coffea, nr rivulet, human excr trap, 4 exx.; Palu region: Tawaeli-Toboli rd (km34), 20-22.xii.1985, Krikken \#pw69a, 500 m, multistr evergr forest, degraded, human excr trap, 33 exx.; Lampah Batang [South: Lompobatang], viii.1941, Lucht, $200 \mathrm{~m}, 1$ ex.

Total 274 exx., 30 records, in MBBJ, RMNH.

\section{Onthophagus sulawesiensis}

Sulawesi: Dumoga Bone NP: Mt Mogogonipa, 2226.viii.1985, Huijbregts \#hh426, 800 m, multistr evergr forest, fish trap, 2 exx., in RMNH; Dumoga Bone NP: Mt Mogogonipa, 22-26.viii.1985, Huijbregts \#hh427b, $1000 \mathrm{~m}$, multistr evergr forest, fish trap, 6 exx. incl. holotype, in RMNH; Lore Lindu NP: Danau Tambing forest, 59.xii.1985, Krikken \#pw51b, 1600 m, multistr evergr forest, fish trap, 1 ex., in RMNH.

Total 9 exx., holotype and paratypes, 3 records, in RMNH.

\section{Onthophagus tambing}

Sulawesi: Kolaka Distr: Watuwila Mosquito Camp, 1315.x.1989, Krikken \& van der Blom \#sw10a, 1150 m, multistr evergr forest, human excr trap, 11 exx., in RMNH; Kolaka Distr: Watuwila Mosquito Camp, 13-15.x.1989, Krikken \& van der Blom \#sw11a, 1150 m, multistr evergr forest, human excr trap, 22 exx. incl. holotype, in RMNH; Lore Lindu NP: Danau Tambing forest, 5-9.xii.1985, Krikken \#pw51a, $1600 \mathrm{~m}$, multistr evergr forest, human excr trap, 186 exx., in RMNH; Lore Lindu NP: Dongi Dongi (garage), 4-9.xii.1985, Krikken \#pw55a, 950 m, multistr evergr forest, dung trap, 4 exx., in RMNH; Lore Lindu NP: Dongi Dongi Shelter, 4-8.xii.1985, Krikken \#pw48a, 940 $\mathrm{m}$, multistr evergr forest, human excr trap, 5 exx., in RMNH.

Total 228 exx., holotype and paratypes, 5 records, in RMNH.

\section{Onthophagus tonywhitteni}

Sulawesi: Lore Lindu NP: Danau Tambing forest, 59.xii.1985, Krikken \#pw51a, 1600 m, multistr evergr forest, human excr trap, 3 exx. incl. holotype, in RMNH.

Total 3 exx., holotype and paratypes, 1 record, in RMNH. Downloaded from BrIll. come4/26/2023 03:52:07AM via free access 


\section{Onthophagus toraut}

Sulawesi: Banggai Distr: Batui: Seseba Estate, 6-9.xi.1989, Krikken \& van der Blom \#sw30a, 80 m, multistr evergr forest, human excr trap, 16 exx., in RMNH; Banggai Distr: Batui: Seseba Estate, 6-9.xi.1989, Krikken \& van der Blom \#sw30b, $80 \mathrm{~m}$, multistr evergr forest, fish trap, 1 ex., in RMNH; Banggai Distr: Kamunu: Luwuk-Poh rd (km2122), 31-5.xi.1989, Krikken \& van der Blom \#sw21a, 220 $\mathrm{m}$, Pinus forest plantation, human excr trap, 12 exx., in RMNH; Banggai Distr: Kamunu: Luwuk-Poh rd (km2122), 31-5.xi.1989, Krikken \& van der Blom \#sw21b, $390 \mathrm{~m}$, Pinus forest plantation, human excr trap, 1 ex., in RMNH; Banggai Distr: Luwuk-Kayutanyo rd (km1718), 30-4.xi.1989, Krikken \& van der Blom \#sw15a, $40 \mathrm{~m}$, limestone forest remnant, human excr trap, 9 exx., in RMNH; Banggai Distr: Luwuk-Kayutanyo rd (km1718), 30-4.xi.1989, Krikken \& van der Blom \#sw15b, 40 $\mathrm{m}$, limestone forest remnant, fish trap, 2 exx., in RMNH; Banggai Distr: Luwuk-Poh rd (km17-18), 31-5.xi.1989, Krikken \& van der Blom \#sw20a, 220 m, multistr evergr forest, degraded, human excr trap, 1 ex., in RMNH; Banggai Distr: Matanyo Forest, N of Kayutanyo, 30-4.xi.1989, Krikken \& van der Blom \#sw16a, 120 m, multistr evergr forest, human excr trap, 35 exx., in RMNH; Banggai Distr: Matanyo Forest, N of Kayutanyo, 30-4.xi.1989, Krikken \& van der Blom \#sw16b, 120 m, multistr evergr forest, fish trap, 3 exx., in RMNH; Banggai Distr: Matanyo Forest, N of Kayutanyo, 30-4.xi.1989, Krikken \& van der Blom \#sw17a, $120 \mathrm{~m}$, multistr evergr forest, human excr trap, 17 exx., in RMNH; Banggai Distr: Matanyo Forest, $\mathrm{N}$ of Kayutanyo, 30-4.xi.1989, Krikken \& van der Blom \#sw17b, 120 m, multistr evergr forest, fish trap, 2 exx., in RMNH; Banggai Distr: Matanyo Forest, N of Kayutanyo, 30-4.xi.1989, Krikken \& van der Blom \#sw18a, $170 \mathrm{~m}$, multistr evergr forest, human excr trap, 33 exx., in RMNH; Banggai Distr: Matanyo Forest, N of Kayutanyo, 30-4.xi.1989, Krikken \& van der Blom \#sw18b, $170 \mathrm{~m}$, multistr evergr forest, fish trap, 10 exx., in RMNH; Banggai Distr: Salodik: Luwuk-Poh rd (km23-24), 315.xi.1989, Krikken \& van der Blom \#sw22a, 390 m, multistr evergr forest, human excr trap, 10 exx., in RMNH; Banggai Distr: Salodik: Luwuk-Poh rd (km23-24), 315.xi.1989, Krikken \& van der Blom \#sw22b, 390 m, multistr evergr forest, fish trap, 4 exx., in RMNH; Dumoga Bone NP: Edwards Subcamp, 2-6.vi.1985, Huijbregts \#hh352, $664 \mathrm{~m}$, multistr evergr forest, human excr trap, 2 exx., in RMNH; Dumoga Bone NP: Page Subcamp, 38.ix.1985, Huijbregts \#hh439, $302 \mathrm{~m}$, multistr evergr forest, human excr bbc trap 0m, 2 exx., in RMNH; Dumoga Bone NP: Toraut, 9-11.v.1985, Huijbregts \#hh313, 217 $\mathrm{m}$, multistr evergr forest edge, human excr trap, 18 exx., in RMNH; Dumoga Bone NP: Toraut, 11-18.v.1985, Huijbregts \#hh321, $217 \mathrm{~m}$, multistr evergr forest edge, human excr trap, 35 exx., in RMNH; Dumoga Bone NP: Toraut, 18-22.v.1985, Huijbregts \#hh329, 217 m, multistr evergr forest edge, human excr trap, 16 exx., in RMNH; Dumoga Bone NP: Toraut, 22-23.v.1985, Huijbregts \#hh333, $217 \mathrm{~m}$, multistr evergr forest edge, fish trap, 3 exx., in RMNH; Dumoga Bone NP: Toraut, 27-31.v.1985, Huijbregts \#hh344, $234 \mathrm{~m}$, multistr evergr forest, flight interception trap, 2 exx., in RMNH; Dumoga Bone NP: Toraut, 31-8.v-vi.1985, Huijbregts \#hh356, 234 m, multistr evergr forest, flight interception trap, 10 exx., in RMNH; Dumoga Bone NP: Toraut, 15-21.viii.1985, Huijbregts \#hh416, $234 \mathrm{~m}$, multistr evergr forest, flight interception trap, 4 exx., in RMNH; Dumoga Bone NP: Toraut R3, 8-10.v.1985, Huijbregts \#hh311, $245 \mathrm{~m}$, multistr evergr forest, human excr trap, 28 exx. incl. holotype, in RMNH; Dumoga Bone NP: Toraut R3, 20-23.v.1985, Huijbregts \#hh332, $245 \mathrm{~m}$, multistr evergr forest, banana trap, 1 ex., in RMNH; Dumoga Bone NP: Toraut R3, 23-27.v.1985, Huijbregts \#hh337, $245 \mathrm{~m}$, multistr evergr forest, banana trap, 1 ex., in RMNH; Dumoga Bone NP: Toraut R3, 27-31.v.1985, Huijbregts \#hh343, $245 \mathrm{~m}$, multistr evergr forest, fungus trap, 4 exx., in RMNH; Dumoga Bone NP: Toraut R3, 31-8.v-vi.1985, Huijbregts \#hh357, $245 \mathrm{~m}$, multistr evergr forest, fungus trap, 9 exx., in RMNH; Dumoga Bone NP: Toraut R3, 16-20.viii.1985, Huijbregts \#hh422, $245 \mathrm{~m}$, multistr evergr forest, human excr bbc trap 0m, 35 exx., in RMNH; Dumoga Bone NP: Toraut R3, 19-27.viii.1985, Huijbregts \#hh433, 245 m, multistr evergr forest, papaya trap, 1 ex., in RMNH; Dumoga Bone NP: Toraut: Maze, 9-15.xi.1985, Krikken \#pw23, $220 \mathrm{~m}$, multistr evergr forest, human excr trap, 170 exx., in RMNH; Kendari Distr: Mekara, $7 \mathrm{~km} \mathrm{~S}$ of Lambuya, 15-18.xi.1989, Krikken \& van der Blom \#sw34a, 70 m, Pinus-Acacia forest plantation, human excr trap, 25 exx., in RMNH; Kolaka Distr: Sanggona Base Camp, 9-12.x.1989, Krikken \& van der Blom \#sw01a, $200 \mathrm{~m}$, second-growth forest, human excr trap, 2 exx., in RMNH; Kolaka Distr: Sanggona Base Camp, 9-12.x.1989, Krikken \& van der Blom \#sw01b, $200 \mathrm{~m}$, second-growth forest, fish trap, 4 exx., in RMNH; Kolaka Distr: Sanggona Base Camp, 13-17.x.1989, Krikken \& van der Blom \#sw03a, $200 \mathrm{~m}$, second-growth forest margin, human excr trap, 10 exx., in RMNH; Kolaka Distr: Sanggona Base Camp, 13-17.x.1989, Krikken \& van der Blom \#sw03b, 200 m, second-growth forest margin, fish trap, 1 ex., in RMNH; Kolaka Distr: Sanggona Base Camp, 13-17.x.1989, Krikken \& van der Blom \#sw05a, 200 m, multistr evergr forest, human excr trap, 3 exx., in RMNH; Lore Lindu NP: Dongi Dongi Shelter, 4-8.xii.1985, Krikken \#pw48a, 940 m, multistr evergr forest, human excr trap, 2 exx., in RMNH; Lore Lindu NP: Marena forest (hill crest), 14-17.xii.1985, Krikken \#pw63a, $650 \mathrm{~m}$, multistr evergr forest, human excr trap, 2 exx., in RMNH; Lore Lindu NP: Marena forest (hill crest), 14-17.xii.1985, Krikken \#pw63b, $650 \mathrm{~m}$, multistr evergr forest, fish trap, 1 ex., in RMNH; Lore Lindu NP: Marena forest (nr river), 14-17.xii.1985, Krikken \#pw64a, $600 \mathrm{~m}$, multistr evergr forest, human excr trap, 5 exx., in RMNH; Lore Lindu NP: Marena forest (nr river), 14-17.xii.1985, Krikken \#pw64b, 600 m, multistr evergr forest, fish trap, 2 exx., in RMNH; Morowali: Ranu river area, 27-20.i-iv.1980, Brendell, carrion trap, 1 ex., in BMNH; Palu region: Tawaeli-Toboli rd (km34), 20-22.xii.1985, Krikken \#pw69a, 500 m, multistr evergr forest, degraded, human excr trap, 5 exx., in RMNH.

Total 560 exx., holotype and paratypes, 45 records, in BMNH, RMNH.

Total 17 taxa, 4649 exx., in 259 records. 